
of Engineers $S_{\circledast}$

Engineer Research and

Development Center

\title{
Evaluation of the WavTrac Expeditionary Mobility Matting System
}

Webster C. Floyd
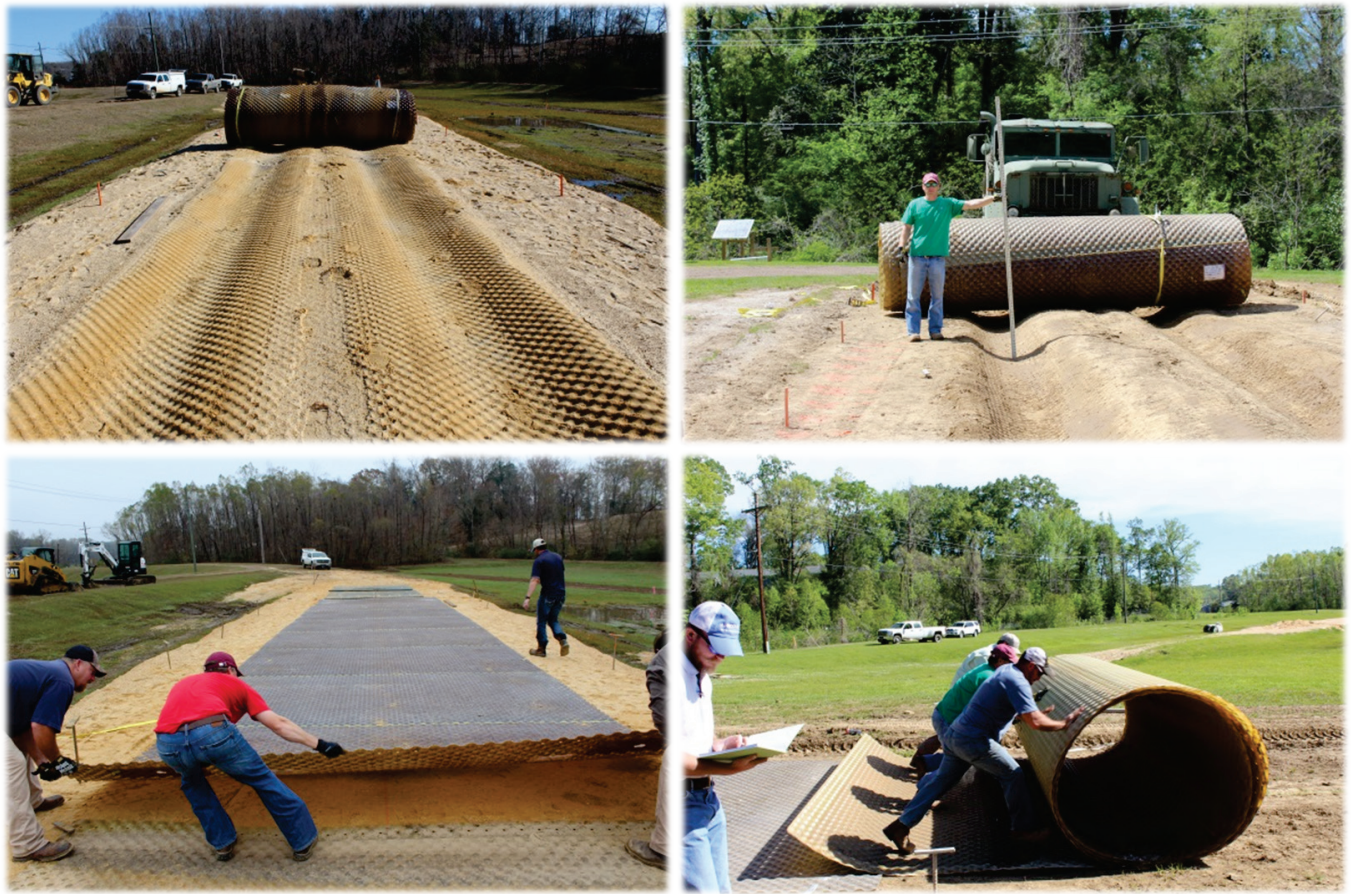
The U.S. Army Engineer Research and Development Center (ERDC) solves the nation's toughest engineering and environmental challenges. ERDC develops innovative solutions in civil and military engineering, geospatial sciences, water resources, and environmental sciences for the Army, the Department of Defense, civilian agencies, and our nation's public good. Find out more at www.erdc.usace.army.mil.

To search for other technical reports published by ERDC, visit the ERDC online library at http://acwc.sdp.sirsi.net/client/default. 


\title{
Evaluation of WavTrac Expeditionary Mobility Matting System
}

\author{
Webster C. Floyd \\ Geotechnical and Structures Laboratory \\ U.S. Army Engineer Research and Development Center \\ 3909 Halls Ferry Road \\ Vicksburg, MS 39180-6199
}

Final report

Approved for public release; distribution is unlimited.
Prepared for Marine Corps System Command 2202 Lester Street
Quantico, VA 22134

Under Work Unit 33143 and Task number 38254J 


\section{Abstract}

The legacy Mo-Mat expeditionary mobility matting system used extensively by the U.S. Marine Corps is no longer manufactured. Work performed by the U.S. Army Engineer Research and Development Center (ERDC) (Rushing and Rowland 2012) indicated that replication of the legacy matting system was feasible. Therefore, the U.S. Marine Corps System Command initiated a Small Business Innovative Research effort in order to identify a small business that could develop a replicate system. This report details the evaluation of the WavTrac prototype expeditionary mobility matting system. Under full-scale truck traffic, the WavTrac system performed comparably to the legacy Mo-Mat system on a loose sand subgrade and outperformed the legacy system on a soft soil subgrade typical of a mud flat crossing.

DISCLAIMER: The contents of this report are not to be used for advertising, publication, or promotional purposes. Citation of trade names does not constitute an official endorsement or approval of the use of such commercial products. All product names and trademarks cited are the property of their respective owners. The findings of this report are not to be construed as an official Department of the Army position unless so designated by other authorized documents. 


\section{Contents}

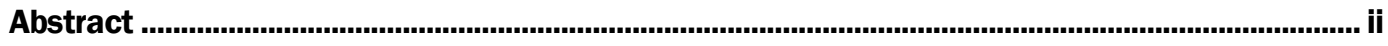

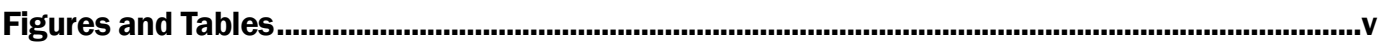

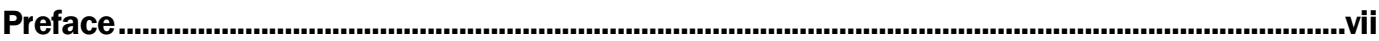

Unit Conversion Factors .................................................................................................................... viii

1 Introduction .............................................................................................................................. 1

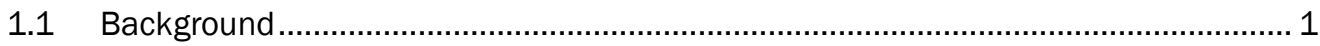

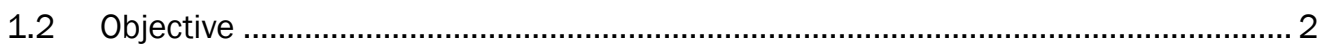

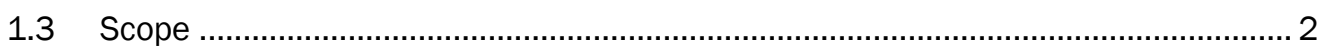

2 Materials................................................................................................................................... 4

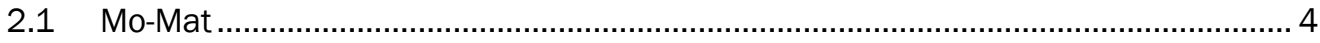

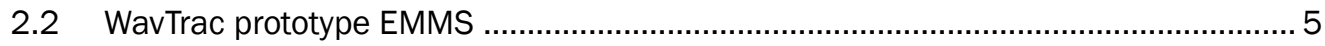

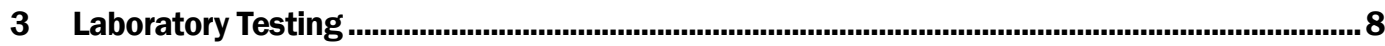

3.1 Summary of test methods.......................................................................... 8

3.1.1 ASTM International (2007) (D3039) Standard test method for tensile properties of polymer matrix composite materials .............................................................. 8

3.1.2 ASTM International (2010a) (D6272) Standard test method for flexural properties of unreinforced and reinforced plastics and electrical insulating materials by four-point bending.....

3.2 Tensile strength testing results............................................................................. 9

3.3 Flexural strength testing results ........................................................................ 11

3.4 Comparison to legacy Mo-Mat EMMS laboratory test results .................................13

4 Full-Scale Test Section Construction ....................................................................................16

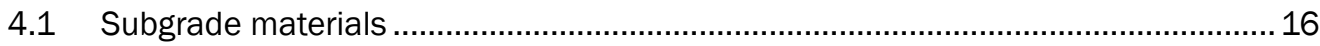

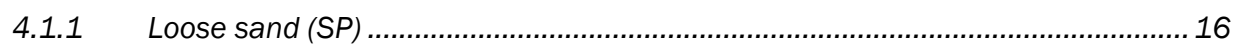

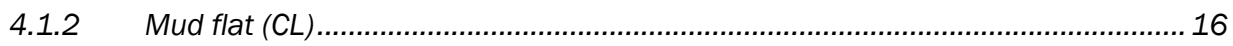

4.2 Full-scale test section construction .............................................................. 17

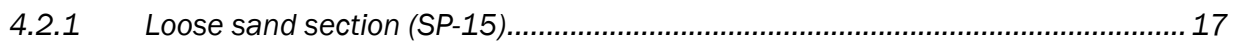

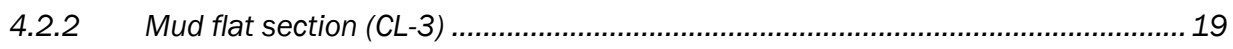

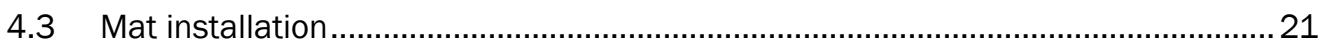

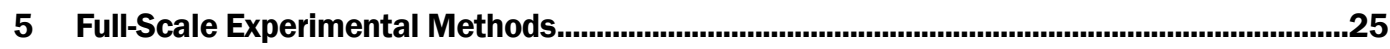

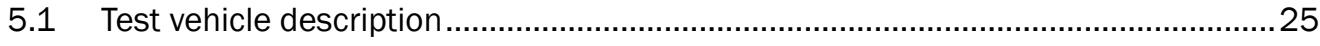

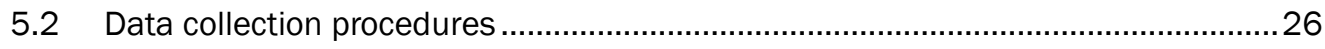

5.2.1 Cross sectioning and data collection locations.....................................................26

5.2.2 Pretest subgrade data collection ....................................................................... 26

5.2.3 Data collection during traffic testing................................................................. 27

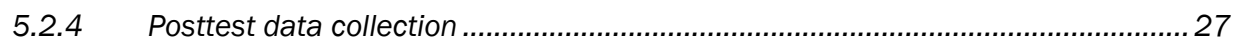




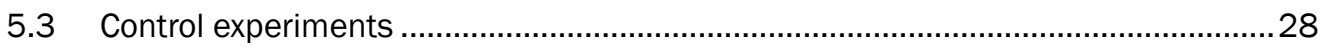

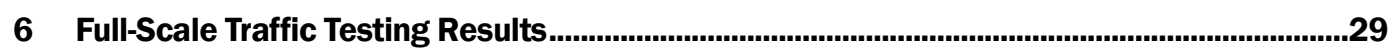

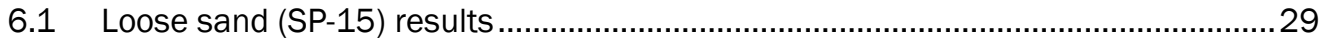

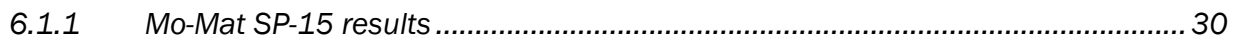

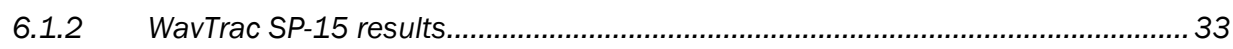

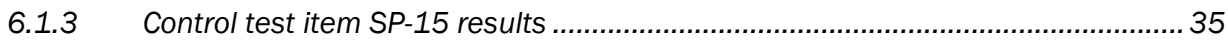

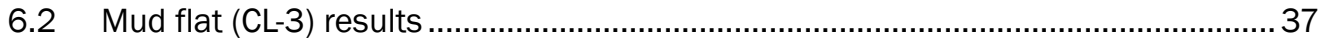

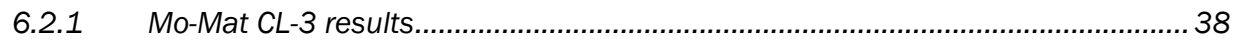

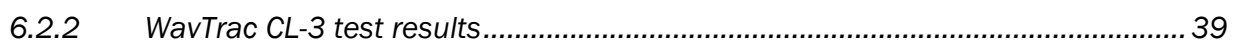

6.2.3 Control test item CL-3 results........................................................................ 43

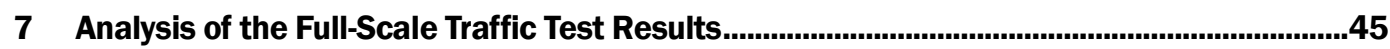

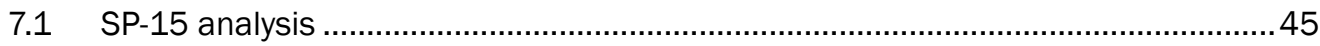

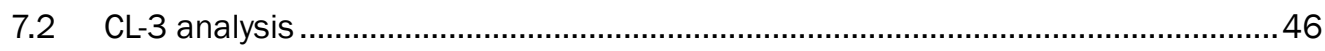

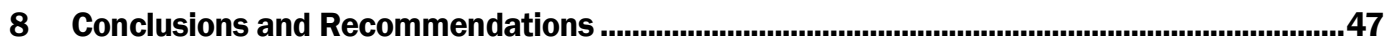

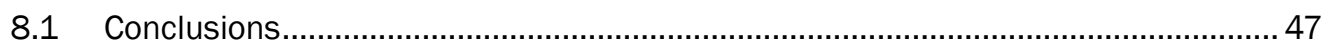

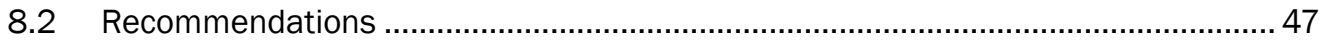

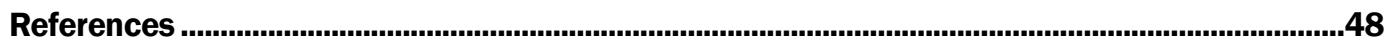

Appendix A: USMC EMMS Requirements Document............................................................49

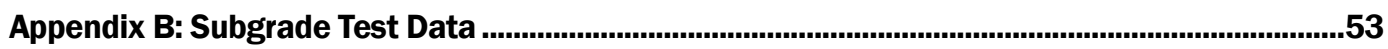

Report Documentation Page 


\section{Figures and Tables}

\section{Figures}

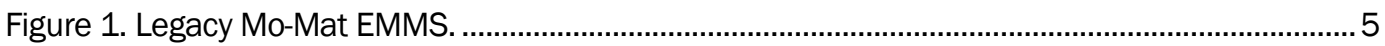

Figure 2. Legacy Mo-Mat EMMS surface texture........................................................................

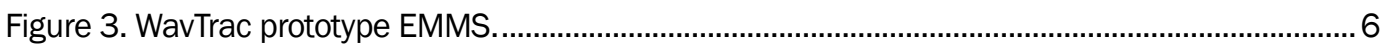

Figure 4. WavTrac prototype EMMS surface texture. ……………………………………….....

Figure 5. WavTrac tensile strength plot - longitudinal. ....................................................................10

Figure 6. WavTrac tensile strength plot - diagonal. .......................................................................10

Figure 7. WavTrac flexural strength plot - longitudinal. ................................................................12

Figure 8. WavTrac flexural strength plot - diagonal. ....................................................................12

Figure 9. SP Material particle size distribution curve...........................................................................17

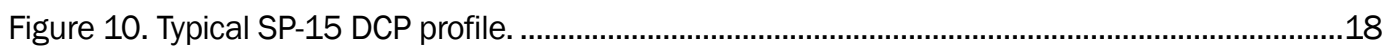

Figure 11. SP-15 section overall. ................................................................................................19

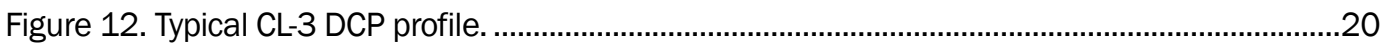

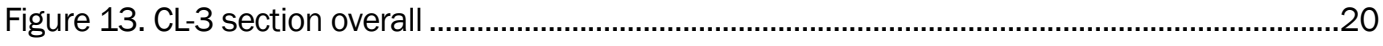

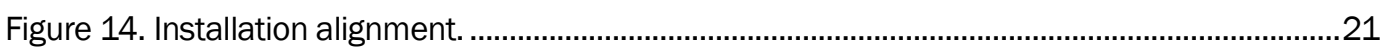

Figure 15. WavTrac installation roll-out. ..................................................................................22

Figure 16. Installation anchoring. …………………………...................................................22

Figure 17. Close-up view of installed T-stake anchor.......................................................................23

Figure 18. Overall SP-15 section with mats. .................................................................................23

Figure 19. Overall CL-3 section with mats and test vehicle................................................................24

Figure 20. USMC 7-ton MTVR test vehicle..................................................................................25

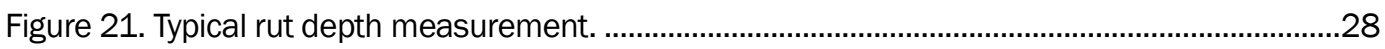

Figure 22. Average rut depth for SP-15 test items. ………...........................................................29

Figure 23. Mo-Mat test item cross-section 1 transverse profiles (SP-15)..........................................31

Figure 24. Mo-Mat test area cross-section 2 transverse profiles (SP-15).........................................31

Figure 25. Mo-Mat test area cross-section 3 transverse profiles (SP-15).......................................32

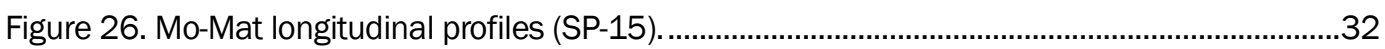

Figure 27. Mo-Mat transverse crack (SP-15) at 2,000 passes..........................................................33

Figure 28. WavTrac test item cross section 1 transverse profiles (SP-15)........................................34

Figure 29. WavTrac test item cross section 2 transverse profiles (SP-15).......................................34

Figure 30. WavTrac test item cross section 3 transverse profiles (SP-15)........................................35

Figure 31. WavTrac longitudinal profiles (SP-15). ......................................................................35

Figure 32. Control test item cross section 1 transverse profiles (SP-15).........................................36

Figure 33. Control test item cross section 2 transverse profiles (SP-15)..........................................36

Figure 34. Control test item cross section 3 transverse profiles (SP-15)...........................................37

Figure 35. Control section longitudinal profiles (SP-15) . ...................................................................3 
Figure 36. Average rut depth for CL-3 test areas. ………….....................................................38

Figure 37. Mo-Mat test area typical damage during early traffic (CL-3)...........................................39

Figure 38. WavTrac test area cross section 1 transverse profiles (CL-3).........................................40

Figure 39. WavTrac test item cross section 2 transverse profiles (CL-3)...........................................40

Figure 40. WavTrac test item cross section 3 transverse profiles (CL-3)......................................... 41

Figure 41. WavTrac longitudinal profiles (CL-3) . ............................................................................. 41

Figure 42. Typical damage from axle scraping..............................................................................42

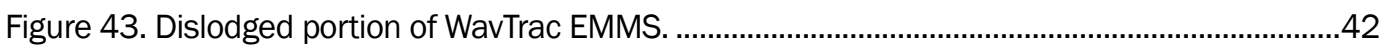

Figure 44. Control test item cross section 1 transverse profiles (CL-3)...........................................43

Figure 45. Control test item cross section 2 transverse profiles (CL-3).............................................43

Figure 46. Control test item cross section 3 transverse profiles (CL-3) ............................................44

Figure 47. Control test item longitudinal profiles (CL-3) . ....................................................................4

\section{Tables}

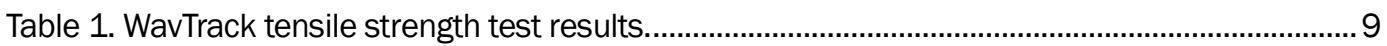

Table 2. WavTrac flexural strength test results..................................................................................11

Table 3. Comparative EMMS tensile strength test results. ..............................................................13

Table 4. Comparative EMMS flexural strength test results. ............................................................14

Table 5. Average rut depth for SP-15 test items. ...........................................................................30

Table 6. Average rut depth for CL-3 test items. …………............................................................38 


\section{Preface}

This study was conducted for the Marine Corps Systems Command. The technical monitor was Jeb S. Tingle.

The work was performed by the Airfields and Pavements Branch (APB) of the Engineering Systems and Materials Division (ESMD), U.S. Army Engineer Research and Development Center (ERDC), Geotechnical and Structures Laboratory (GSL). At the time of publication, Dr. Timothy W. Rushing was Chief, APB; Dr. Gordon W. McMahon was Chief, ESMD; and Nicholas Boone was the Technical Director for Force Projection and Maneuver Support. The Deputy Director of ERDC-GSL was Dr. William P. Grogan, and the Director was Bartley P. Durst.

COL Bryan S. Green was the Commander of ERDC, and Dr. David W. Pittman was the Director. 


\section{Unit Conversion Factors}

\begin{tabular}{|l|c|l|}
\hline Multiply & By & To Obtain \\
\hline degrees (angle) & 0.01745329 & radians \\
\hline feet & 0.3048 & meters \\
\hline inches & 0.0254 & meters \\
\hline miles per hour & 0.44704 & meters per second \\
\hline ounces (mass) & 0.02834952 & kilograms \\
\hline pounds (force) & 4.448222 & newtons \\
\hline pounds (force) per square inch & 6.894757 & kilopascals \\
\hline pounds (mass) & 0.45359237 & kilograms \\
\hline pounds (mass) per square foot & 4.882428 & kilograms per square \\
& & meter \\
\hline square feet & 9.09290304 & square meters \\
\hline tons (2,000 pounds, mass) & 907.1847 & kilograms \\
\hline yards & 0.9144 & meters \\
\hline
\end{tabular}




\section{Introduction}

\subsection{Background}

The U.S. Marine Corps' (USMC) mission includes the requirement to support expeditionary forces and sustainment activities. The USMC's broad mission requires operations in all types of terrain including beaches, marshes, mud flats, urban terrain, and mountains. While initial tactical forces are equipped with high mobility vehicles, follow-on sustainment vehicles have reduced mobility characteristics relative to forward units. Although poor terrain conditions may not cause vehicle immobilization due to the capabilities of the USMC equipment, they may result in reduced logistical throughput and excessive wear on the equipment. For this reason, expeditionary road surfaces have been used to enhance vehicle mobility and expedite throughput across difficult terrain.

One category of expeditionary road surfacing includes lightweight matting, such as the legacy USMC Mo-Mat expeditionary mobility matting system (EMMS). Unfortunately, Mo-Mat is no longer manufactured, and stockpiled inventory of this matting system has been practically depleted. To find a replacement system, the Marine Corps Systems Command (MCSC) initiated several requests for information to identify potential candidates available on the commercial market. Based on a review of product literature, several systems seemed promising for use as temporary roads across sandy soils and mud flats, prompting MCSC to evaluate several commercial-off-theshelf (COTS) mat systems under military truck traffic in a study by Rushing et al. (2007). Although many of the systems were able to support the required vehicle loadings, none of the COTS systems met all USMC requirements. Therefore, MCSC further refined its requirement for EMMS (Appendix A), funded a feasibility study for the re-creation of the original Mo-Mat system, and supported design efforts for development of new systems. The results of this feasibility study are compiled in Rushing and Rowland (2012), where test results indicated that replication of the performance characteristics of the legacy Mo-Mat system was feasible.

As a result of the effort by Rushing and Rowland (2012), the MCSC began the Small Business Innovation Research (SBIR) process through the Navy SBIR office in order to identify a small business with the innovative potential and capability to develop a durable, low-cost soil stabilization 
mat optimized for automated pultrusion manufacturing in 2010 (Navy SBIR FY2010.2 N102-109). Based on technical merit, feasibility, and commercial potential of research and development efforts proposed by qualified small businesses, XCraft, Inc. was selected as the awardee for N102-109. The evaluation described in this technical report includes the laboratory and full-scale evaluation of the prototype WavTrac EMMS produced by XCraft, Inc.

\subsection{Objective}

The objective of this project was to verify that the performance of the WavTrac prototype EMMS meets the MCSC requirements given in Appendix A and is comparable to the legacy Mo-Mat EMMS for future procurement purposes. This project generated performance, durability, and logistics information to support USMC decisions concerning acquisition and procurement of roadway matting systems. The specific requirements evaluated during this project include the following:

1. The EMMS must support a minimum of 2,000 passes of a 7-ton Medium Tactical Vehicle Replacement (MTVR) truck loaded to a standard off-road payload capacity when placed over a loose sand subgrade with California Bearing Ratio (CBR) of 15 percent.

2. The EMMS must support a minimum of 500 passes of a 7-ton MTVR truck loaded to its off-road payload capacity when placed over a soft fine-grained subgrade with a CBR of 3 percent.

3. The EMMS must be capable of deploying at a minimum rate of $2,500 \mathrm{sq} f \mathrm{ft}$ per man-hour with a four-person crew.

4. The EMMS must be capable of being retrieved at a minimum rate of $400 \mathrm{sq} \mathrm{ft}$ per man-hour of effort.

\subsection{Scope}

The project objective was accomplished by conducting laboratory tensile and bending tests on samples of material from the supplied WavTrac prototype EMMS for comparison to legacy Mo-Mat laboratory test data reported by Rushing and Rowland (2012). Additionally, full-scale traffic tests were conducted on the legacy Mo-Mat and prototype replicate WavTrac systems over subgrade conditions representative of both loose sand and mud flat crossings. All laboratory and full-scale traffic testing was performed at the U.S Army Engineer Research and Development Center (ERDC) in Vicksburg, MS. 
Chapter 2 provides a detailed description of the EMMS evaluated in this effort. Chapter 3 describes the laboratory test methods and results. Chapter 4 describes the subgrade materials, full-scale test section construction process, and mat installation. Chapter 5 provides a full-scale experimental method, while Chapters 6 and 7 summarize results, conclusions, and recommendations. Appendix A provides a copy of the MCSC requirements for EMMS as of November 2011, and Appendix B gives raw data from subgrade testing. 


\section{Materials}

This chapter provides technical descriptions and images of both the legacy Mo-Mat EMMS and the prototype replicate WavTrac EMMS. Both mat systems take advantage of a 45-deg directional reinforcing material shift from the longitudinal axis of the mat which allows the mat to roll up for storage and shipment.

\subsection{Mo-Mat}

The legacy Mo-Mat EMMS was a rolled fiberglass panel system developed and marketed by Air Logistics Corporation in Pasadena, CA. The panels were molded in a waffle-weave pattern from a proprietary fiberglassreinforced material called STRATOGLAS $®$. The STRATOGLAS $₫$ material was made of four plies of $10 \mathrm{oz} / \mathrm{yd}^{2}, 45$-deg unidirectional stitched E-Glass. The glass material was molded with a thermoset resin to create a Mo-Mat panel. Panels were tan in color and had a nonskid material applied to the wearing surface. Typical mat dimensions were $12 \mathrm{ft}, 2$ in. wide by $48 \mathrm{ft}, 6 \mathrm{in}$. long. Each mat weighed approximately $600 \mathrm{lb}$ or approximately $1.07 \mathrm{lb} / \mathrm{ft}^{2}$. The node spacing in the longitudinal and transverse directions was approximately $4 \mathrm{in}$., while the diagonal node spacing was approximately $2.8 \mathrm{in}$. The Mo-Mat system was designed for temporary roadways across mud and sand subgrades and for helipads and light aircraft parking. MoMat has been used extensively by the USMC since the late 1960 s but is no longer manufactured. The Mo-Mat EMMS used for this evaluation was acquired from a USMC warehouse and stored outdoors following evaluation by Rushing and Rowland (2012) prior to its use for this effort. Upon receipt from the USMC, a packaging slip with the Mo-Mat delivery indicated that the product had been manufactured and packaged in 1969. Although not all components were included in this evaluation, a complete Mo-Mat kit was delivered to ERDC including six Mo-Mat panels, anchor assemblies, edge reinforcement, repair kits, and recovery straps. Mats were delivered for testing on a pallet in a single roll of approximate 4 -ft diam and weighing $3,750 \mathrm{lb}$. Figure 1 is a photo showing legacy Mo-Mat EMMS overall, while Figure 2 shows a close-up image of the surface texture. 
Figure 1. Legacy Mo-Mat EMMS.

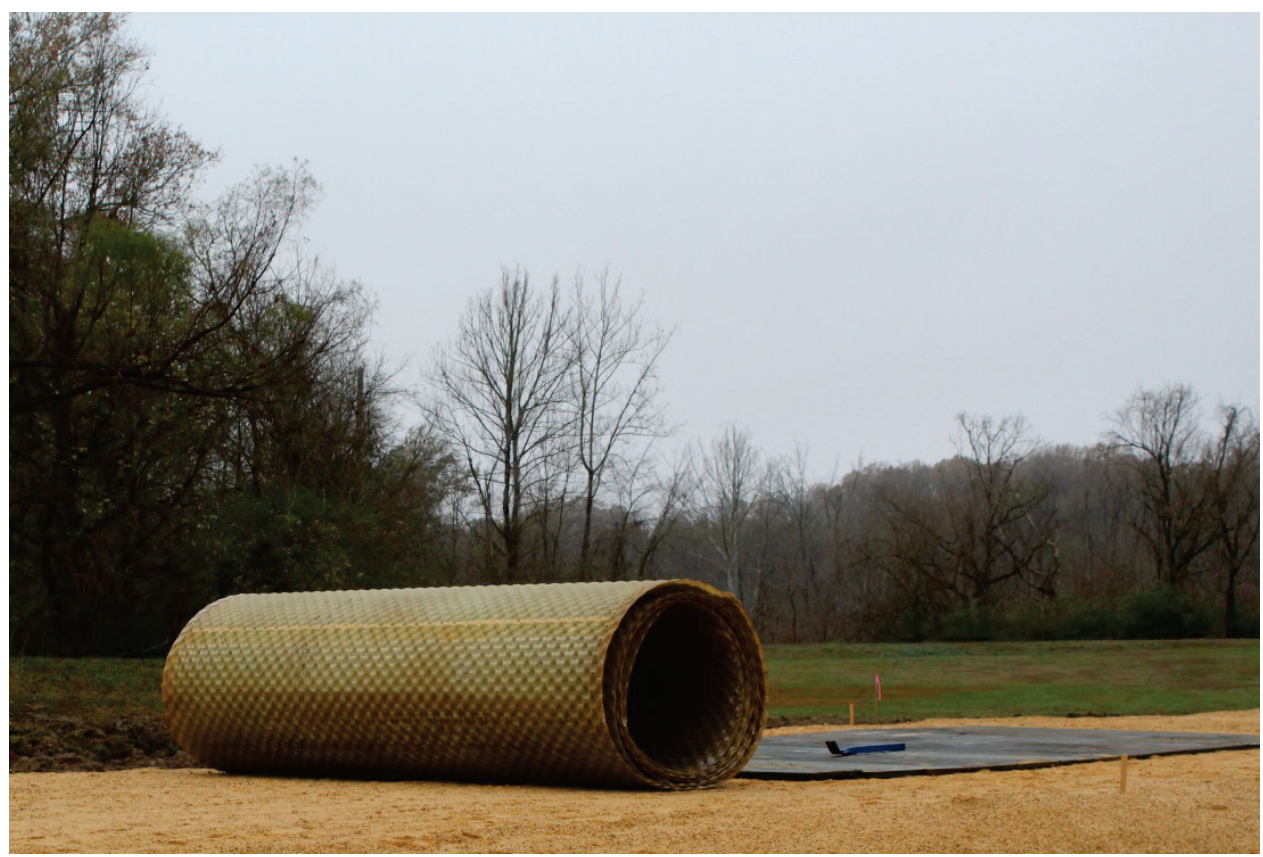

Figure 2. Legacy Mo-Mat EMMS surface texture.

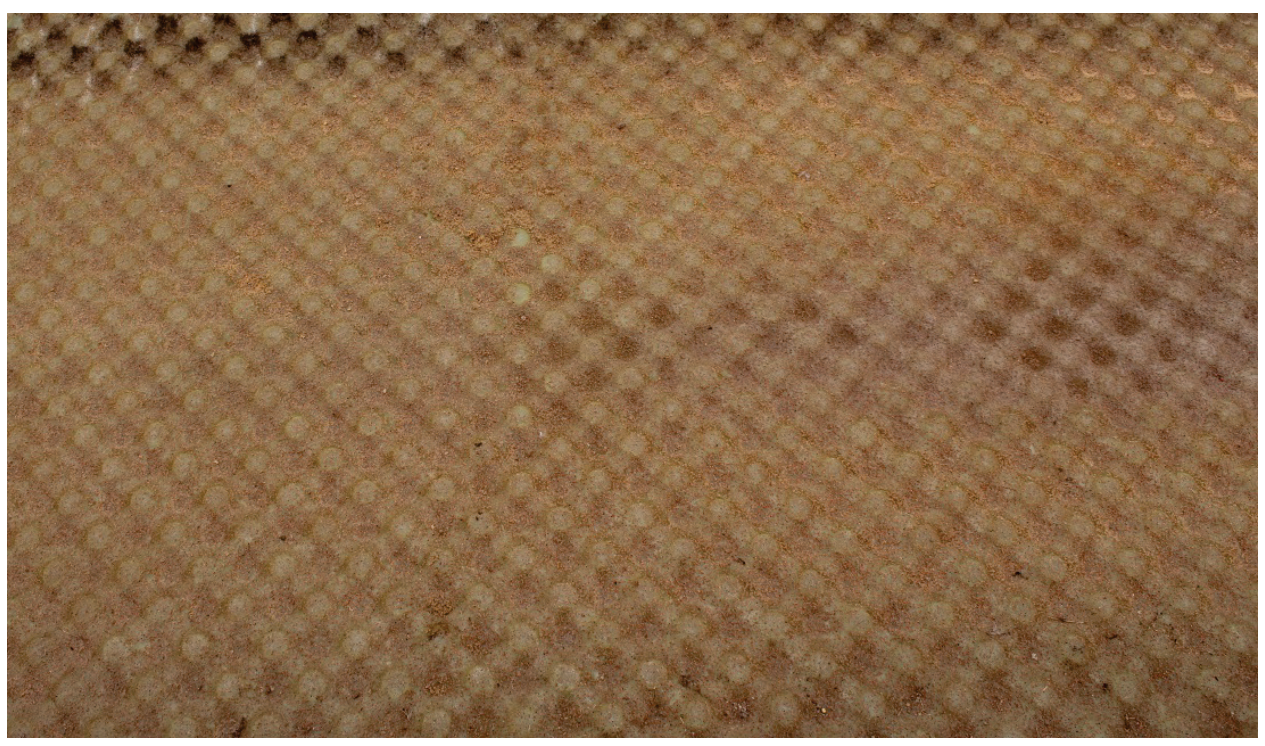

\subsection{WavTrac prototype EMMS}

The WavTrac prototype EMMS was developed under Navy SBIR N102-109 by XCraft, Inc. and was delivered to ERDC on 2 November 2015. WavTrac mats were stored under a protective shelter prior to installation and traffic testing. Mat panels were fabricated by XCraft, Inc. using commercially available E-grade fiberglass at $1.2 \mathrm{lb} / \mathrm{ft}^{2}$ and Derakane thermosetting vinyl ester resin. Catalyst and resin promoters as well as post-curing cycles used by XCraft, Inc. are considered proprietary and were not disclosed to ERDC. 
According to the manufacturer, the WavTrac EMMS has a fiber volume fraction of approximately 63 percent. The mats were constructed using a light resin transfer molding (LRTM) pultrusion process to form individual panels of $14 \mathrm{ft}$ by $8 \mathrm{ft}$, of which eight are bonded together via a commercially available acrylic adhesive with particulate modifiers to form an approximate 14 -ft by $60-\mathrm{ft}$ section. Each mat weighed approximately $966 \mathrm{lb}$ or $1.15 \mathrm{lb} / \mathrm{ft}^{2}$. Panels were brown to dark brown in color and had a nonskid material applied to the wearing surface. Panels were molded in a waffle-weave pattern with a final surface profile similar to that of the legacy Mo-Mat EMMS. The node spacing in the longitudinal and transverse directions was approximately 3 in., while the node spacing in the diagonal direction was approximately $2.2 \mathrm{in}$. This closer node spacing with respect to the legacy Mo-Mat EMMS is expected to provide improved performance under vehicular traffic. Figure 3 is an overall photo of the prototype WavTrac EMMS, while Figure 4 provides a close-up image of the surface texture.

Figure 3. WavTrac prototype EMMS.

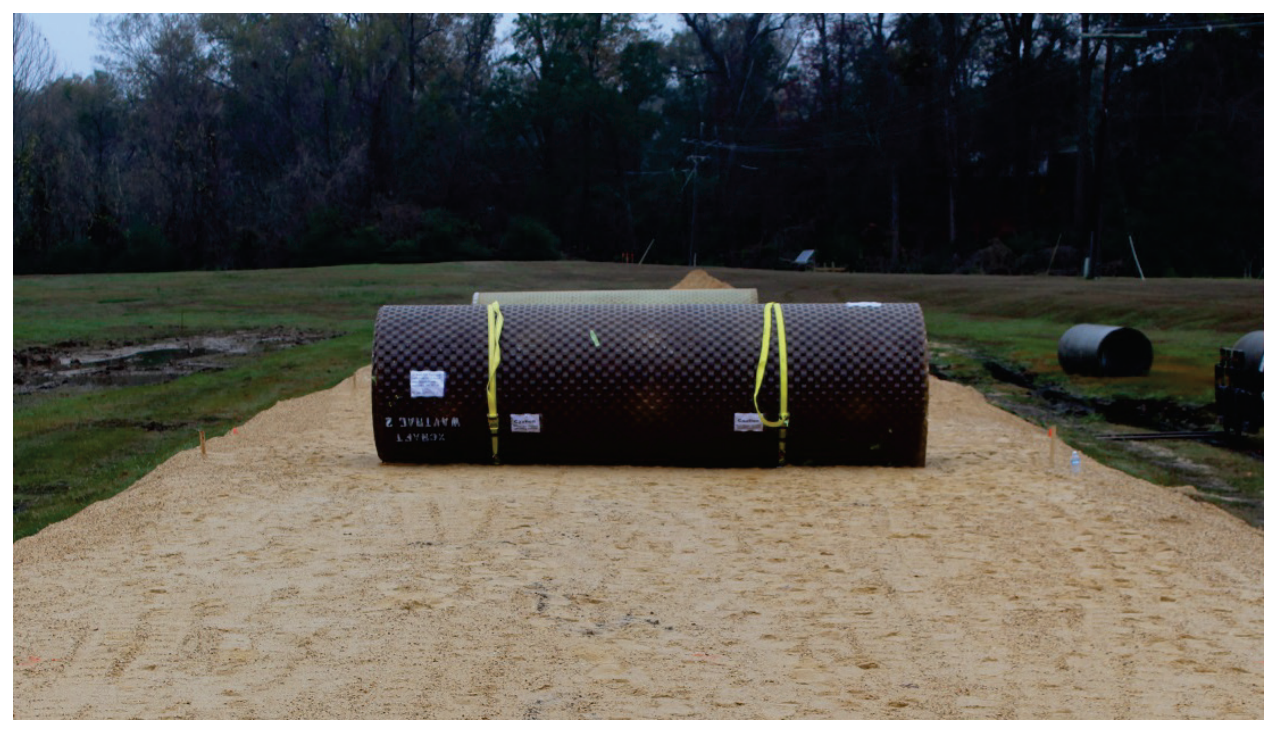


Figure 4. WavTrac prototype EMMS surface texture.

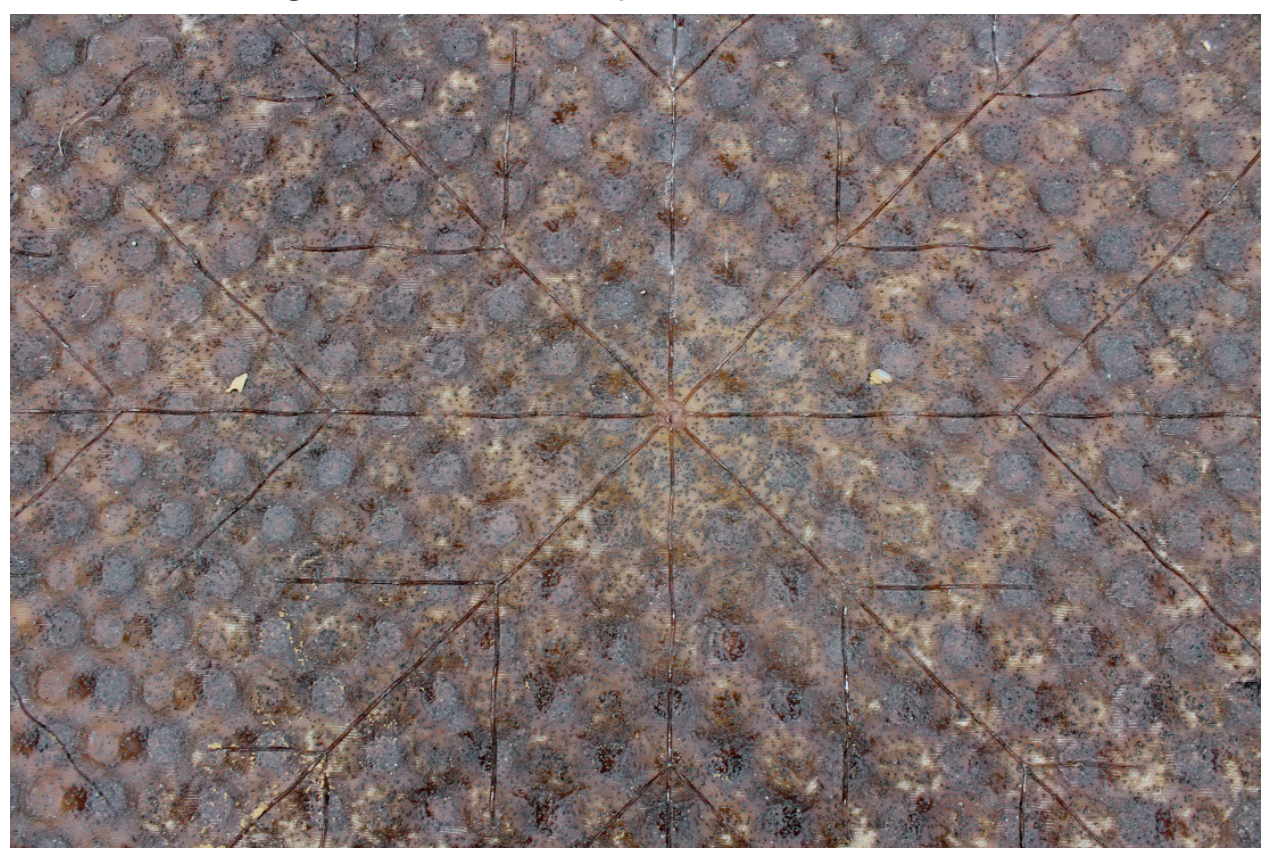




\section{Laboratory Testing}

Laboratory testing was conducted utilizing the same test methods and sample preparation methods described by Rushing and Rowland (2012). Results from laboratory testing of the WavTrac EMMS are directly compared to results reported by Rushing and Rowland (2012) in this chapter.

\subsection{Summary of test methods}

\subsubsection{ASTM International (2007) (D3039) Standard test method for tensile properties of polymer matrix composite materials}

ASTM International (2007)(D3039) Standard test method for tensile properties of polymer matrix composite materials tension tests were performed on specimens taken from the WavTrac prototype EMMS. Test specimens were $4 \mathrm{in}$. wide by $12 \mathrm{in}$. long and taken at o deg and $45 \mathrm{deg}$ from the longitudinal axis. Displacement-controlled loading was applied at a rate of $0.05 \mathrm{in} . / \mathrm{min}$ using a 60,000-lbf capacity Instron load frame located at ERDC. Due to the irregular cross-sectional shape of the WavTrac prototype EMMS, the grips utilized for tensile testing on the Instron load frame could not effectively grasp the specimens. Thus (to create a flat surface for tensile specimen gripping), a two-part, high-strength epoxy adhesive was injected into a rectangular mold. WavTrac specimens were inserted into the mold to create grips on each end of test specimens as recommended by Rushing and Rowland (2012). The epoxy was ULTRABOND 1300, manufactured by Adhesives Technology Corporation. All specimens were tested with the nonskid surface facing to the test operator's right-hand direction.

\subsubsection{ASTM International (2010a) (D6272) Standard test method for flexural properties of unreinforced and reinforced plastics and electrical insulating materials by four-point bending}

ASTM D6272 Standard test method for flexural properties of unreinforced and reinforced plastics and electrical insulating materials by four-point bending tests were performed on specimens taken from the WavTrac prototype EMMS. Test specimens were 4 in. wide by $12 \mathrm{in.} \mathrm{long} \mathrm{and} \mathrm{taken} \mathrm{at}$ o deg and 45 deg from the longitudinal axis. The support span was 9 in. long, and the loading noses were spaced at $3 \mathrm{in}$. apart. Constant displacement loading was applied at a rate of $0.43 \mathrm{in} . / \mathrm{min}$ using a $60,000-\mathrm{lbf}$ 
capacity Instron load frame located at ERDC. All specimens were tested with the nonskid surface facing upward.

\subsection{Tensile strength testing results}

The results of tensile strength testing of the WavTrac prototype EMMS are provided in Table 1. Figures 5 and 6 provide plots of tensile load versus tensile elongation for both the longitudinal and diagonal directions, respectively. As was expected, and due to the 45-deg reinforcement direction shift from the longitudinal direction, the WavTrac prototype EMMS exhibited a higher resistance to tensile failure in the diagonal direction than in the longitudinal direction. The average of four longitudinal tensile strength tests indicates that the prototype mat system has an average ultimate tensile strength of 7,733 lbf at an average tensile extension at maximum load of 0.653 in. when tested under the previously described test conditions. This value is approximately 2,300 lbf less than the average of five diagonal tensile strength tests, which was 10,011 lbf at an average tensile extension at maximum load of $0.542 \mathrm{in}$. These results equate to a 23 percent increase in tensile strength and a 17 percent decrease in extension at maximum load when tested in the diagonal direction compared to the longitudinal direction. Of note is the fact that the decrease in extension at maximum load for the diagonal direction with respect to the longitudinal direction indicates a higher directional tensile modulus and a more brittle failure mode in the diagonal direction.

Table 1. WavTrack tensile strength test results.

\begin{tabular}{|l|r|r|r|r|}
\hline & \multicolumn{2}{|c|}{ Longitudinal } & \multicolumn{2}{c|}{ Diagonal } \\
\hline Specimen I D & Load, lb & Extension, in & Load, lb & Extension, in \\
\hline $\mathbf{1}$ & 7424 & 0.544 & 10312 & 0.585 \\
\hline $\mathbf{2}$ & 8517 & 0.680 & 10733 & 0.638 \\
\hline 3 & 7662 & 0.712 & 12451 & 0.548 \\
\hline 4 & 7328 & 0.676 & 9323 & 0.513 \\
\hline 5 & -- & -- & 7234 & 0.428 \\
\hline Min. & 7328 & 0.544 & 7234 & 0.428 \\
\hline Max. & 8517 & 0.712 & 12451 & 0.638 \\
\hline AVG & 7733 & 0.653 & 10011 & 0.542 \\
\hline Std. Dev. & 541 & 0.074 & 1920 & 0.079 \\
\hline COV & 0.07 & 0.11 & 0.19 & 0.15 \\
\hline
\end{tabular}


Figure 5. WavTrac tensile strength plot - longitudinal.

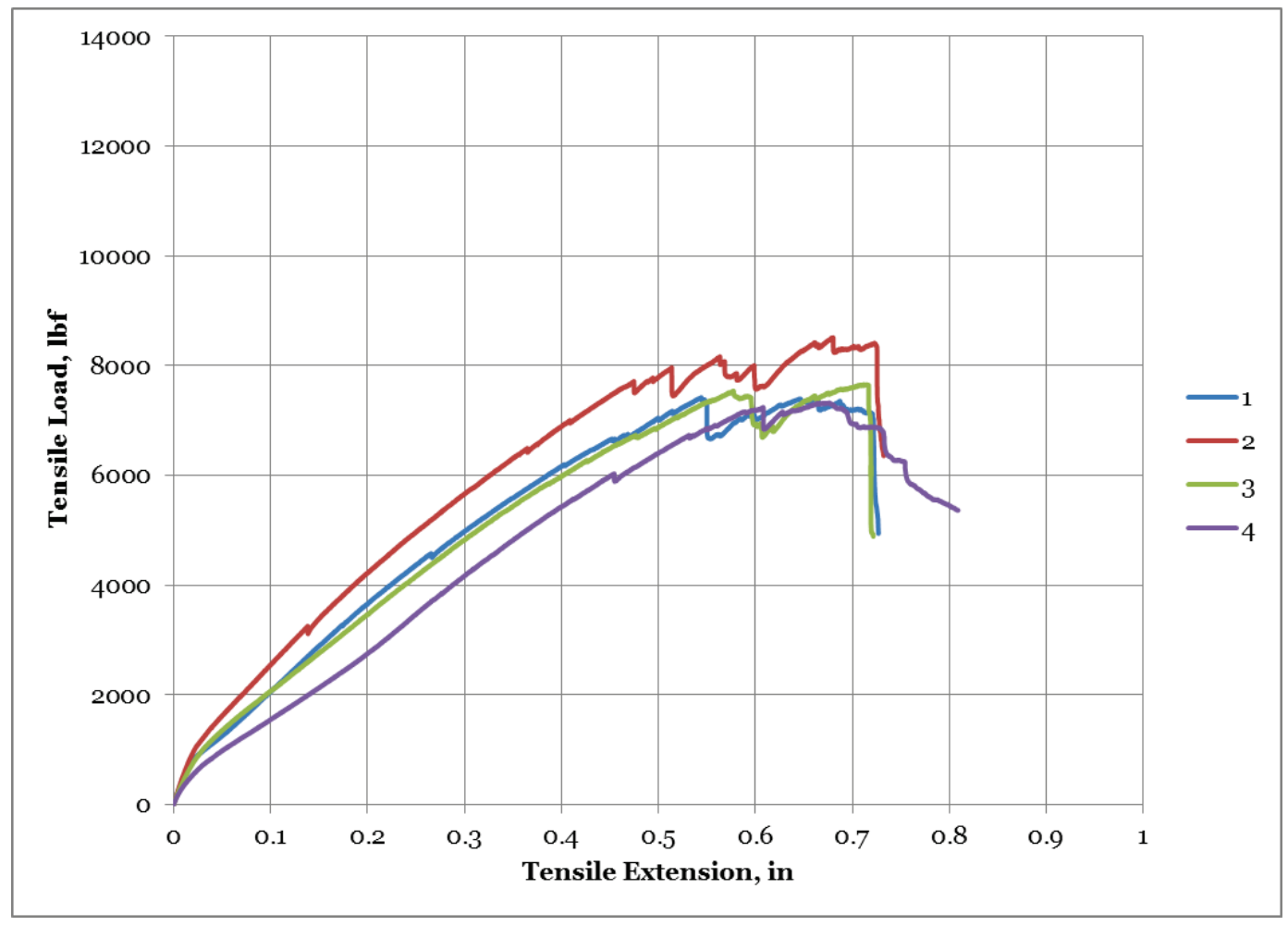

Figure 6. WavTrac tensile strength plot - diagonal.

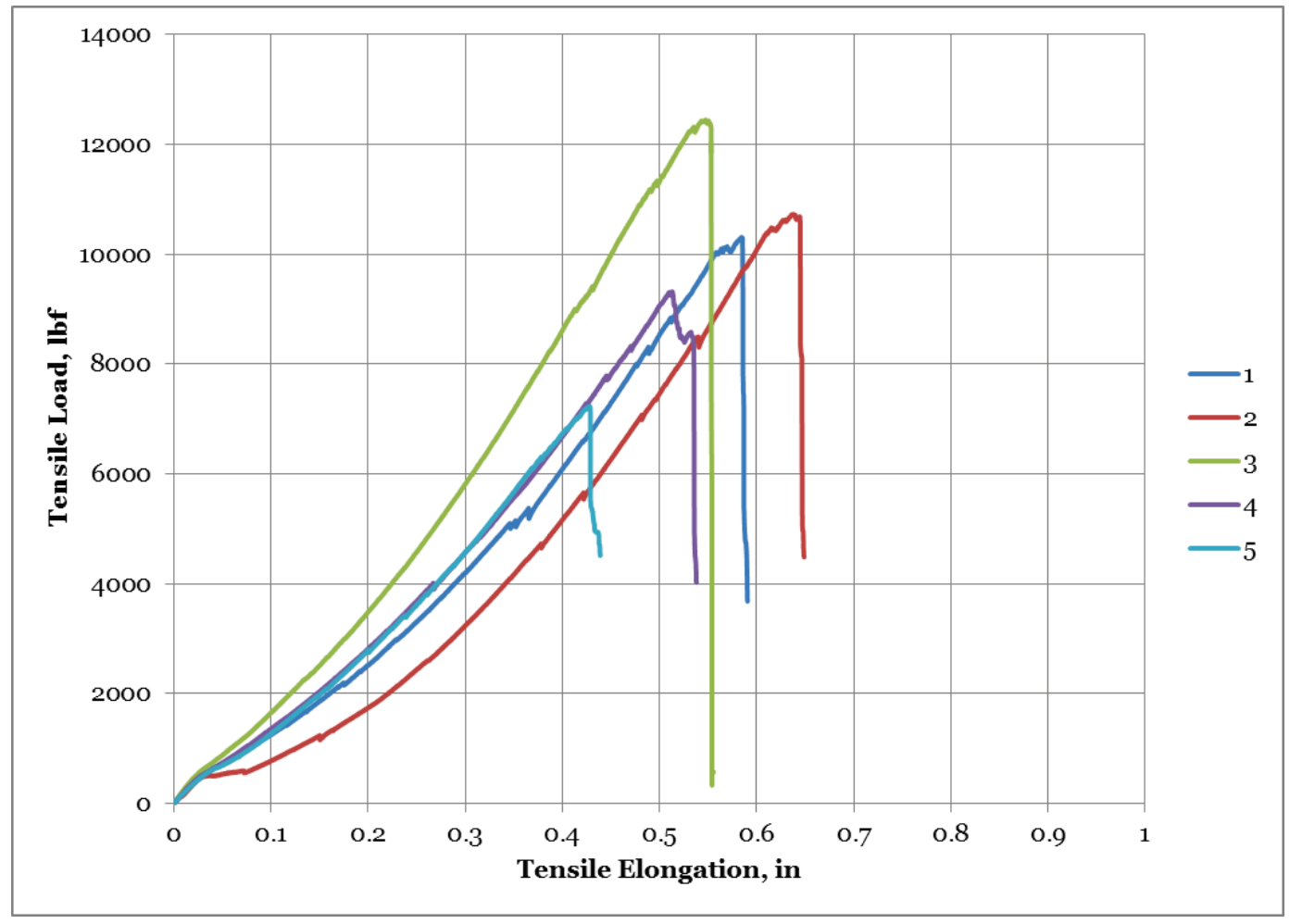




\subsection{Flexural strength testing results}

The results of the flexural strength testing of the WavTrac prototype EMMS are provided in Table 2. Figures 7 and 8 provide plots of flexural load versus flexural elongation for both the longitudinal and diagonal directions, respectively. As was expected, and due to the 45-deg reinforcement direction shift from the longitudinal direction, the WavTrac prototype EMMS exhibited a higher resistance to flexural failure in the diagonal direction than in the longitudinal direction. The average of five longitudinal flexural strength tests indicates that the prototype mat system has an average ultimate flexural load of $259.8 \mathrm{lbf}$ at an average flexural extension at maximum load of $2.237 \mathrm{in}$. when tested under the previously described test conditions. This value is approximately $65 \mathrm{lbf}$ less than the average of five diagonal flexural strength tests, which was $325 \mathrm{lbf}$, at an average flexural extension at maximum load of 1.4304 in. These results equate to a 20 percent increase in flexural strength and a 36 percent decrease in extension at maximum flexural load when tested in the diagonal direction compared to the longitudinal direction. Of note is the fact that the decrease in extension at maximum load for the diagonal direction with respect to the longitudinal direction indicates a higher directional flexural modulus and a more brittle failure mode in the diagonal direction.

Table 2. WavTrac flexural strength test results.

\begin{tabular}{|l|r|r|r|r|}
\hline & \multicolumn{2}{|c|}{ Longitudinal } & \multicolumn{2}{c|}{ Diagonal } \\
\hline Specimen I D & Load, lb & Extension, in & Load, lb & Extension, in \\
\hline 1 & 280.0 & 2.353 & 340.0 & 1.342 \\
\hline 2 & 281.0 & 2.378 & 307.0 & 1.712 \\
\hline 3 & 255.0 & 2.323 & 386.0 & 1.151 \\
\hline 4 & 262.0 & 2.269 & 286.0 & 1.358 \\
\hline 5 & 221 & 1.859 & 306.0 & 1.589 \\
\hline Min. & 221.0 & 1.859 & 286.0 & 1.151 \\
\hline Max. & 281.0 & 2.378 & 386.0 & 1.712 \\
\hline AVG & 259.8 & 2.237 & 325 & 1.430 \\
\hline Std. Dev. & 24.4 & 0.215 & 39.2 & 0.221 \\
\hline COV & 0.09 & 0.10 & 0.12 & 0.15 \\
\hline
\end{tabular}


Figure 7. WavTrac flexural strength plot - longitudinal.

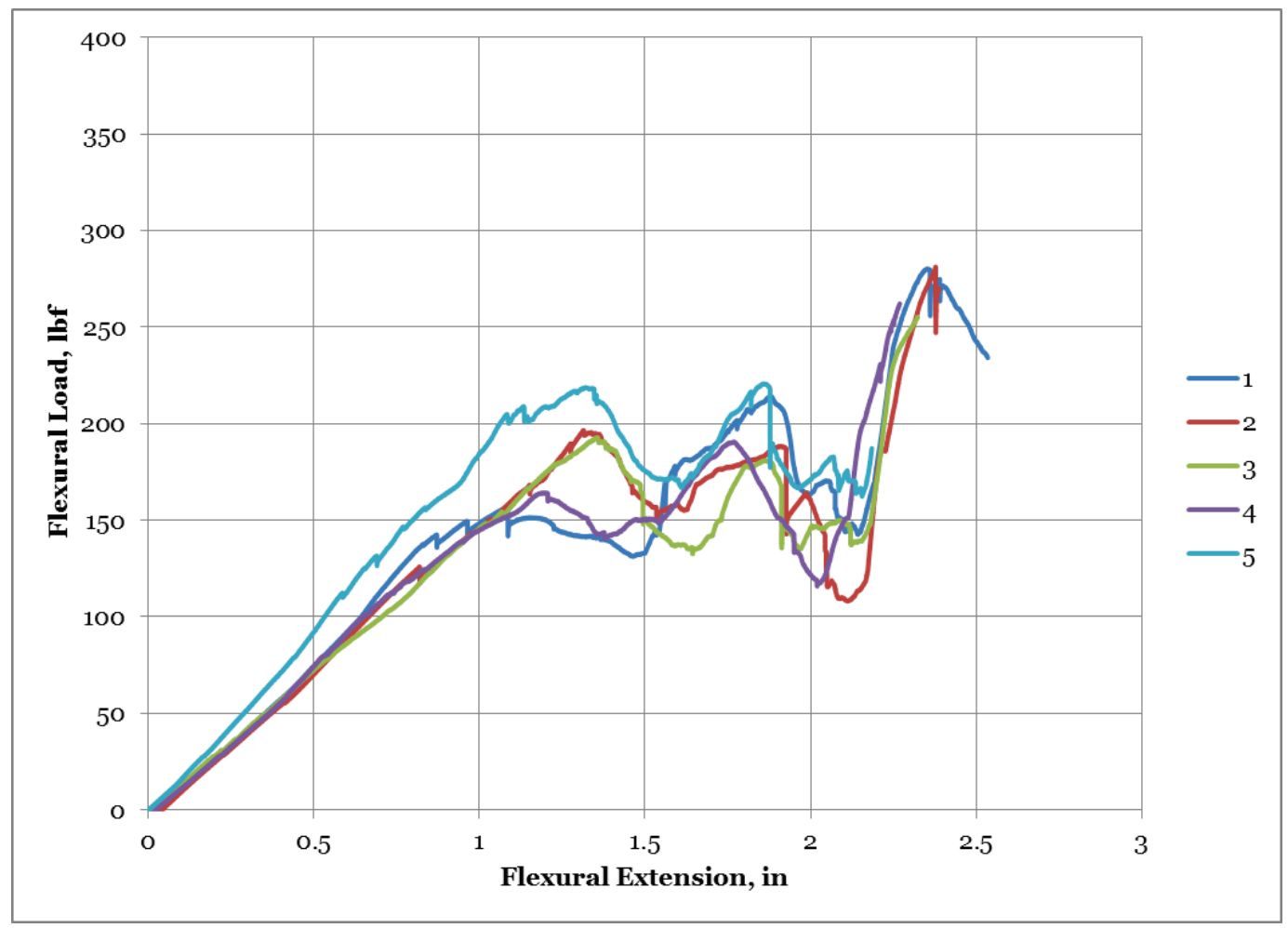

Figure 8. WavTrac flexural strength plot - diagonal.

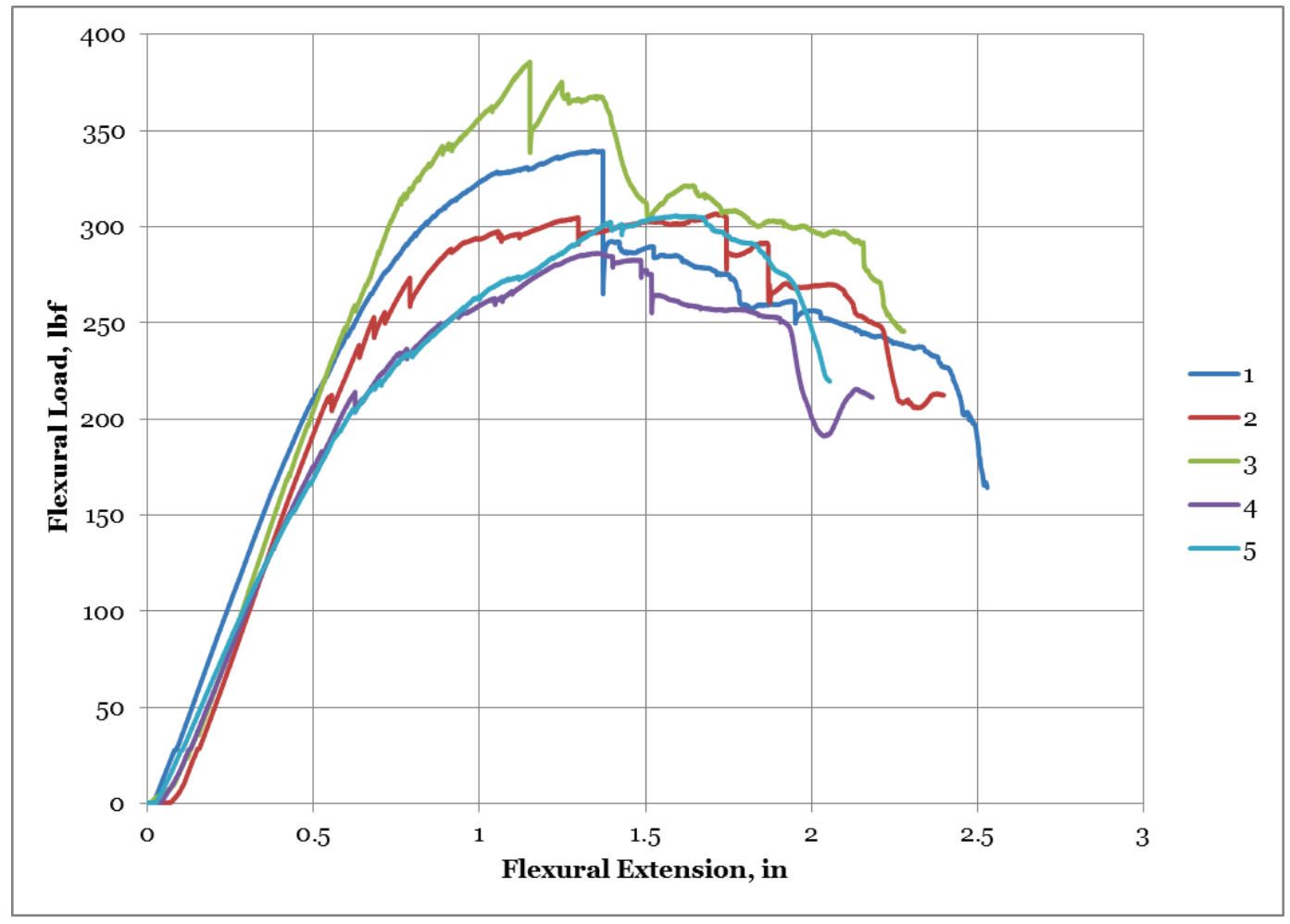




\subsection{Comparison to legacy Mo-Mat EMMS laboratory test results}

The test methods selected to evaluate the tensile and flexural strengths of the WavTrac prototype replicate EMMS were specifically selected to be equivalent to those methods described by Rushing and Rowland (2012) in order for laboratory strength results of this effort to be directly compared to those reported. Table 3 summarizes the tensile strength testing results for both the WavTrac and the legacy Mo-Mat EMMS, while Table 4 summarizes the flexural strength testing results for both systems. All reported values are taken from Rushing and Rowland (2012).

Table 3. Comparative EMMS tensile strength test results.

\begin{tabular}{|c|c|c|c|c|}
\hline \multicolumn{5}{|c|}{ WavTrac EMMS } \\
\hline & \multicolumn{2}{|c|}{ Longitudinal } & \multicolumn{2}{|c|}{ Diagonal } \\
\hline Specimen ID & Load, lb & Extension, in & Load, lb & Extension, in \\
\hline 1 & 7424 & 0.544 & 10312 & 0.585 \\
\hline 2 & 8517 & 0.680 & 10733 & 0.638 \\
\hline 3 & 7662 & 0.712 & 12451 & 0.548 \\
\hline 4 & 7328 & 0.676 & 9323 & 0.513 \\
\hline 5 & -- & -- & 7234 & 0.428 \\
\hline Min. & 7328 & 0.544 & 7234 & 0.428 \\
\hline Max. & 8517 & 0.712 & 12451 & 0.638 \\
\hline AVG & 7733 & 0.653 & 10011 & 0.542 \\
\hline Std. Dev. & 541 & 0.074 & 1920 & 0.079 \\
\hline $\mathrm{COV}$ & 0.07 & 0.11 & 0.19 & 0.15 \\
\hline \multicolumn{5}{|c|}{ Mo-Mat EMMS } \\
\hline & \multicolumn{2}{|c|}{ Longitudinal } & \multicolumn{2}{|c|}{ Diagonal } \\
\hline Specimen ID & Load, lb & Extension, in & Load, lb & Extension, in \\
\hline 1 & 4415 & 0.3 & -- & -- \\
\hline 2 & 4382 & 0.3 & -- & -- \\
\hline 3 & 2822 & 0.4 & -- & -- \\
\hline 4 & -- & -- & -- & -- \\
\hline 5 & -- & -- & -- & -- \\
\hline Min. & 2822 & 0.3 & -- & -- \\
\hline Max. & 4415 & 0.4 & -- & - \\
\hline AVG & 3873 & 0.3 & -- & - \\
\hline Std. Dev. & 910 & 0.1 & -- & -- \\
\hline $\mathrm{COV}$ & 0.24 & 0.17 & -- & - \\
\hline
\end{tabular}

Note: locations within Tables 3 and 4 denoted with “--" indicate unknown values. 
Table 4. Comparative EMMS flexural strength test results.

\begin{tabular}{|c|c|c|c|c|}
\hline \multicolumn{5}{|c|}{ WavTrac EMMS } \\
\hline & \multicolumn{2}{|c|}{ Longitudinal } & \multicolumn{2}{|c|}{ Diagonal } \\
\hline Specimen ID & Load, lb & Extension, in & Load, lb & Extension, in \\
\hline 1 & 280.0 & 2.353 & 340.0 & 1.342 \\
\hline 2 & 281.0 & 2.378 & 307.0 & 1.712 \\
\hline 3 & 255.0 & 2.323 & 386.0 & 1.151 \\
\hline 4 & 262.0 & 2.269 & 286.0 & 1.358 \\
\hline 5 & 221 & 1.859 & 306.0 & 1.589 \\
\hline Min. & 221.0 & 1.859 & 286.0 & 1.151 \\
\hline Max. & 281.0 & 2.378 & 386.0 & 1.712 \\
\hline AVG & 259.8 & 2.237 & 325 & 1.430 \\
\hline Std. Dev. & 24.4 & 0.215 & 39.2 & 0.221 \\
\hline $\mathrm{COV}$ & 0.09 & 0.10 & 0.12 & 0.15 \\
\hline \multicolumn{5}{|c|}{ Mo-Mat EMMS } \\
\hline & \multicolumn{2}{|c|}{ Longitudinal } & \multicolumn{2}{|c|}{ Diagonal } \\
\hline Specimen ID & Load, lb & Extension, in & Load, lb & Extension, in \\
\hline 1 & 111.8 & 1.6 & 263.0 & 0.9 \\
\hline 2 & 129.1 & 1.6 & 232.0 & 1.1 \\
\hline 3 & 152.0 & 1.7 & 283.0 & 1.1 \\
\hline 4 & 157.0 & 1.6 & 274.0 & 1.3 \\
\hline 5 & 168 & 1.7 & 207.0 & 1.1 \\
\hline Min. & 111.8 & 1.6 & 207.0 & 0.9 \\
\hline Max. & 168.0 & 1.7 & 283.0 & 1.3 \\
\hline AVG & 143.6 & 1.6 & 251.8 & 1.1 \\
\hline Std. Dev. & 22.7 & 0.1 & 31.6 & 0.1 \\
\hline COV & 0.16 & 0.03 & 0.13 & 0.13 \\
\hline
\end{tabular}

A comparison of the longitudinal tensile strength of the WavTrac prototype EMMS to the legacy Mo-Mat EMMS indicates that the WavTrac system exhibits a 50 percent higher ultimate tensile strength with a 46 percent approximate increase in the extension at maximum tensile load. The increased strength paired with the increased extension at maximum tensile load indicates that the WavTrac system is more structurally robust than the legacy Mo-Mat EMMS and can experience larger deformations without tensile failure. Due to unavailable data for tensile strength testing in the diagonal direction for the legacy Mo-Mat EMMS, no comparison was made with the tensile strength test data in the diagonal direction.

A comparison of the flexural strength of the WavTrac prototype EMMS to the legacy Mo-Mat EMMS indicates that in the longitudinal direction the prototype EMMS exhibits a 45 percent increase in maximum flexural load 
and a 28 percent increase in flexural extension at maximum load. This same trend holds true when comparing the diagonal direction flexural strength of the two EMMSs. The prototype replicate system has a 23 percent increase in flexural load capacity and a 23 percent increase in flexural extension at maximum load. These higher flexural strengths indicate that the WavTrac prototype EMMS is more effective at transferring load from the mat surface to the subgrade without flexural failure than the legacy Mo-Mat EMMS.

Overall, the WavTrac prototype replicate EMMS has more desirable physical strength and percent elongation at failure properties than the legacy Mo-Mat EMMS. These more desirable physical properties serve to increase both the load-bearing capacity and the fatigue life of the mat system. With identical traffic and subgrade strength, the WavTrac EMMS can be expected to have a longer life cycle under loading than the Mo-Mat EMMS. 


\section{Full-Scale Test Section Construction}

Full-scale test sections were constructed to evaluate the WavTrac prototype replicate EMMS and the legacy Mo-Mat EMMS over simulated loose beach sand and mud flat crossings. These test sections were constructed in order to verify that the WavTrac EMMS is comparable in performance to the legacy EMMS and meets MCSC requirements set forth in the November 2011 requirements document (Appendix A). The following sections describe the materials and construction procedures used to evaluate the matting systems.

\subsection{Subgrade materials}

\subsubsection{Loose sand (SP)}

The material used to simulate a loose beach sand subgrade crossing was procured for the test from a local aggregate supplier (Vinco Inc. of Vicksburg, MS). The loose sand material was classified according to the Unified Soil Classification System (USCS), ASTM International (2011) (D2487) as a poorly graded sand (SP) material. Figure 9 provides a particle size distribution curve for the SP material. Less than 0.5 percent by mass was reported to pass the \#200 sieve. The small amount of fines present were nonplastic.

\subsubsection{Mud flat (CL)}

The material utilized to construct the mud flat test section was an existing cohesive soil present at the test site at ERDC. The material was dredge spoil material that had been transported to the site during the construction of a nearby lake during the 1980 's. This material was primarily composed of native loess deposits of silts and clays common in the Vicksburg, MS, region. Classification according to ASTM International (2010b) (D4318), indicated that the cohesive soil was a CL material with average liquid limit of 43 and average plastic limit of 27. These values yield a plasticity index of 16. It should be noted that the average plasticity index of the material fell slightly above the A-line of the USCS plasticity chart (with respect to the average liquid limit of the material). However, based on past experience with this material, the mud flat material was classified as CL. 
Figure 9. SP Material particle size distribution curve.

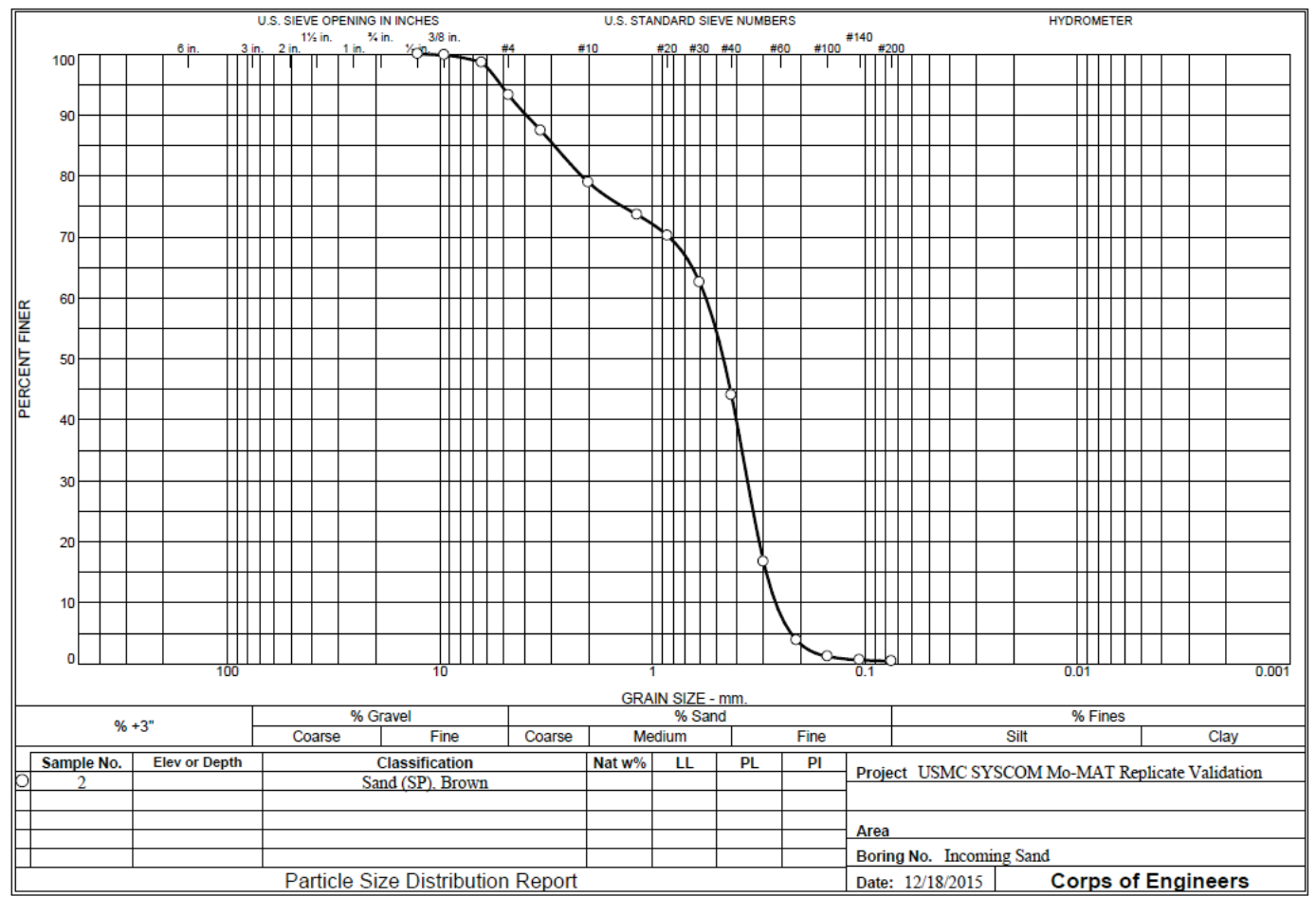

\subsection{Full-scale test section construction}

The full-scale test sections described in this report are defined in terms of their subgrade type and California Bearing Ratio (CBR). The following definitions will be used to describe the subgrade conditions investigated in this report:

- SP-15: loose sand test section with a target CBR of 15 percent and

- CL-3: cohesive, low plasticity silty/clayey test section with target CBR of 3 percent.

Detailed descriptions of test section construction and dimensions are included in the remainder of this subsection. All pertinent subgrade data captured during testing are available in Appendix B.

\subsubsection{Loose sand section (SP-15)}

The SP-15 section was constructed at the ERDC, Vicksburg, MS, installation. The material was procured from the vendor noted in Section 4.1.1 and delivered to ERDC in December 2015. The material was placed atop a previously used SP section in a single lift of approximately 18 in., yielding a total depth of approximately 54 in. of SP material. The test 
section was approximately $20 \mathrm{ft}$ wide and $200 \mathrm{ft}$ long in order to accommodate the two EMMSs and a control section. A dynamic cone penetrometer (DCP) with a 10.1-lb hammer was used to characterize the bearing capacity of the completed test section according to ASTM International (2015) (D6951) and Webster et al. (1992). Figure 10 shows a typical profile for DCP data on the SP-15 section. As is typical with bearing capacity and strength measurements in cohesionless soils, the apparent strength of the material increases with confinement and overburden pressure. In this case, 15 to 20 in. of overburden is necessary for the effective strength of the material to be measured with the DCP. In order to facilitate the starting and stopping of the test vehicle on the SP-15 section, AM-2 matting was installed on both the leading and trailing edges of the length of the section on which the matting systems were to be installed. Figure 11 is an overall photo of the SP-15 section.

Figure 10. Typical SP-15 DCP profile.

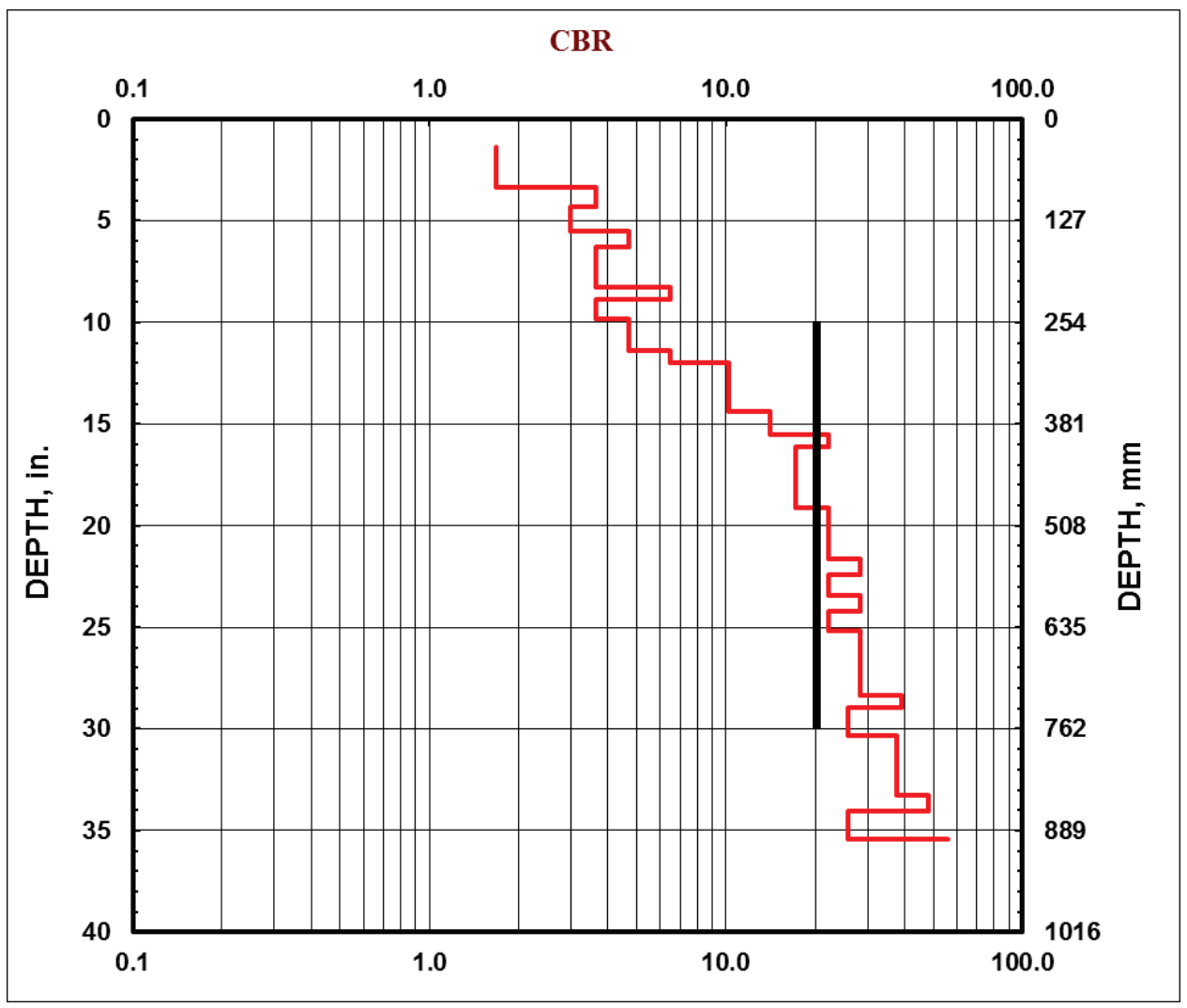


Figure 11. SP-15 section overall.

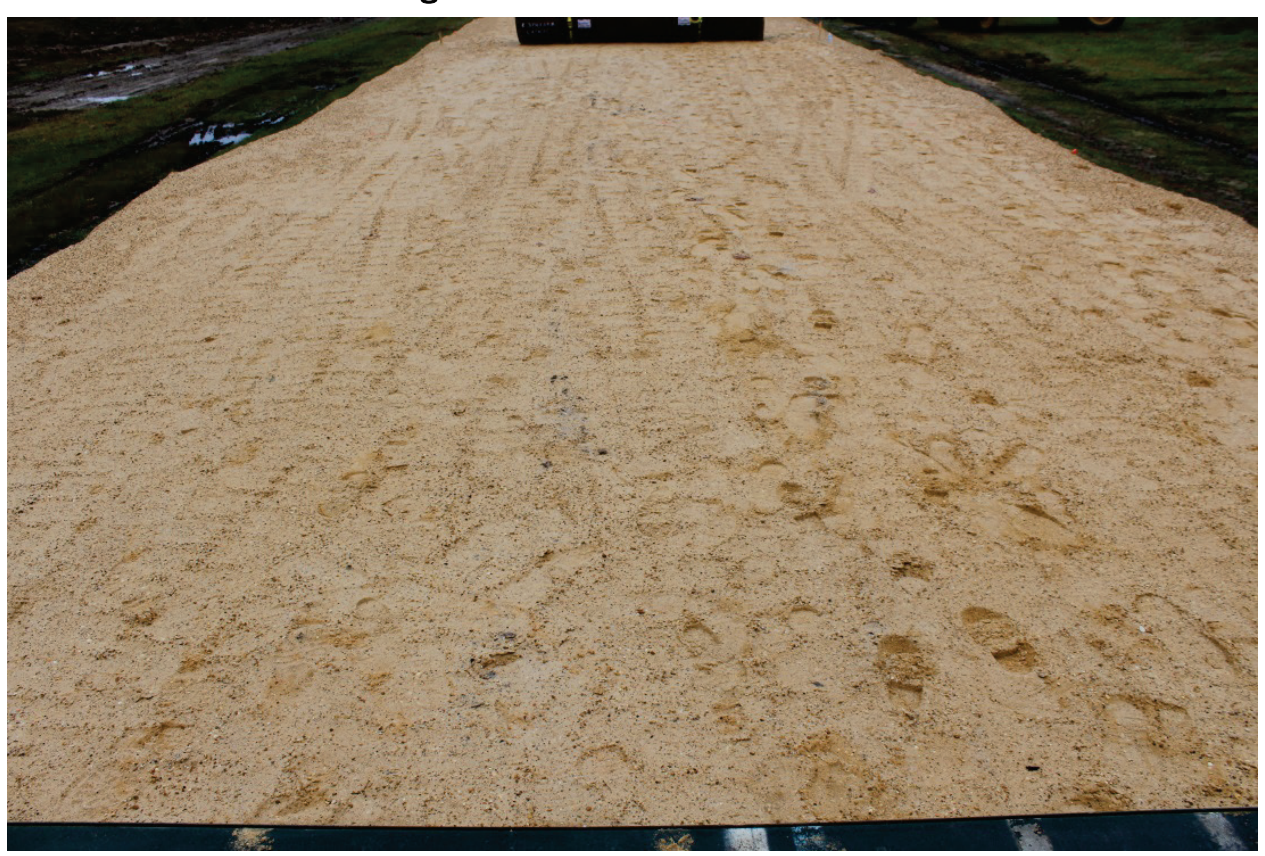

\subsubsection{Mud flat section (CL-3)}

The CL-3 test section was constructed near the SP-15 test section. The location identified for the CL-3 section was covered with grass, so it was necessary to clear and grub the top of the section clean and to create a relatively constant slope with a motor grader. Following scraping of the section, a compact track loader with a bucket attachment was used to perform final smoothing of the section. However, due to the soft soil conditions present, it was not possible to achieve a surface as smooth as that achieved during the SP-15 test section construction. The CL-3 section was approximately $200 \mathrm{ft}$ by $20 \mathrm{ft}$ in size. In order to quantify the bearing capacity of the completed CL-3 section, a DCP with 10.1-lb hammer was utilized. Figure 12 provides a typical DCP profile for the CL-3 section. AM-2 matting was used, as in the SP-15 section, to facilitate starting and stopping of the test vehicle on the leading and trailing edges of the section on which the matting systems were to be installed. Figure 13 is an overall photo of the CL-3 section. 
Figure 12. Typical CL-3 DCP profile.

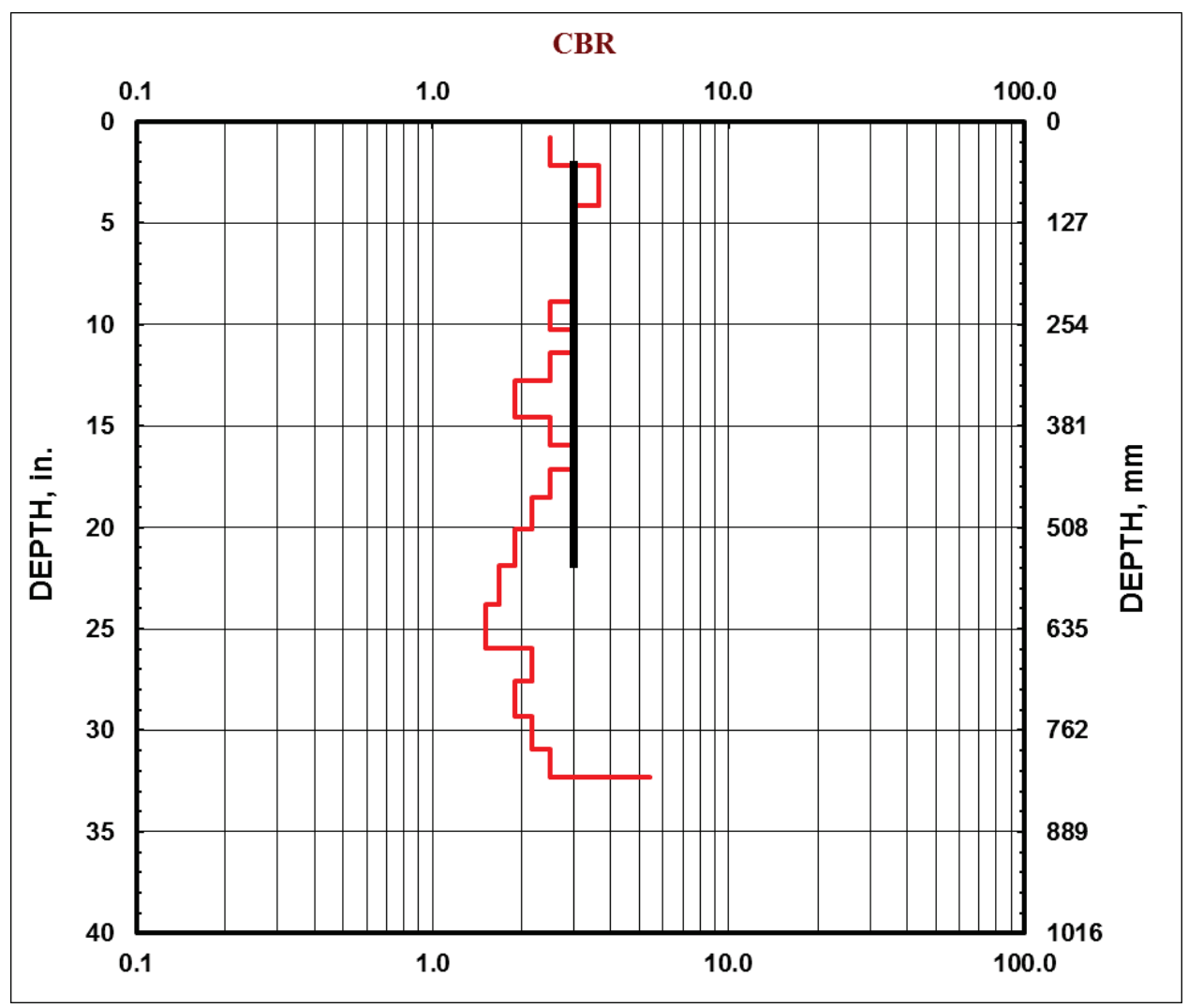

Figure 13. CL-3 section overall

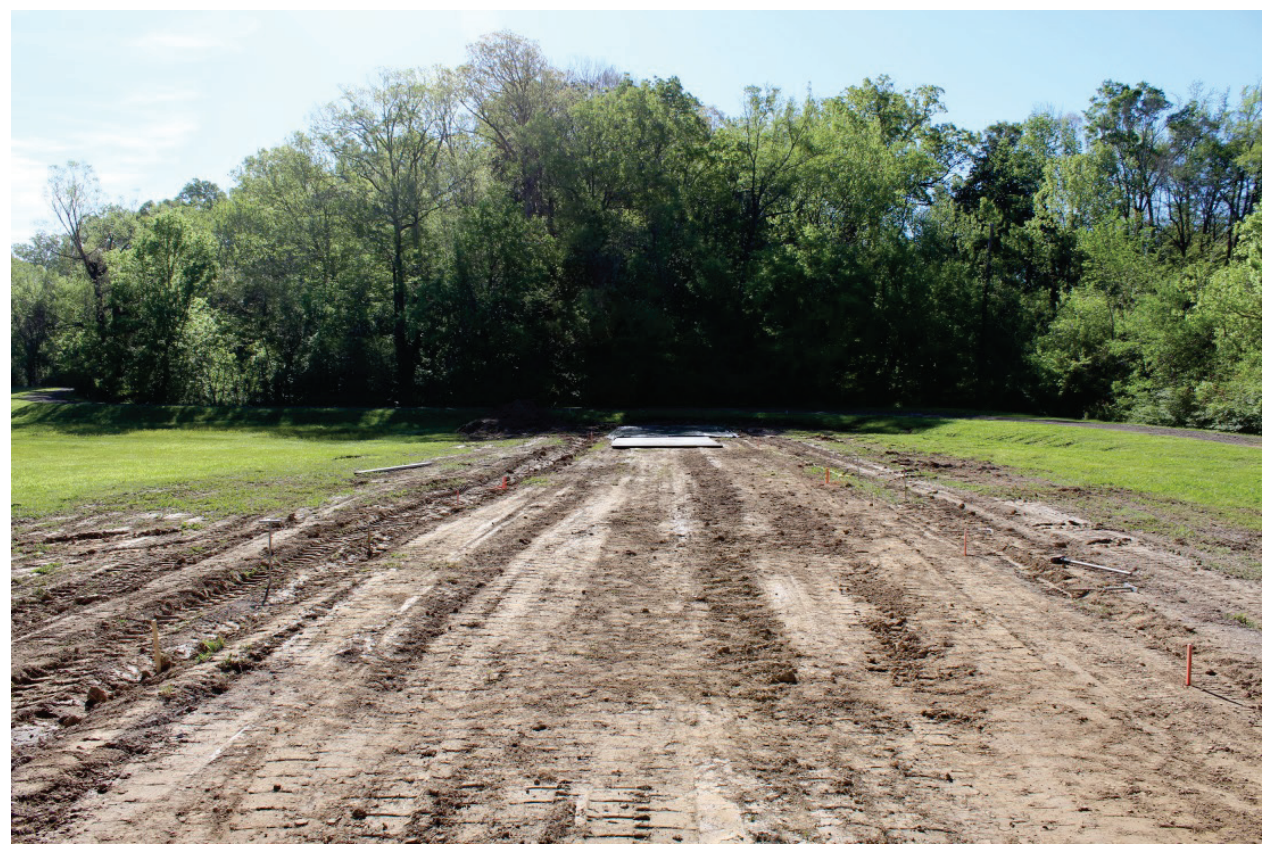




\subsection{Mat installation}

The Mo-Mat and WavTrac prototype EMMSs were installed by rolling out the mat panels. To monitor installation rate in a repeatable manner, a string line was used to mark the centerline of the 20-ft-wide test section. Then, using a four-man installation team, each mat was unrolled along this marked centerline and anchored. In order to simulate the use of material handling equipment (MHE), three of the four installation personnel were used to unroll the mat. Following unrolling, it was assumed that the fourth installer would have had ample time to exit the MHE and assist with anchoring the mat. So, three personnel were used for unrolling, and four were used for anchoring. Figures 14, 15, and 16 show the typical installation process for EMMS. Mats were anchored using Tstakes. The stakes were installed at all four corners of the mats as well as at 12-ft intervals along the mat edges. Figure 17 below shows a close-up view of an installed T-stake anchor. Figures 18 and 19 show overall pictures of the two test sections with matting installed.

Figure 14. Installation alignment.

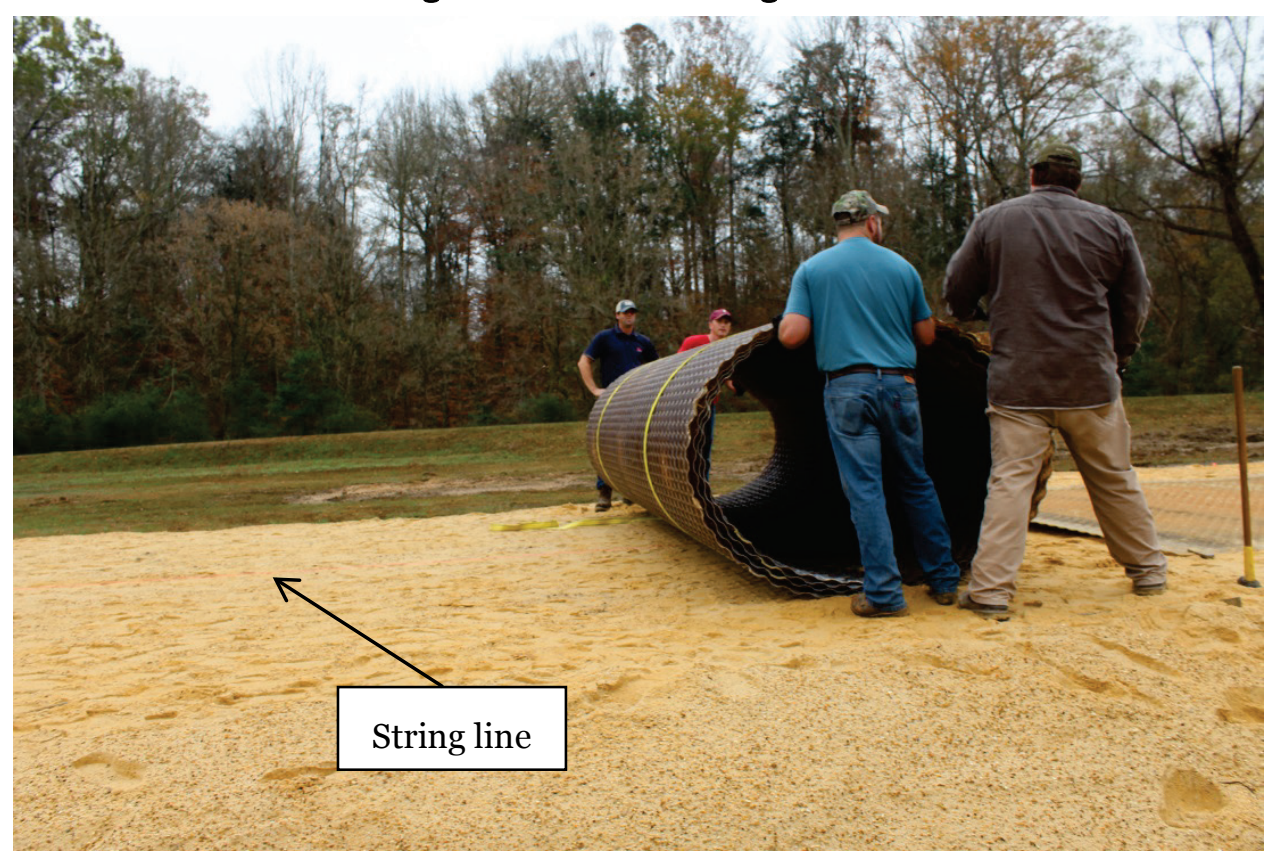


Figure 15. WavTrac installation roll-out.

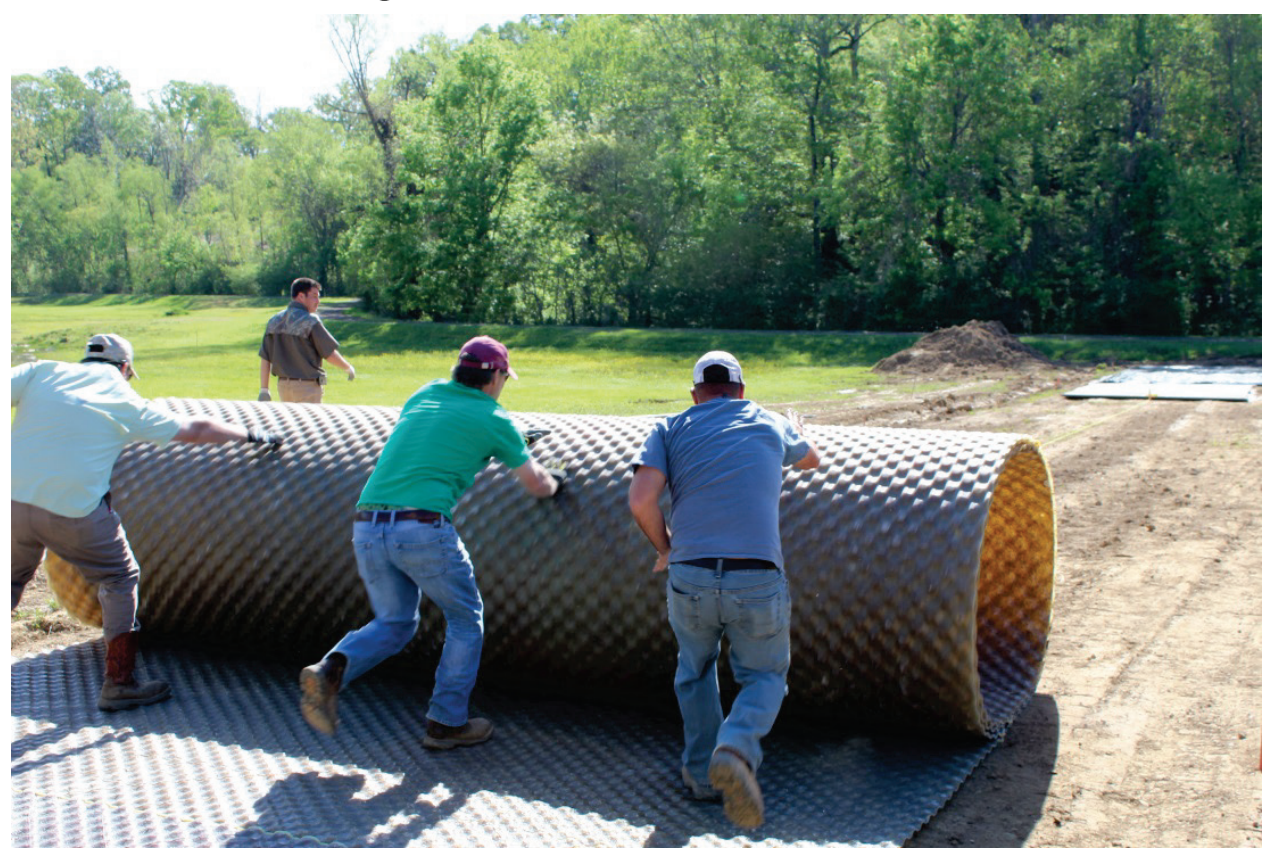

Figure 16. Installation anchoring.

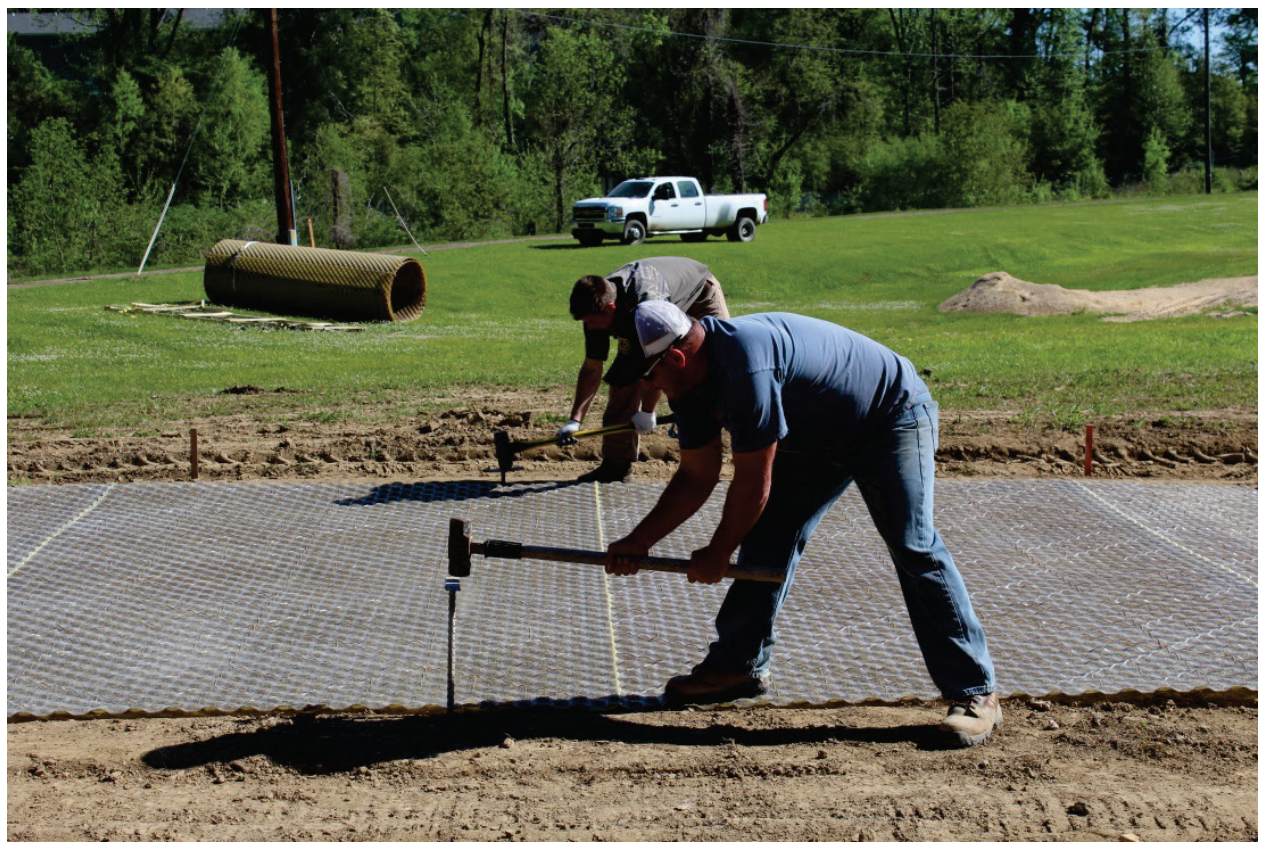


Figure 17. Close-up view of installed T-stake anchor.

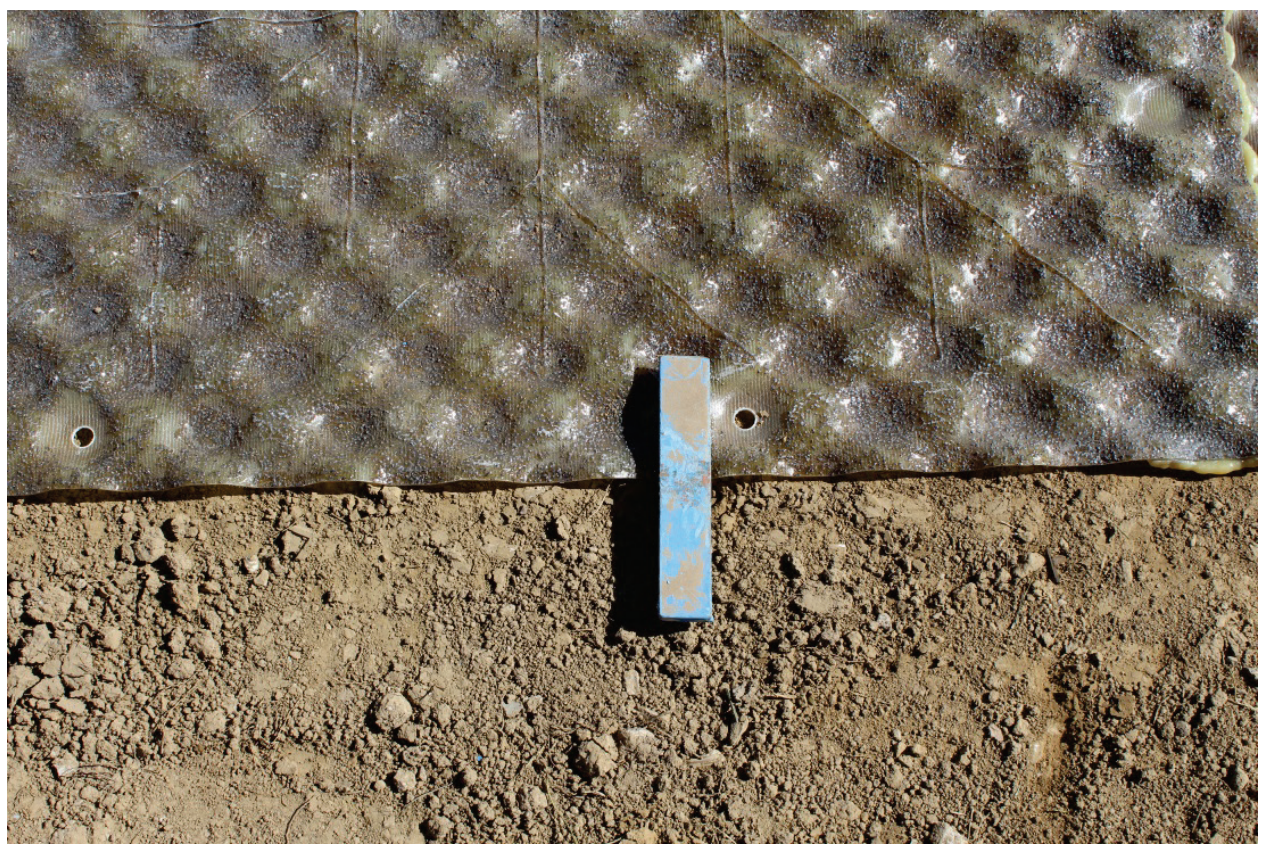

Figure 18. Overall SP-15 section with mats.

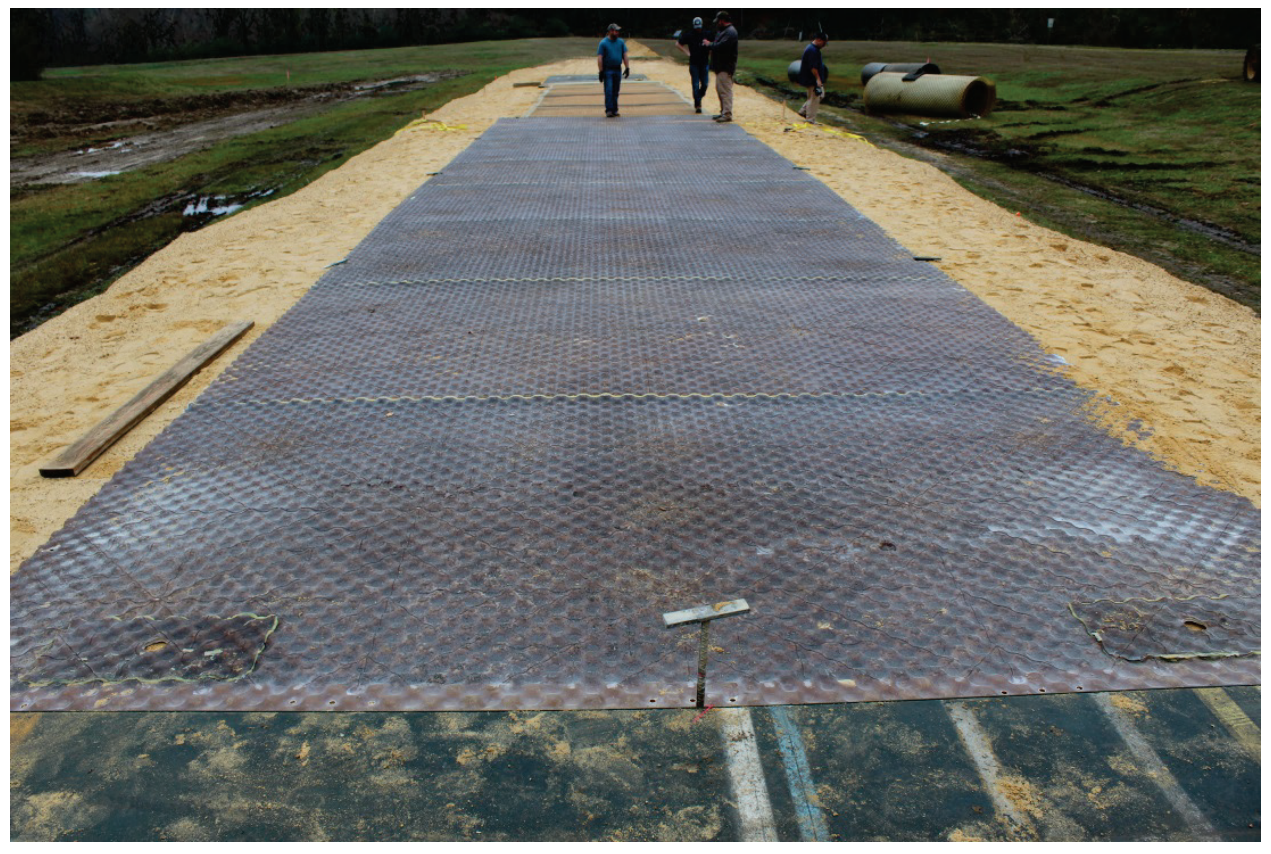


Figure 19. Overall CL-3 section with mats and test vehicle.

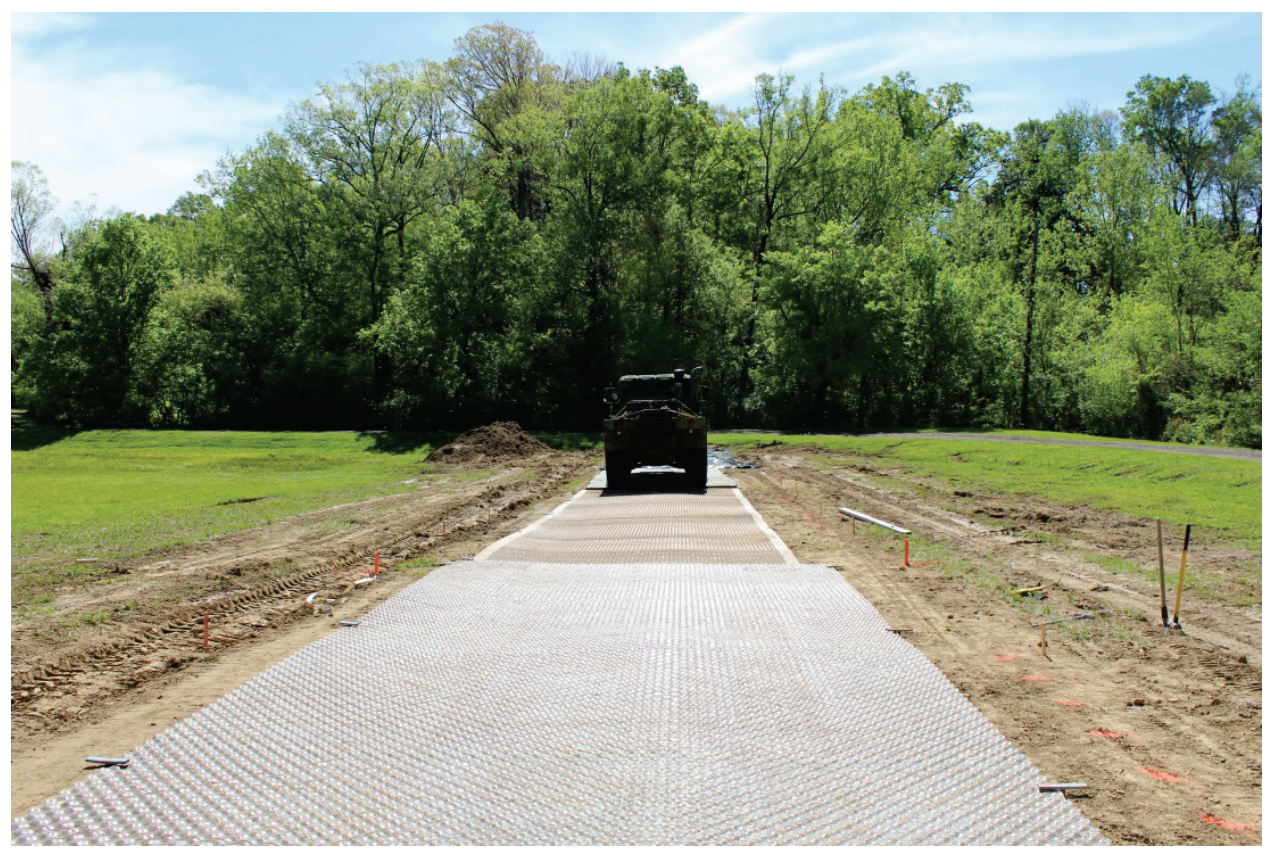




\section{Full-Scale Experimental Methods}

As discussed previously, the test sections were trafficked with representative military truck traffic to evaluate the performance of the EMMSs under relevant operating conditions. This chapter includes sections describing the test vehicle, data collection procedure, performance threshold criteria, and control section evaluation used to evaluate the performance of the WavTrac prototype EMMS.

\subsection{Test vehicle description}

Both the SP-15 and the CL-3 test sections were trafficked with the same USMC 7-ton MTVR transport vehicle. The test vehicle was loaded to a maximum off-road 7-ton payload capacity with lead weights which were centered and secured above the vehicle's rear axles. The vehicle tire pressure was adjusted to the recommended "cross-country" pressure of $28 \mathrm{psi}$ and $35 \mathrm{psi}$ in the front and rear axles, respectively. According to the load distribution placard adhered to the test vehicle, the front axle weight was $15,290 \mathrm{lb}$ while the combined weight of the two rear axles was $29,310 \mathrm{lb}$ at a maximum off-road payload capacity of 7 tons. During traffic operations the MTVR test vehicle traversed forward and backward across the test section at approximately 5 to $10 \mathrm{mph}$ until the test was complete. Care was taken to ensure that the test vehicle applied channelized traffic by keeping the wheel path consistent. Figure 20 shows a photo of the test vehicle.

Figure 20. USMC 7-ton MTVR test vehicle.

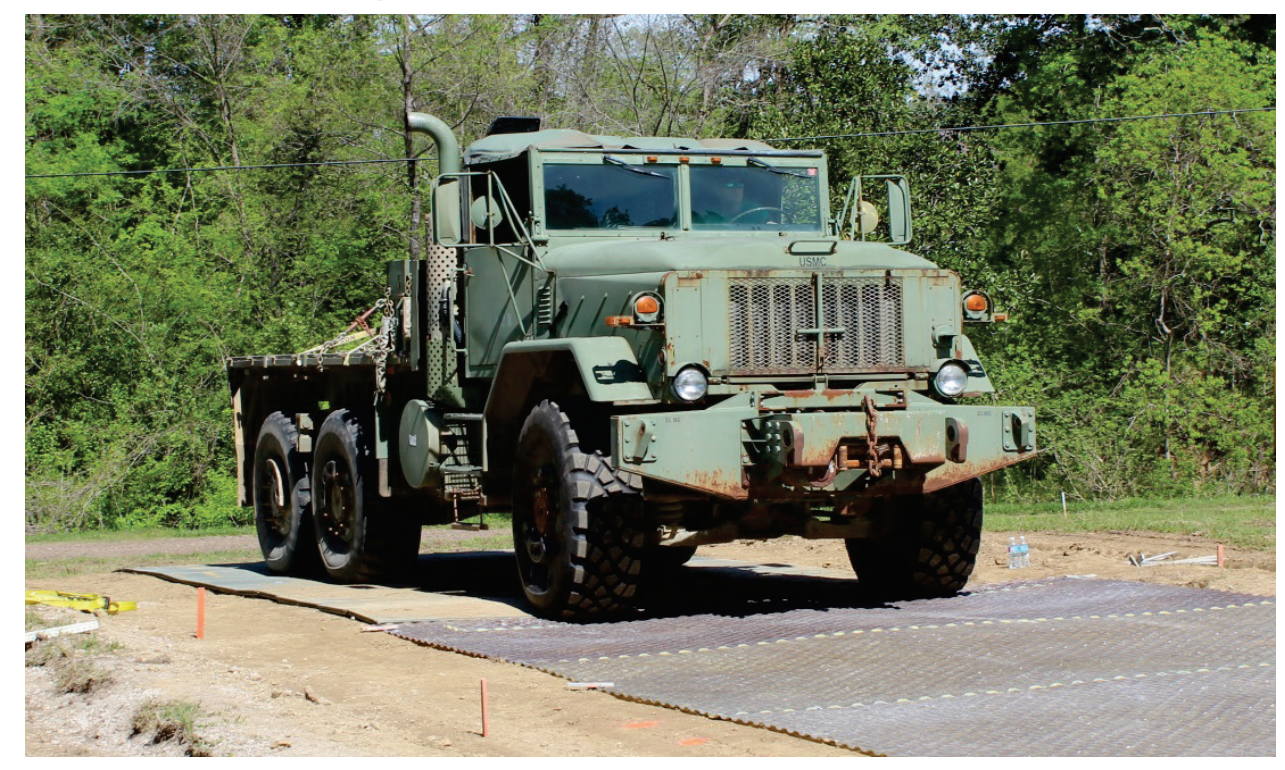




\subsection{Data collection procedures}

Data were collected prior to traffic on both the subgrade and the mat surfaces as well as at predetermined intervals during traffic operations. Following traffic and mat removal, rod and level surveys were performed to quantify subgrade rutting response to traffic loading.

\subsubsection{Cross sectioning and data collection locations}

Each respective test section was divided into three test areas: WavTrac, MoMat, and control. Each test area was further subdivided by its quarter points into four equal sections, of which the three interior intersections of the quarter sections were used for data collection locations. These three interior intersections are referred to herein as cross section 1, cross section 2, and cross section 3. Survey data were collected across each of these three crosssections and longitudinally in the right wheel path between cross sections 1 and 3. The exclusion of the leading and trailing quarter portions of the test areas was intentional to avoid any skewing of the rut accumulation data caused by entering/exiting the section or accelerating/decelerating of the test vehicle at the mat transitions. For the WavTrac test areas, the spacing between cross sections was $15 \mathrm{ft}$. For the Mo-Mat test areas, the spacing between the cross sections was approximately $12 \mathrm{ft}$. Spacing between cross sections for the SP-15 control test area was $15 \mathrm{ft}$, while spacing between cross sections for the CL-3 control test area was $16 \mathrm{ft}$. The premature failure of the Mo-Mat EMMS on the CL-3 section allowed for the extension of the control area to $64 \mathrm{ft}$, which, in turn, allowed more distance between control area cross sections when compared to the SP-15 control area.

\subsubsection{Pretest subgrade data collection}

Prior to the installation of EMMS on the test areas, pretest data were collected on each prepared subgrade test area. Pretest rod and level survey data collected included longitudinal profile measurements at $2-\mathrm{ft}$ increments between cross sections 1 and 3 and transverse cross-section measurements across each of the three cross sections. Measurements taken in transverse cross-section readings were collected systematically across the cross section at the following locations: (1) on the subgrade (left), (2) $1.5 \mathrm{ft}$ from the mat's left edge, (3) in the left wheel path, (4) on the centerline of the section, (5) in the right wheel path, (6) $1.5 \mathrm{ft}$ from the mat's right edge, and (7) on the subgrade (right). In addition, as described in Section 4, DCP 
readings were taken to estimate the bearing capacity of the subgrade material, and samples were taken for laboratory material characterizations.

The installation rate for both matting systems was monitored using the personnel grouping described in Section 4.3. Following EMMS deployment and installation and prior to traffic testing, longitudinal profile measurements and transverse cross-section measurements were taken on the mat surfaces using the same data collection scheme previously described.

\subsubsection{Data collection during traffic testing}

Previous evaluations of EMMS indicated that the rate of rut formation and permanent deformation was nearly logarithmic. Therefore, most of the rutting and plastic deformation in the system occurred during the first few passes until the system was "seated." Data collection intervals were selected based on this expected logarithmic rut accumulation trend to be at 5, 10, 20, 50, 100, 200, 500, 1000, 1500, and 2000 passes. All measurements taken on the mat surface were taken with the mat pressed down to contact with the subgrade. When a scheduled data collection point was reached, the following actions occurred:

1. Each mat surface was visually inspected for damage.

2. Rut depths were measured in the right wheel path using a rut bar and folding ruler at all three cross-section locations of each test area (Figure 21).

3. Rod and level profile measurements were taken at 2-ft intervals along the right wheel path between cross sections one and three for all test areas.

4. Rod and level transverse cross-section measurements were taken at the previously described locations for all cross sections of each test area.

\subsubsection{Posttest data collection}

Following the completion of full-scale traffic operations, the test vehicle was removed from the section. Final traffic data were collected on the mat surface. Then, the matting systems were removed with a personnel group of four technicians. The recovery rate was recorded during removal.

After the removal of the EMMS, posttest data collection began with rod and level surveying. The longitudinal profile between cross section 1 and cross section 3 was measured, as was the transverse rut profile across all three cross sections for all test areas. For the WavTrac test area on the CL3 test section, a DCP profile was taken in the right wheel path at each of the three cross sections in order to determine if there was any change in subgrade bearing capacity during testing. 
Figure 21. Typical rut depth measurement.

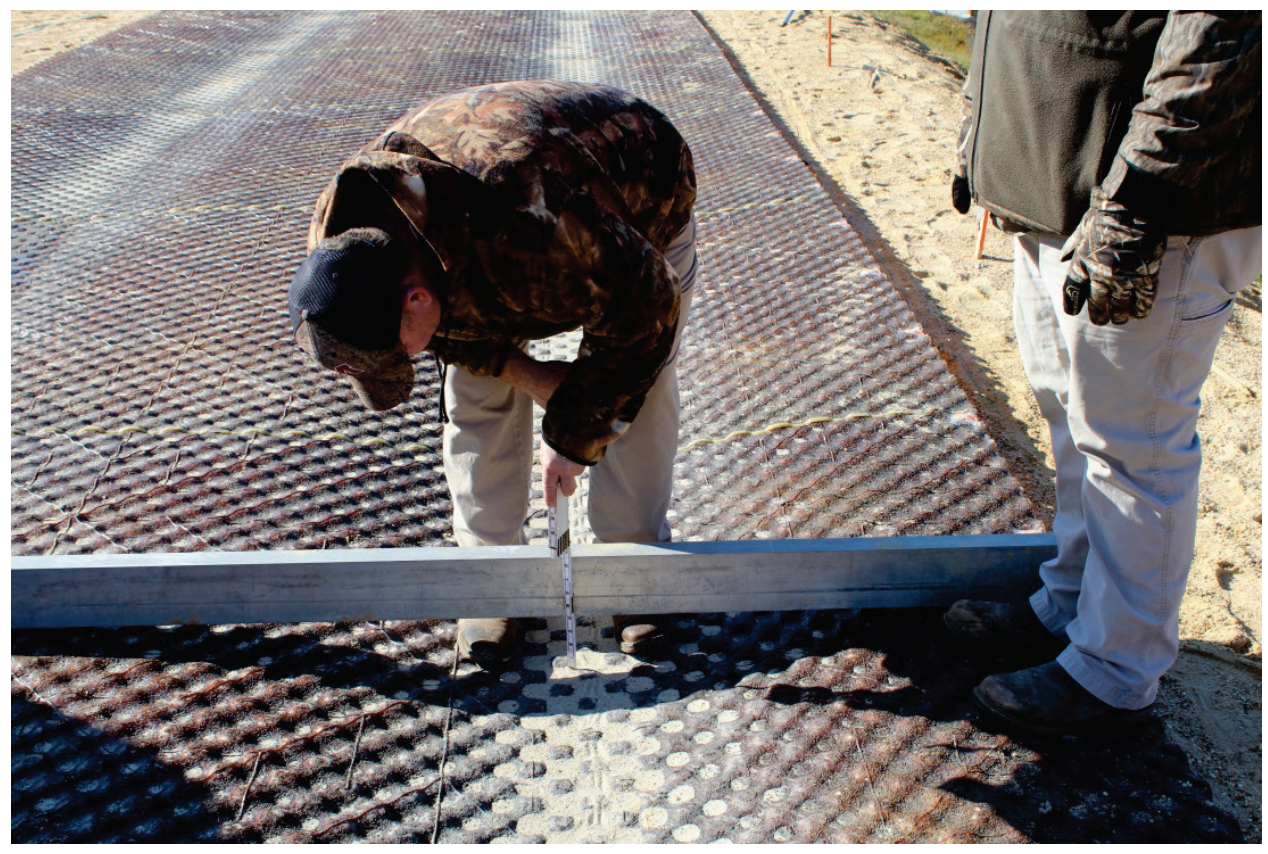

\subsection{Control experiments}

In order to quantify the subgrade response to full-scale MTVR traffic operations, control test areas were established for both the SP-15 and CL-3 test sections. Traffic operations on the control areas were performed directly on the subgrade; no EMMSs were deployed in these areas. Data collection intervals were shorter for control test area traffic operations due to the accelerated rate of rut accumulation. The comparison between rut accumulation versus vehicle passes for the control areas against the test areas where EMMSs were deployed is a direct means of quantifying the advantage of using an EMMS. These comparisons will be made in the remainder of this document. 


\section{Full-Scale Traffic Testing Results}

The following sections describe the results from the EMMS evaluations described in Chapter 5. The results have been separated by subgrade type. The intent of this test effort was to determine whether the performance of the WavTrac prototype EMMS met the requirements set forth by the MCSC (Appendix A) and was, at a minimum, comparable to that of the legacy Mo-Mat EMMS.

\subsection{Loose sand (SP-15) results}

Section 6.1 includes the results of full-scale traffic testing of both EMMS and the control test item on the SP-15 subgrade. Results are divided by test item and directly compared to one another. Figure 22 contains the comparative results of the average rut depth across cross sections 1 to 3 versus the number of MTVR passes for all three test items of the SP-15 test section as measured with a rut bar and folding ruler in the right wheel path. Table 5 provides a tabular presentation of the data used to construct Figure 22.

Figure 22. Average rut depth for SP-15 test items.

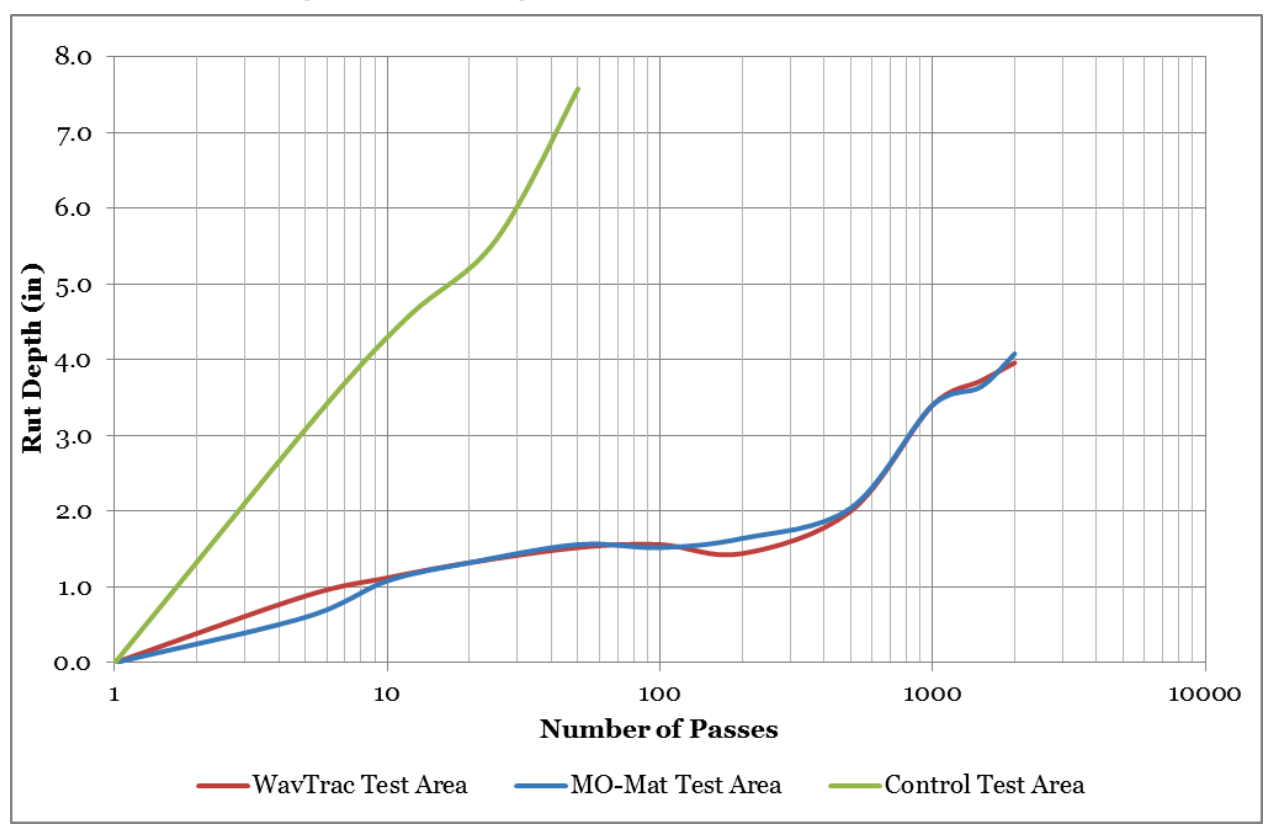


Table 5. Average rut depth for SP-15 test items.

\begin{tabular}{|l|l|l|l|l|l|}
\hline \multicolumn{2}{|c|}{ Control Test Item } & \multicolumn{2}{c|}{ WavT rac Test Item } & \multicolumn{2}{c|}{ Mo-Mat Test Item } \\
\hline $\begin{array}{l}\text { Number } \\
\text { of Passe }\end{array}$ & $\begin{array}{l}\text { Average Rut } \\
\text { Depth, in }\end{array}$ & $\begin{array}{l}\text { Number of } \\
\text { Passes }\end{array}$ & $\begin{array}{l}\text { Average Rut } \\
\text { Depth, in }\end{array}$ & $\begin{array}{l}\text { Number } \\
\text { of Passes }\end{array}$ & $\begin{array}{l}\text { Average Rut } \\
\text { Depth, in }\end{array}$ \\
\hline 0 & 0.0 & 0 & 0.0 & 0 & 0.0 \\
\hline 6 & 3.4 & 5 & 0.9 & 5 & 0.6 \\
\hline 12 & 4.6 & 10 & 1.1 & 10 & 1.1 \\
\hline 25 & 5.6 & 20 & 1.3 & 20 & 1.3 \\
\hline 50 & 7.6 & 50 & 1.5 & 50 & 1.6 \\
\hline-- & -- & 100 & 1.6 & 100 & 1.5 \\
\hline-- & -- & 200 & 1.4 & 200 & 1.6 \\
\hline-- & -- & 500 & 2.0 & 500 & 2.0 \\
\hline-- & -- & 1000 & 3.4 & 1000 & 3.4 \\
\hline-- & -- & 1500 & 3.7 & 1500 & 3.6 \\
\hline-- & -- & 2000 & 4.0 & 2000 & 4.1 \\
\hline
\end{tabular}

\subsubsection{Mo-Mat SP-15 results}

As described in Section 5.2, the installation rate of the Mo-Mat EMMS was recorded. For the SP-15 Mo-Mat test area, the installation rate was $2,950 \mathrm{ft}^{2} /$ man-hr.

Following installation, traffic operations were initiated. The average rate of rut accumulation under full-scale traffic testing for the SP-15 Mo-Mat test item can be seen in Figure 22. Figures 23, 24, and 25 present the change in cross-sectional profile for each of the three cross sections at all data collection traffic intervals, while Figure 26 depicts the change in longitudinal profile between cross sections 1 and 3 versus the number of MTVR passes for the Mo-Mat EMMS on the SP-15 subgrade. The only damage to the Mo-Mat EMMS during traffic operations on the SP-15 test section was noted during the 1,500 to 2,000 pass interval to be an approximately 12-in. transverse crack just outside of cross section 3 (Figure 27). The crack was attributed to entrance/exit effects on the EMMS and was not considered to affect the trafficability of the Mo-Mat. It should be noted that the Mo-Mat item used for this testing was manufactured in 1969 and was relatively brittle compared to a newer mat. The brittle condition could have promoted crack development in the system.

Following the completion of full-scale traffic testing, the Mo-Mat EMMS was recovered from the SP- 15 test section at a rate of $4,350 \mathrm{ft}^{2} / \mathrm{man}$-hour. Timing data were collected using a team of four personnel. 
Figure 23. Mo-Mat test item cross section 1 transverse profiles (SP-15).

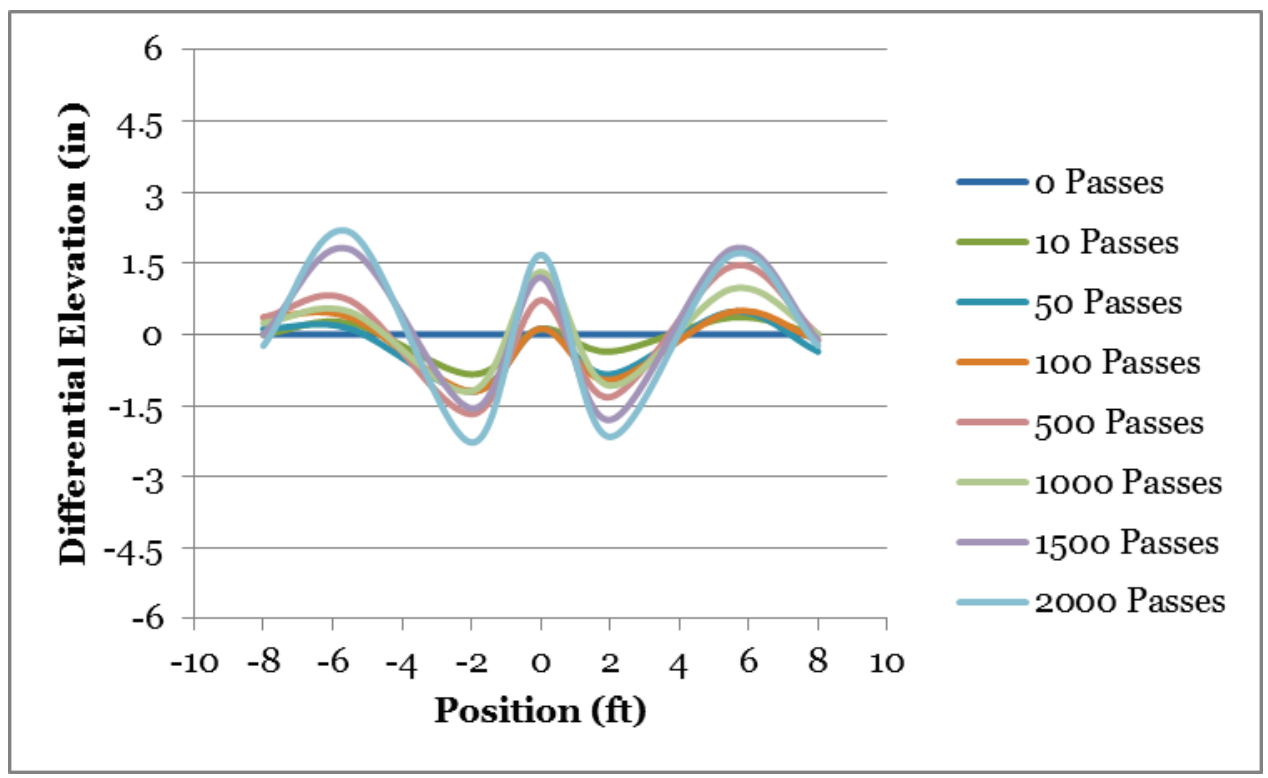

Figure 24. Mo-Mat test area cross section 2 transverse profiles (SP-15).

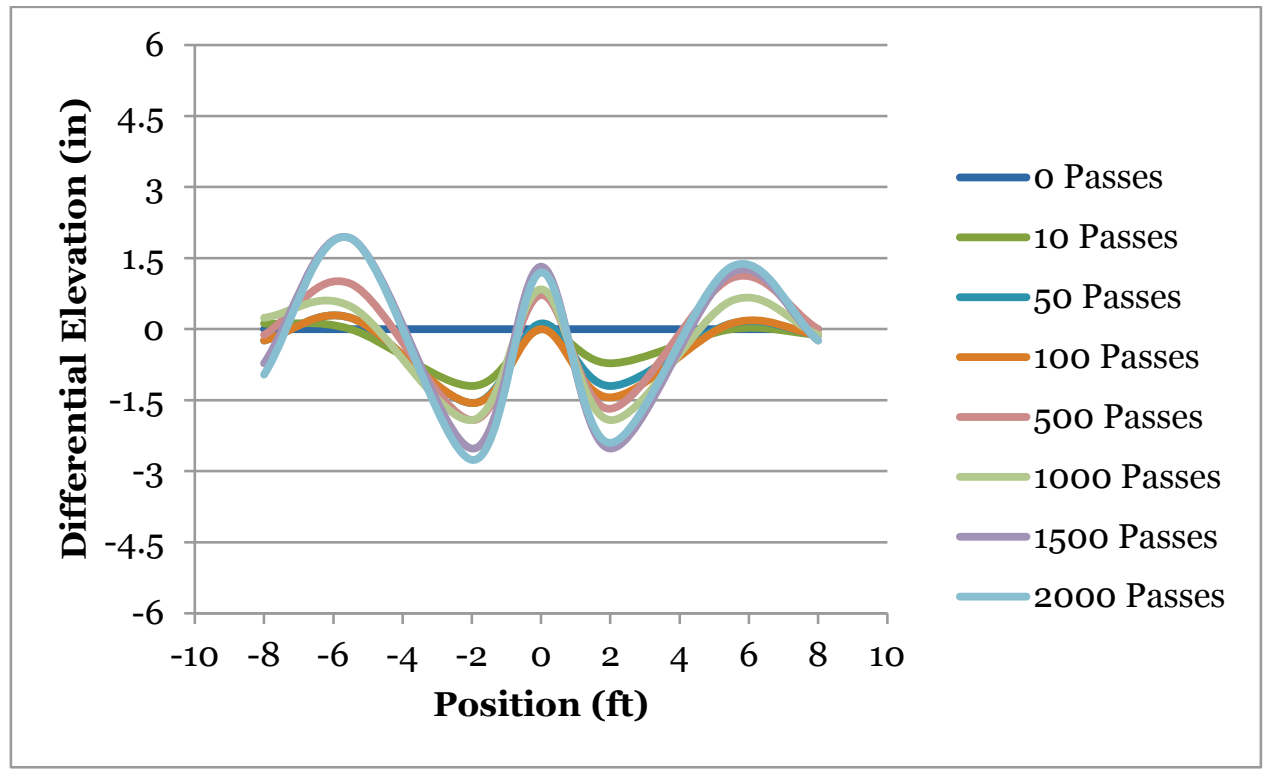


Figure 25. Mo-Mat test area cross section 3 transverse profiles (SP-15).

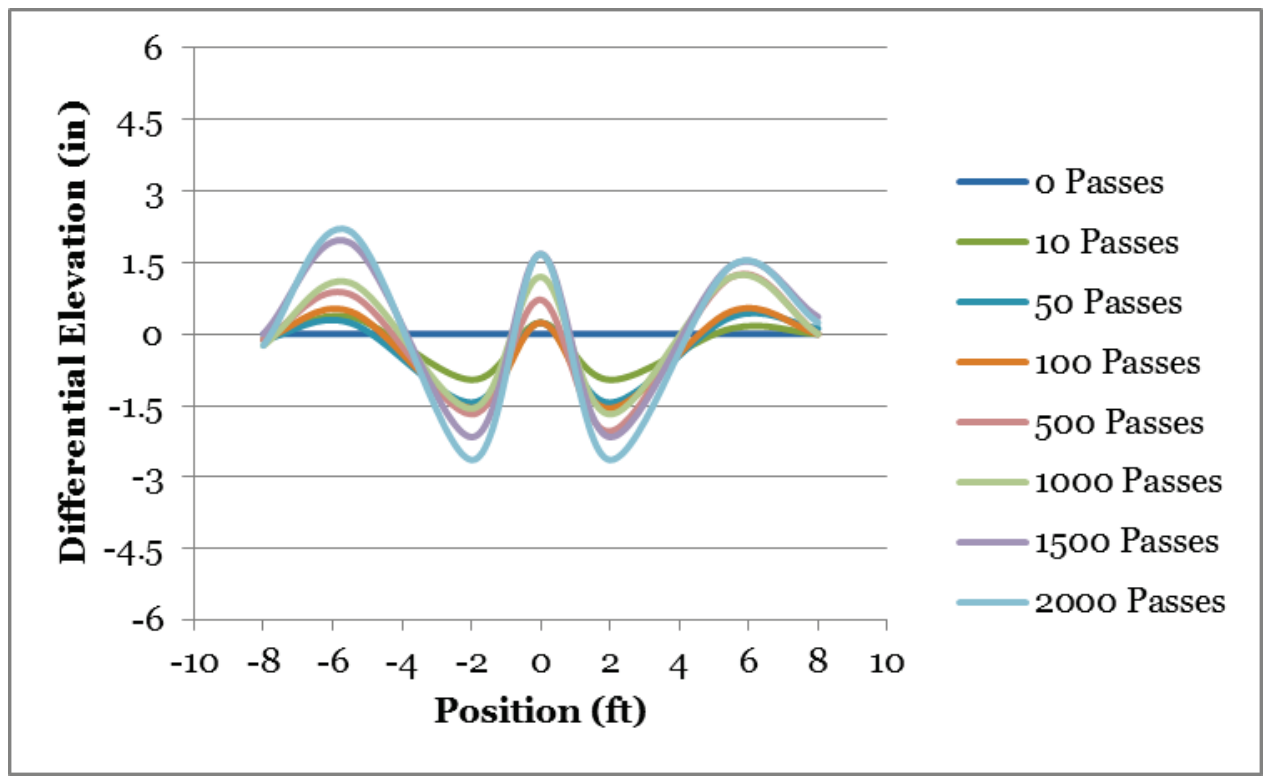

Figure 26. Mo-Mat longitudinal profiles (SP-15).

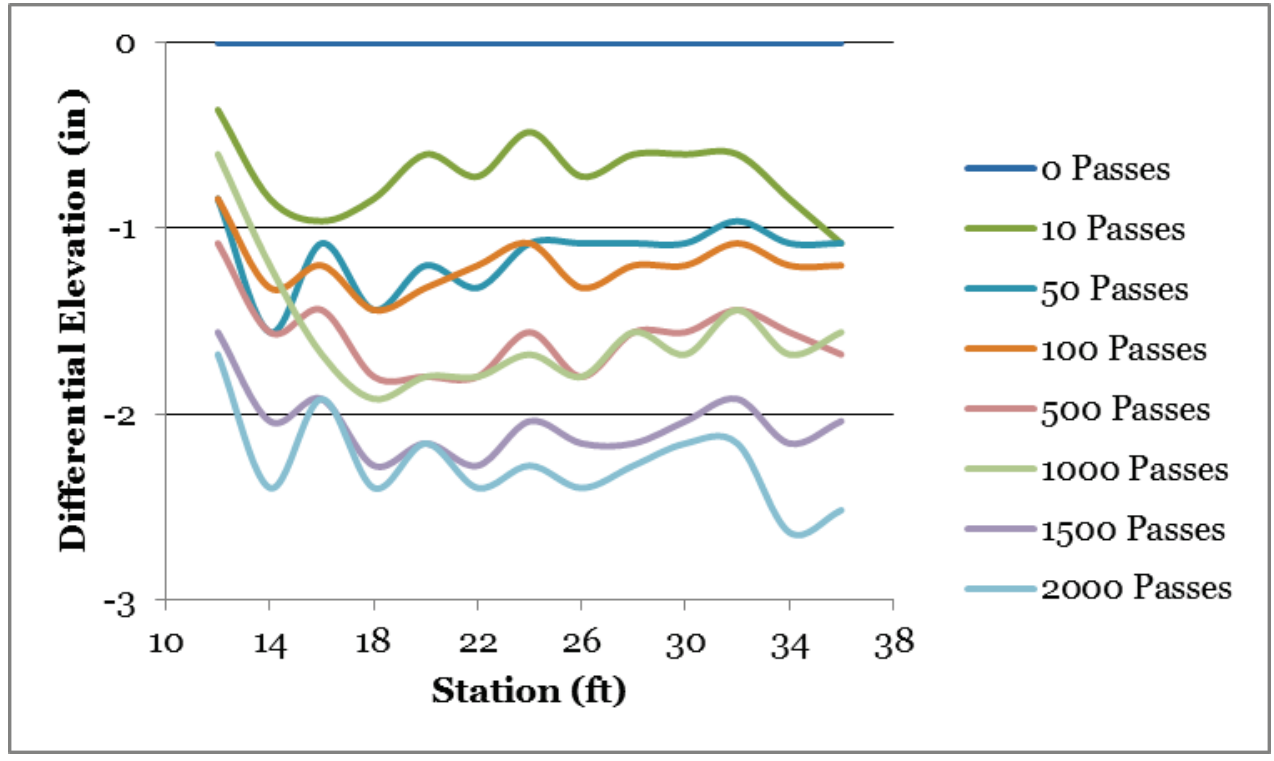


Figure 27. Mo-Mat transverse crack (SP-15) at 2,000 passes.

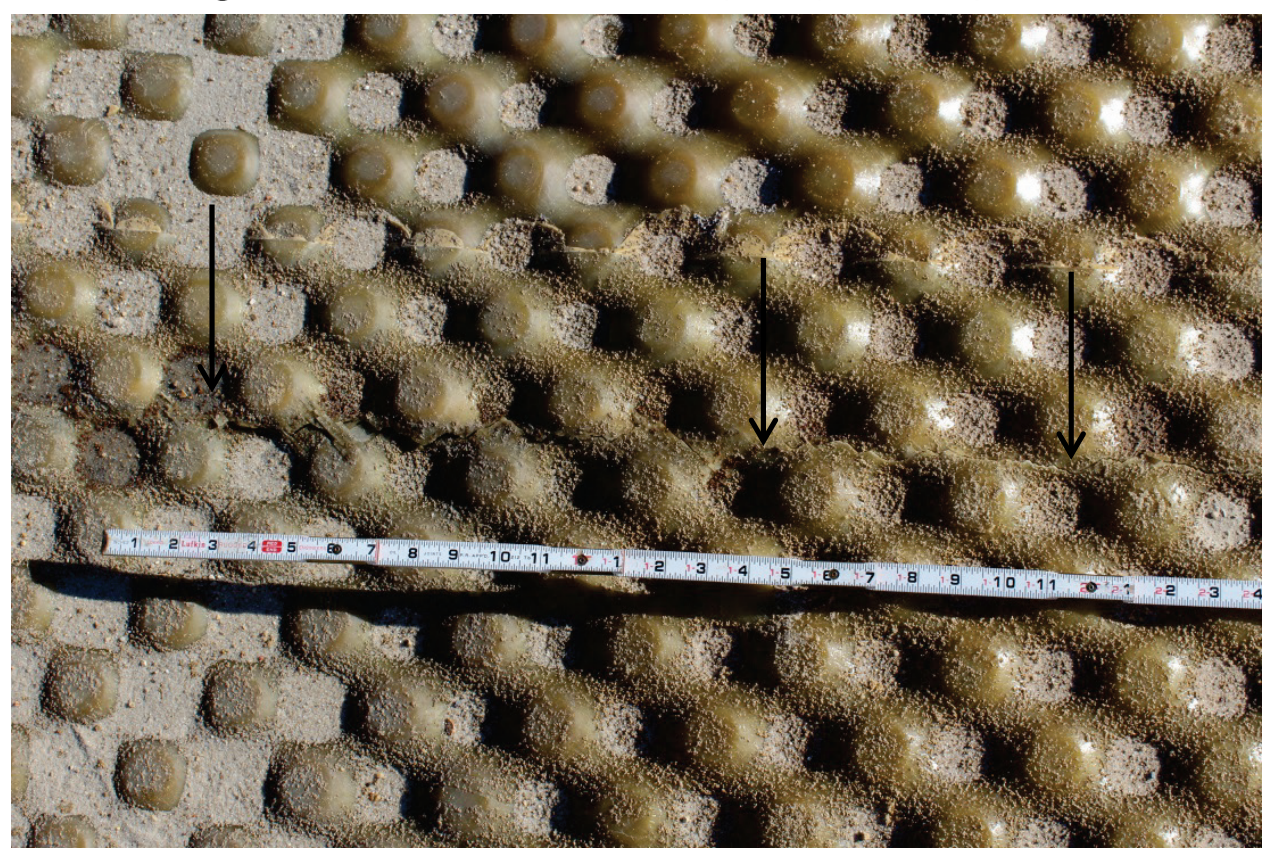

\subsubsection{WavTrac SP-15 results}

As described in Section 5.2, the installation rate of the WavTrac prototype EMMS was recorded. For the SP-15 WavTrac test item, installation rate was $2,520 \mathrm{ft}^{2} / \mathrm{man}-\mathrm{hr}$.

Following installation, traffic operations were initiated. The average rate of rut accumulation under full-scale traffic testing for the SP-15 WavTrac test item can be seen in Figure 22. Figures 28, 29, and 30 present the change in cross-sectional profile for each of the three cross sections at all data collection traffic intervals, while Figure 31 depicts the change in longitudinal profile between cross sections 1 and 3 versus the number of MTVR passes for the WavTrac EMMS on the SP-15 subgrade. No damage was noted to the WavTrac EMMS during full-scale traffic operations on the SP-15 subgrade.

Following the completion of full-scale traffic testing, the WavTrac prototype EMMS was recovered from the SP-15 test section at a rate of 4,o0o $\mathrm{ft}^{2} /$ man-hour. Timing data were collected using a team of four personnel. 
Figure 28. WavTrac test item cross section 1 transverse profiles (SP-15).

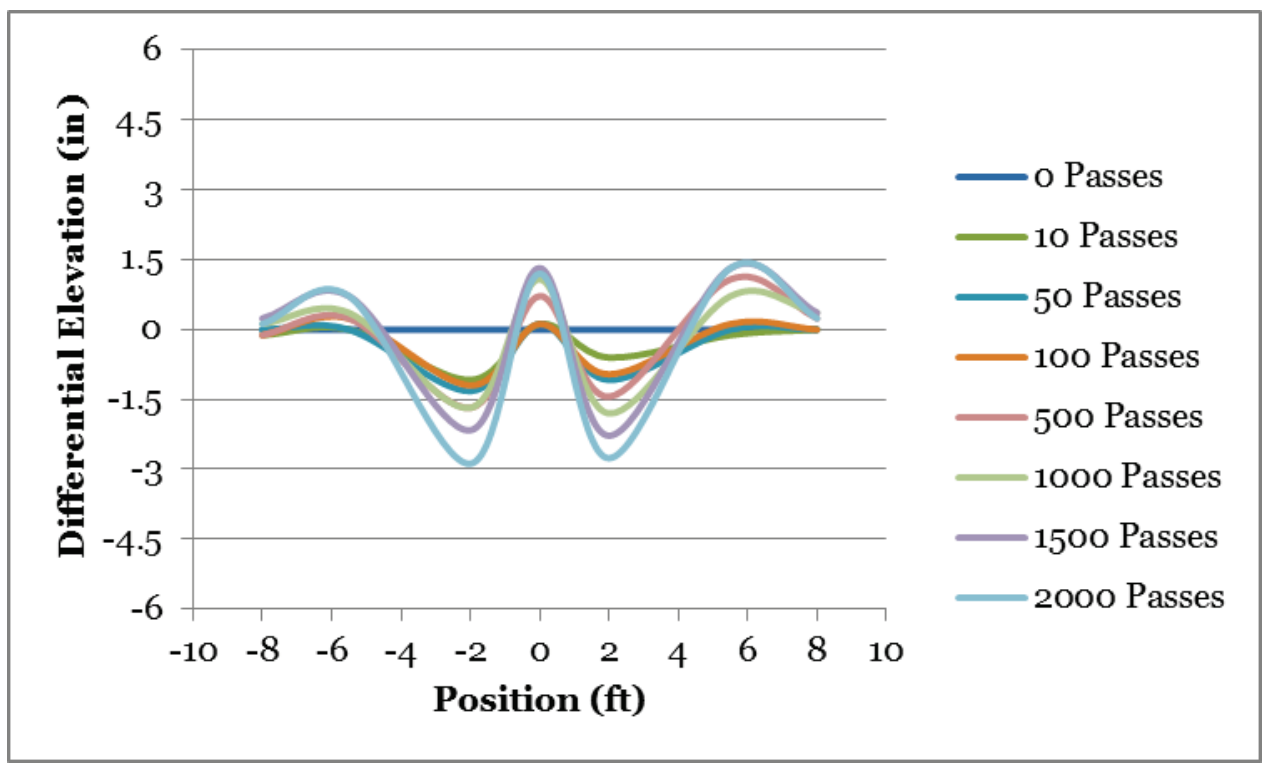

Figure 29. WavTrac test item cross section 2 transverse profiles (SP-15).

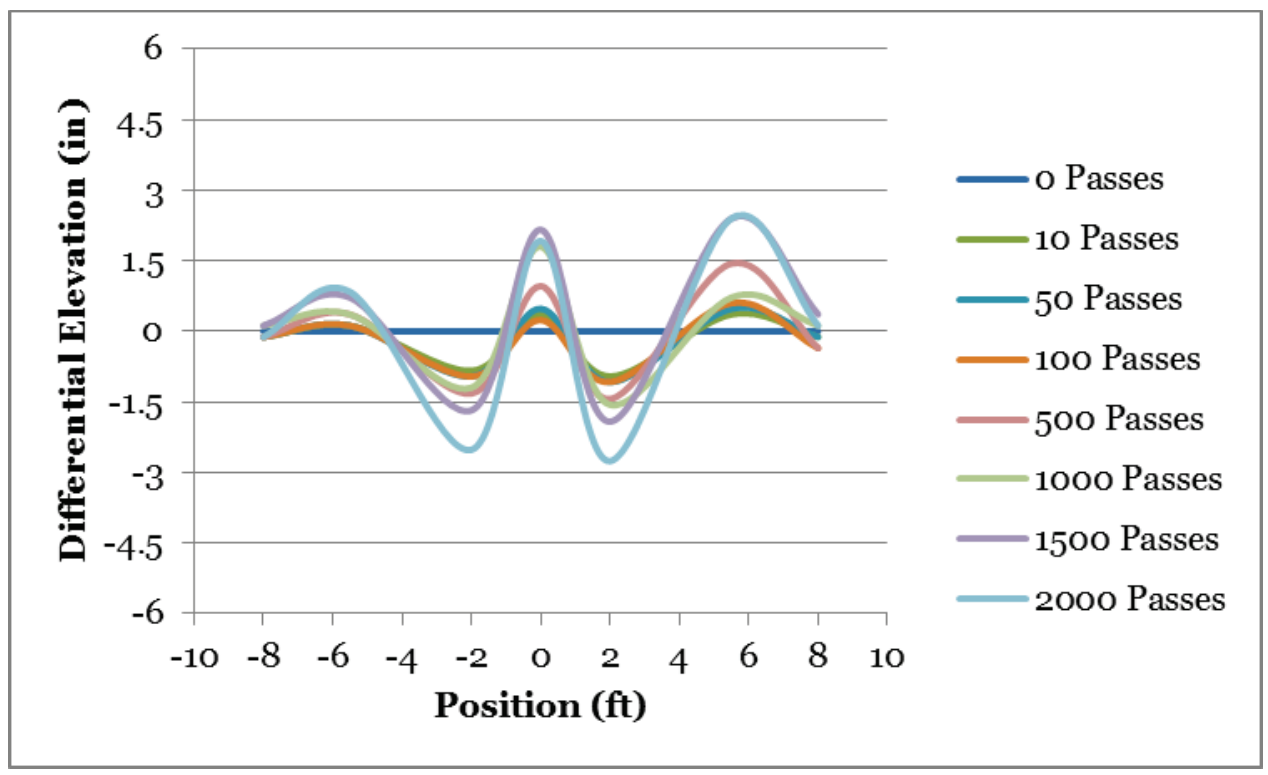


Figure 30. WavTrac test item cross section 3 transverse profiles (SP-15).

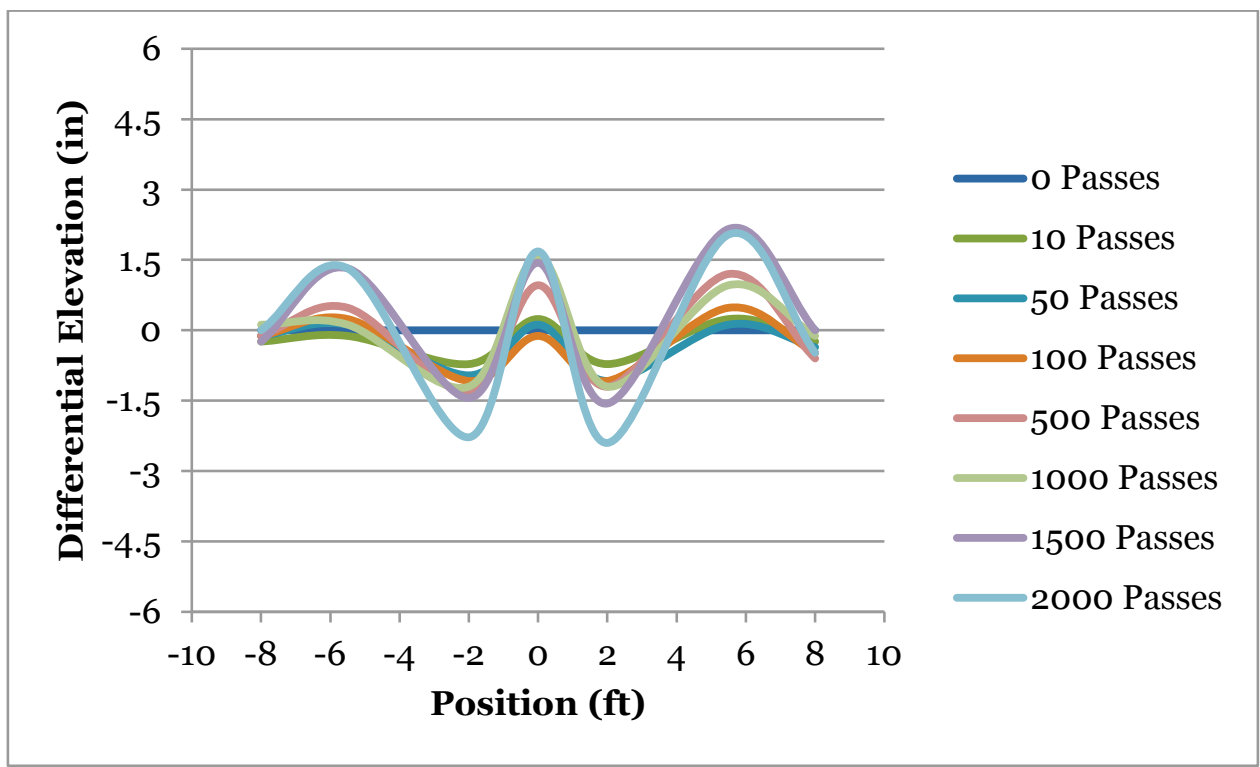

Figure 31. WavTrac longitudinal profiles (SP-15).

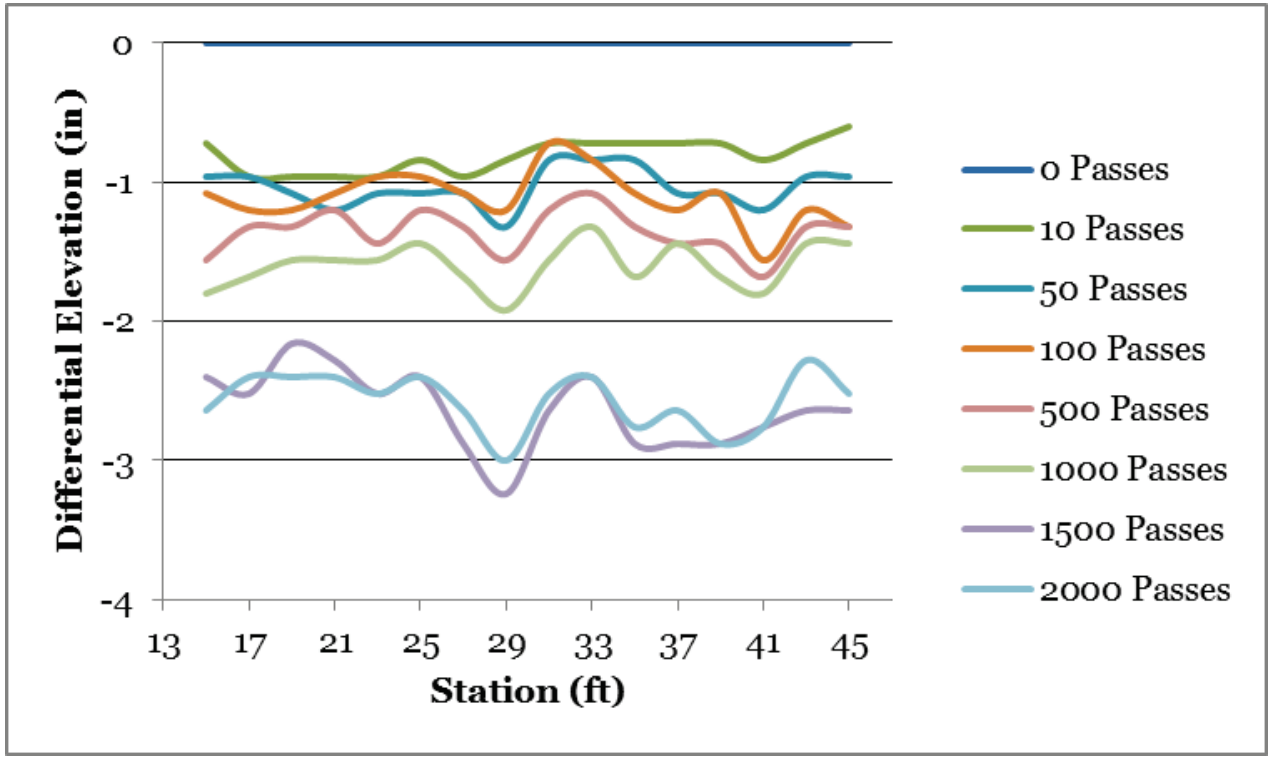

\subsubsection{Control test item SP-15 results}

Traffic on the control test item was applied directly to the SP-15 subgrade by the MTVR test vehicle. A total of 50 passes was applied to the test item during testing. Figure 22 shows the average rate of rut accumulation under full-scale traffic testing for the SP-15 control test item. Figures 32,33 , and 34 present the change in cross-sectional profile for each of the three cross sections at all data collection traffic intervals, while Figure 35 depicts the change in longitudinal profile between cross sections 1 and 3 versus the number of MTVR passes for the control test area on the SP-15 subgrade. 
Figure 32. Control test item cross section 1 transverse profiles (SP-15).

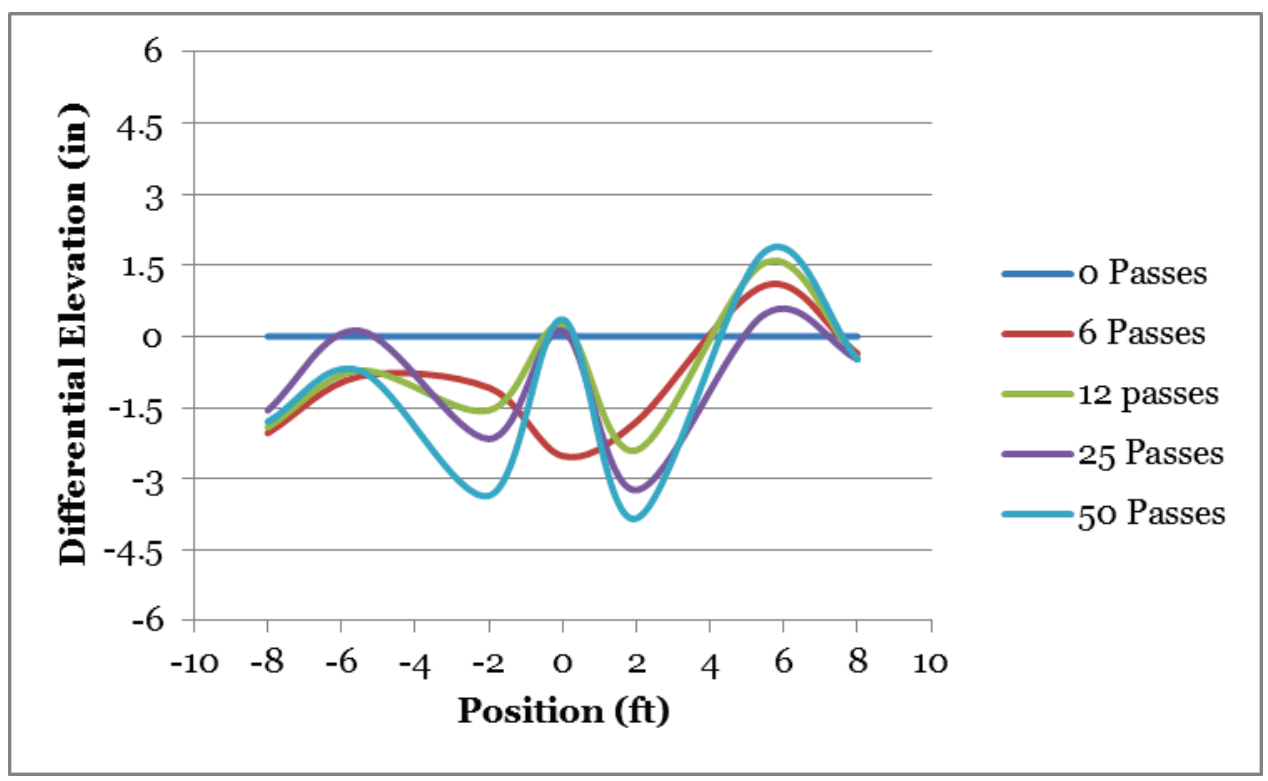

Figure 33. Control test item cross section 2 transverse profiles (SP-15).

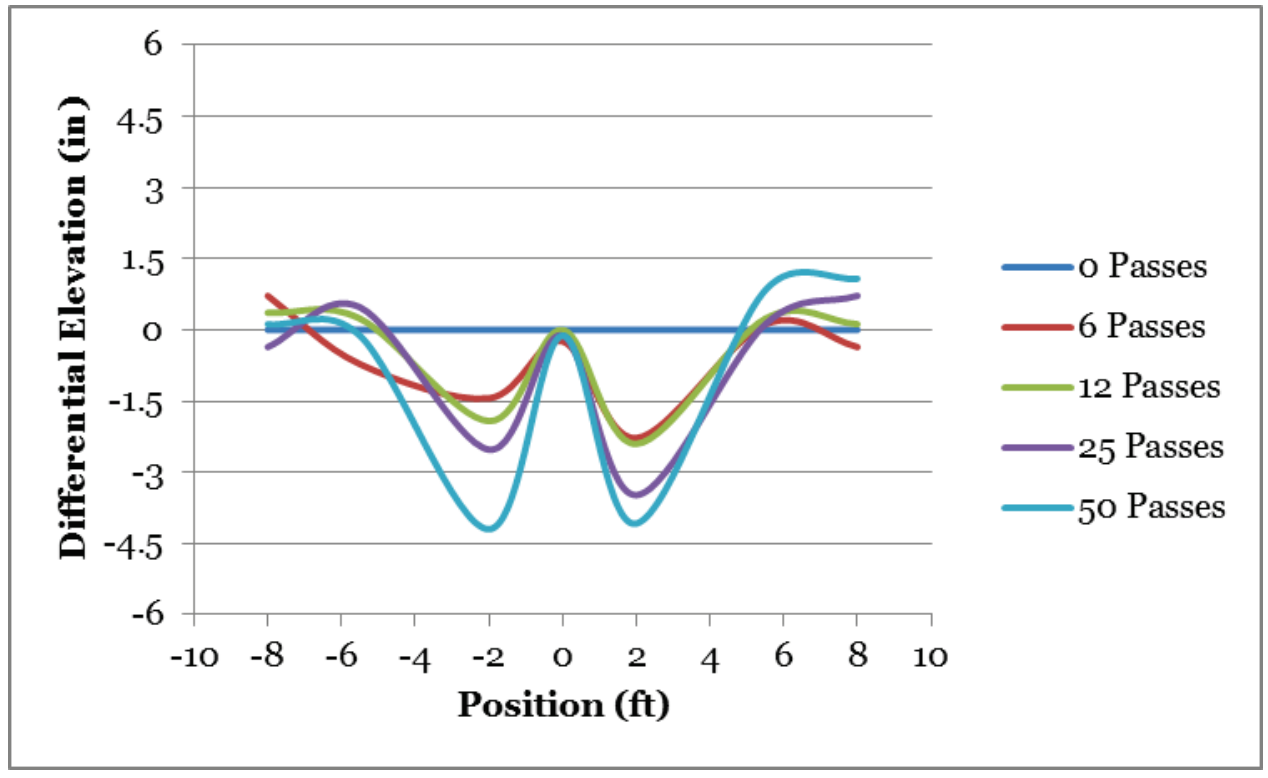


Figure 34. Control test item cross section 3 transverse profiles (SP-15).

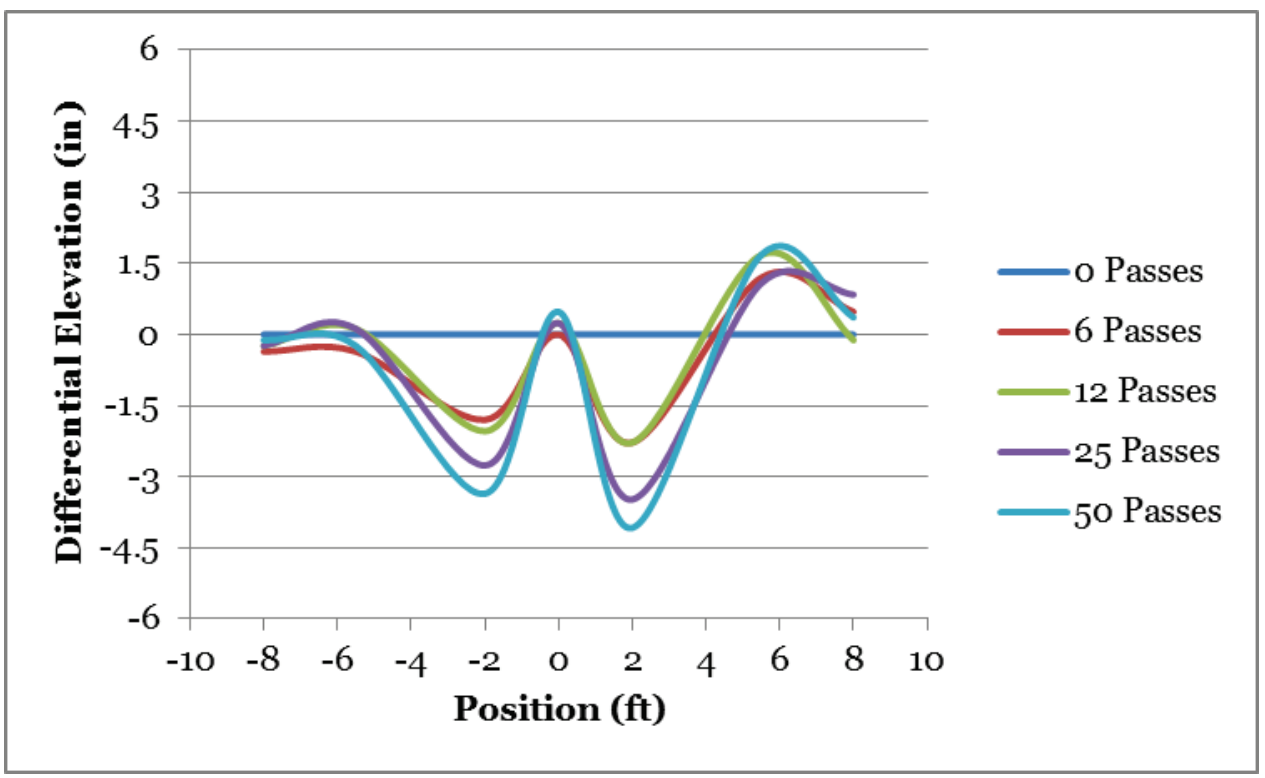

Figure 35. Control section longitudinal profiles (SP-15).

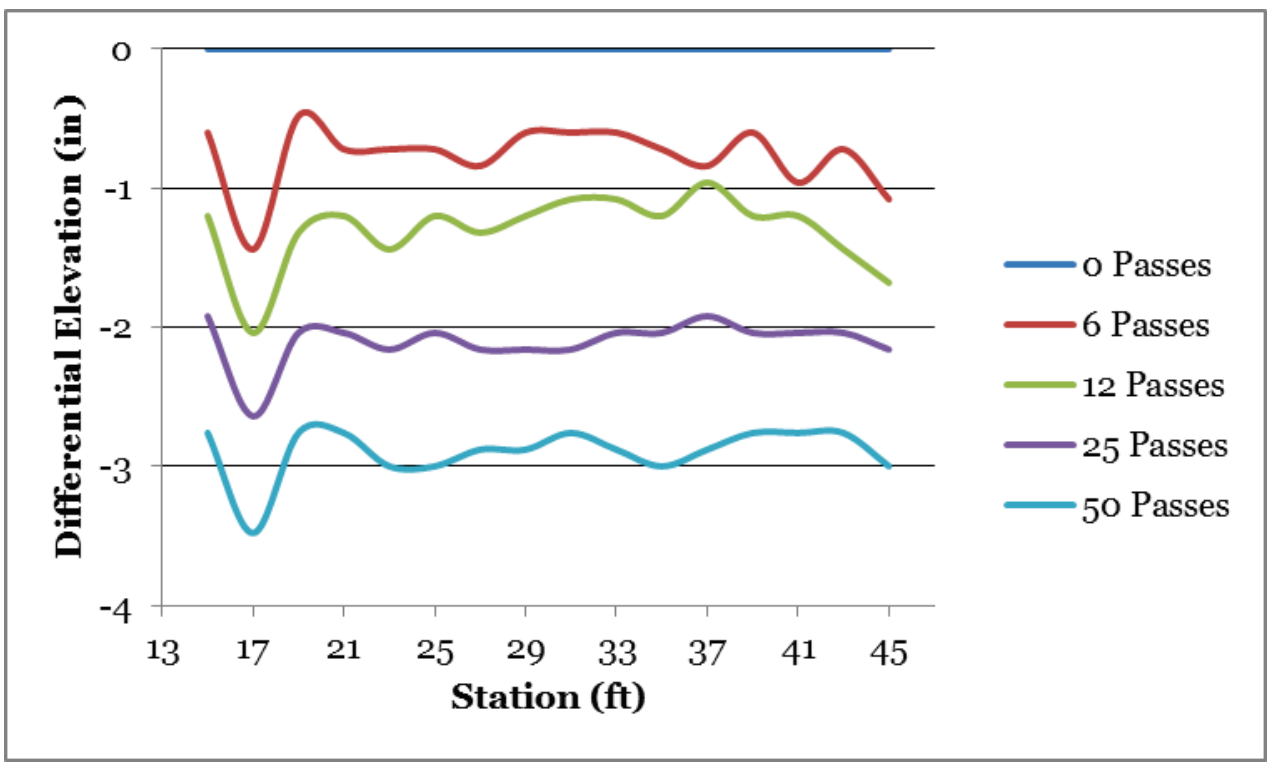

\subsection{Mud flat (CL-3) results}

Section 6.2 includes the results of full-scale traffic testing of both the EMMS and the control test area on the CL-3 subgrade. Results are divided by test item and directly compared to one another. Figure 36 contains the comparative results of the average rut depth across cross sections 1 to 3 versus the number of MTVR passes for all three test items of the CL-3 test section as measured with a rut bar and folding ruler in the right wheel path. Table 6 provides a tabular presentation of the data used to construct Figure 36. 
Figure 36. Average rut depth for CL-3 test areas.

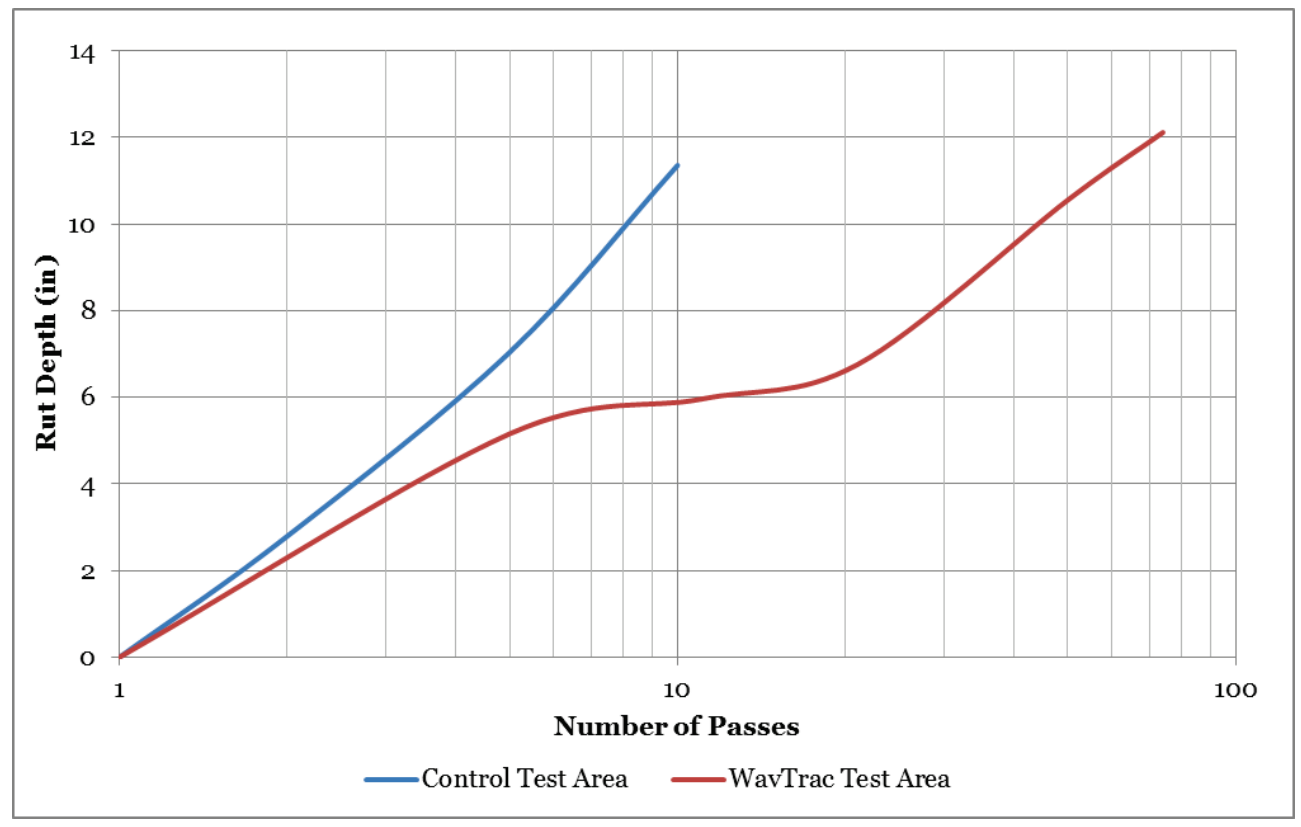

Table 6. Average rut depth for CL-3 test items.

\begin{tabular}{|l|l|l|l|}
\hline \multicolumn{2}{|c|}{ Control Test Area } & \multicolumn{2}{c|}{ WavT rac Test Area } \\
\hline $\begin{array}{l}\text { Number of } \\
\text { Passes }\end{array}$ & $\begin{array}{l}\text { Average Rut } \\
\text { Depth, in }\end{array}$ & $\begin{array}{l}\text { Number of } \\
\text { Passes }\end{array}$ & $\begin{array}{l}\text { Average Rut } \\
\text { Depth, in }\end{array}$ \\
\hline 0 & 0.0 & 0 & 0.0 \\
\hline 1 & 2.8 & 5 & 5.2 \\
\hline 5 & 7.0 & 11 & 6.0 \\
\hline 10 & 11.4 & 21 & 6.8 \\
\hline-- & -- & 50 & 10.6 \\
\hline-- & -- & 74 & 12.1 \\
\hline
\end{tabular}

\subsubsection{Mo-Mat CL-3 results}

As described in Section 5.2, the installation rate of the Mo-Mat legacy EMMS was monitored. For the CL-3 Mo-Mat test item, the installation rate was $7,082 \mathrm{ft}^{2} /$ man-hr.

Following installation, full-scale traffic operations were initiated. After four passes of the test vehicle, the legacy Mo-Mat system failed in mat breakage. The failure was in the form of several severe transverse cracks from which the EMMS completely separated into multiple pieces. It is expected that the premature failure of the Mo-Mat on this subgrade was due to the large deformations from traffic loading on soft soil and the brittle behavior of the mat due to age. Figure 37 shows typical damage to the Mo-Mat system during the first four passes, which resulted in severe 
mat breakage and the stoppage of traffic operations on the test area. Cross-sectional transverse profiles and longitudinal profiles are not provided for this test area.

Due to severe mat breakage, the Mo-Mat EMMS was not able to be effectively recovered from the CL-3 test section. No recovery timing data are reported for this scenario.

Figure 37. Mo-Mat test area typical damage during early traffic (CL-3).

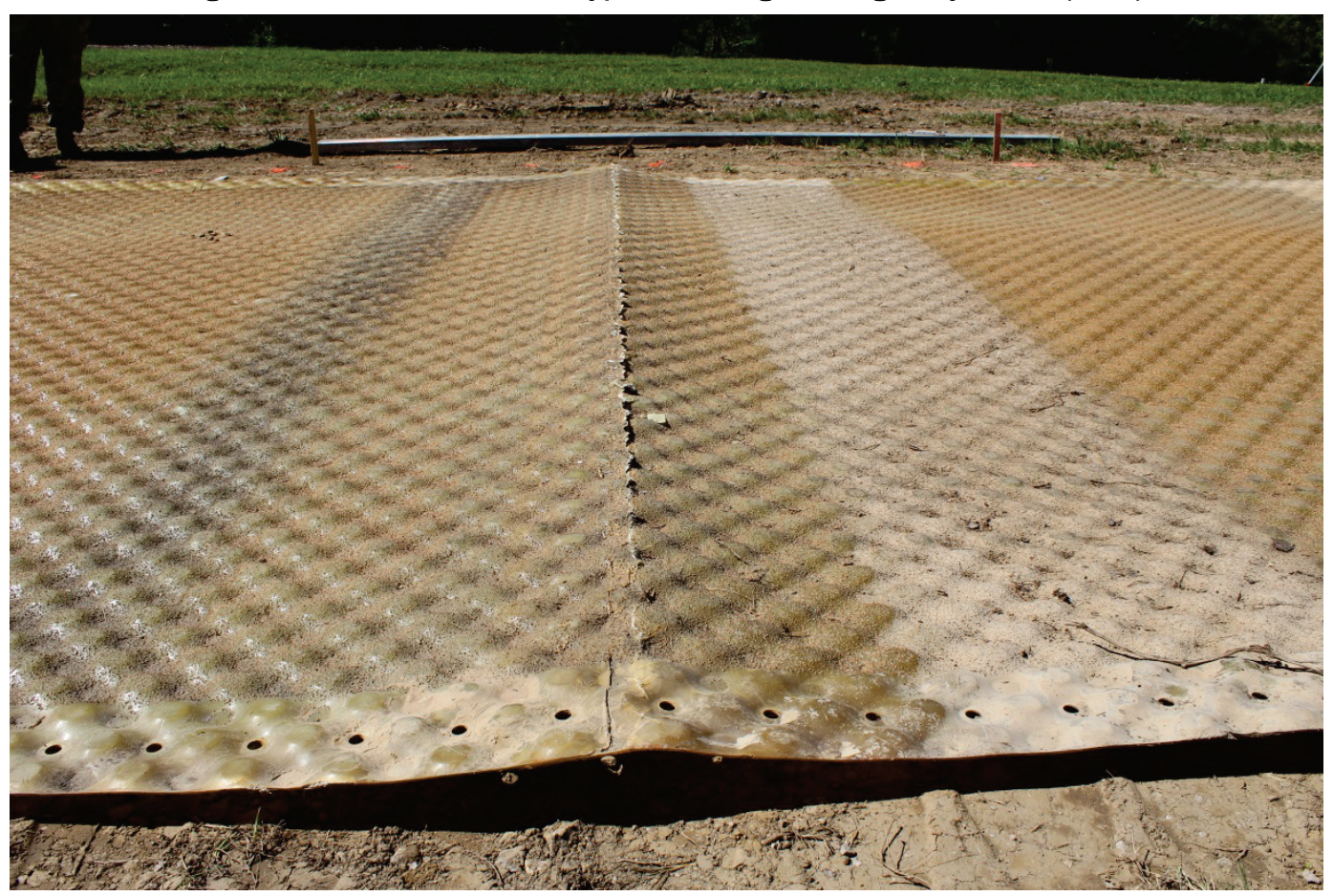

\subsubsection{WavTrac CL-3 test results}

As described in Section 5.2, the installation rate of the WavTrac prototype EMMS was monitored. For the CL-3 WavTrac test item, the installation rate was $5,214 \mathrm{ft}^{2} / \mathrm{man}-\mathrm{hr}$.

Following installation, traffic operations were initiated. The average rate of rut accumulation under full-scale traffic testing for the CL-3 WavTrac test item can be seen in Figure 36. Figures 38, 39, and 40 present the change in cross-sectional profile for each of the three cross sections at all data collection traffic intervals, while Figure 41 depicts the change in longitudinal profile between cross sections 1 and 3 versus the number of MTVR passes for the WavTrac EMMS on the CL-3 subgrade. Beginning on pass no. 24, the front axle housing on the test vehicle began to scrape the upheaved 
center of the WavTrac EMMS between the developed ruts. Traffic was continued until pass no. 74, when the test vehicle dislodged an approximately $2-\mathrm{ft}^{2}$ area of the WavTrac EMMS from the rest of the mat. Figure 42 shows typical damage from axle scraping, while Figure 43 shows the dislodged portion of the EMMS.

Figure 38. WavTrac test area cross section 1 transverse profiles (CL-3).

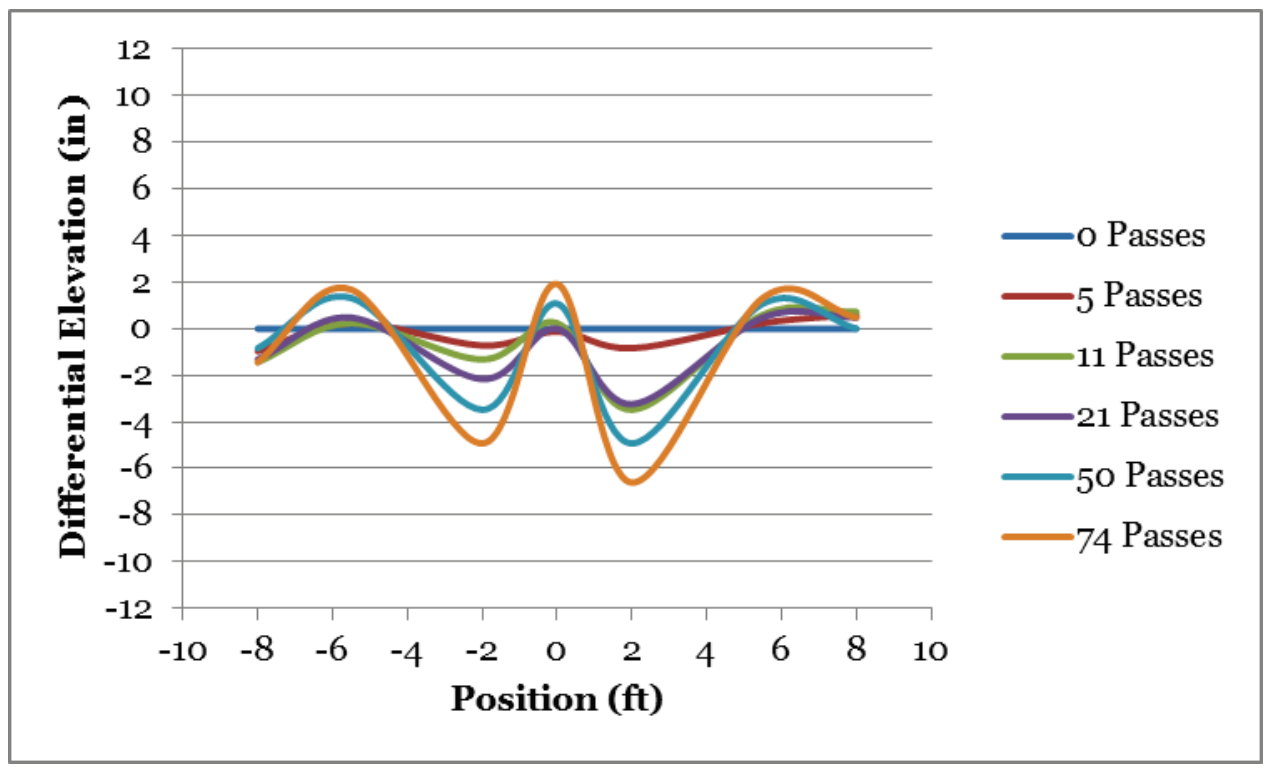

Figure 39. WavTrac test item cross section 2 transverse profiles (CL-3).

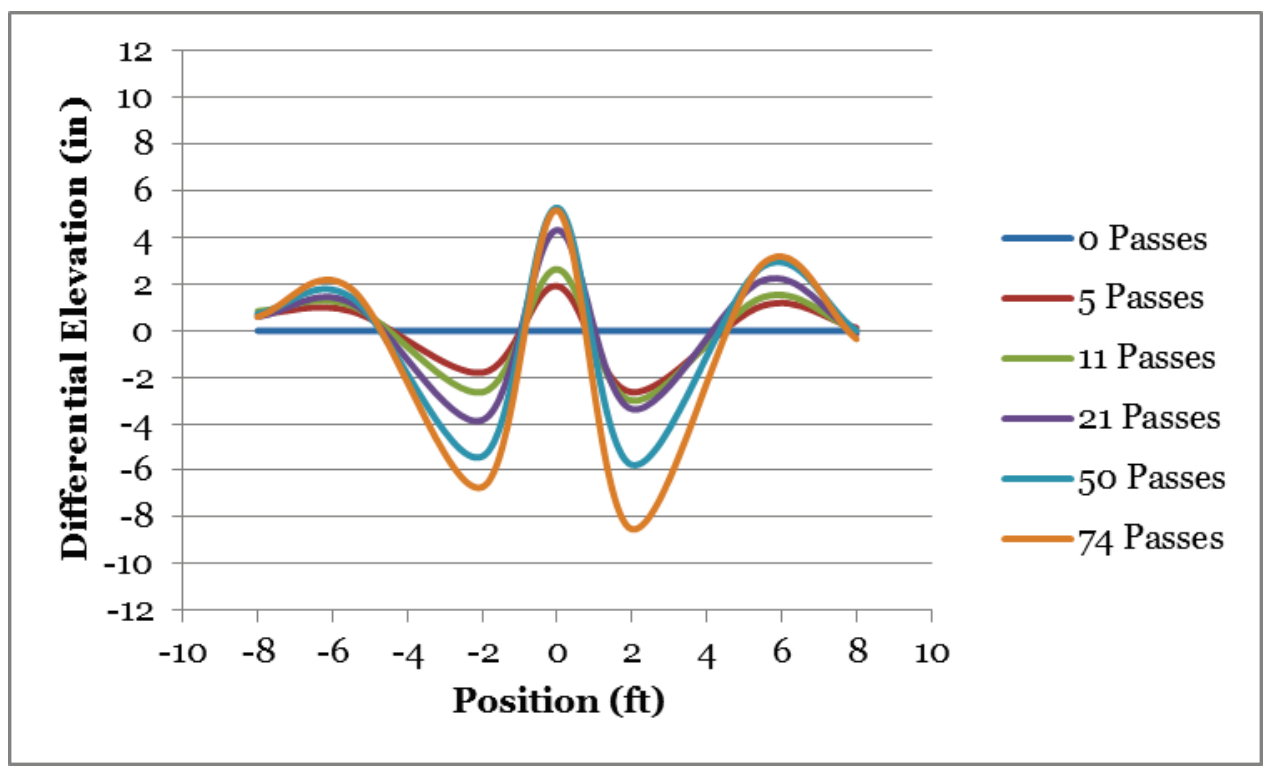


Figure 40. WavTrac test item cross section 3 transverse profiles (CL-3).

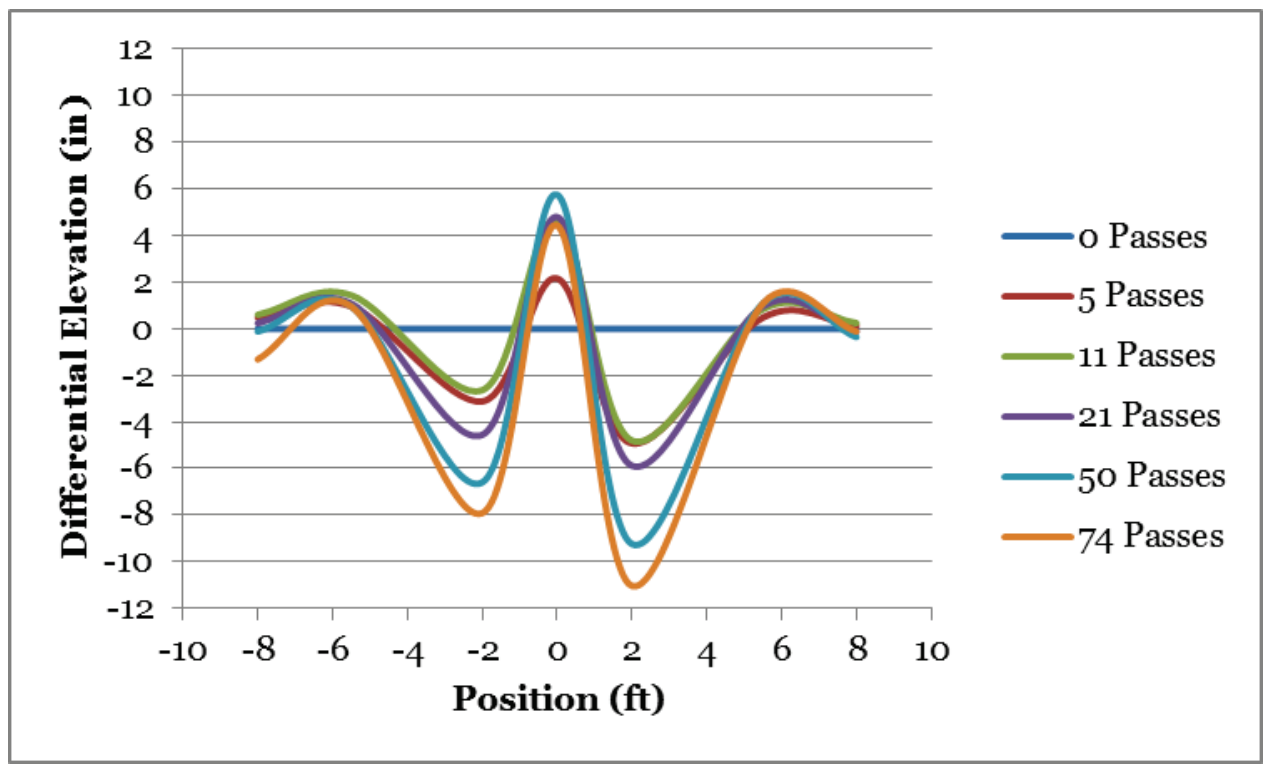

Figure 41. WavTrac longitudinal profiles (CL-3).

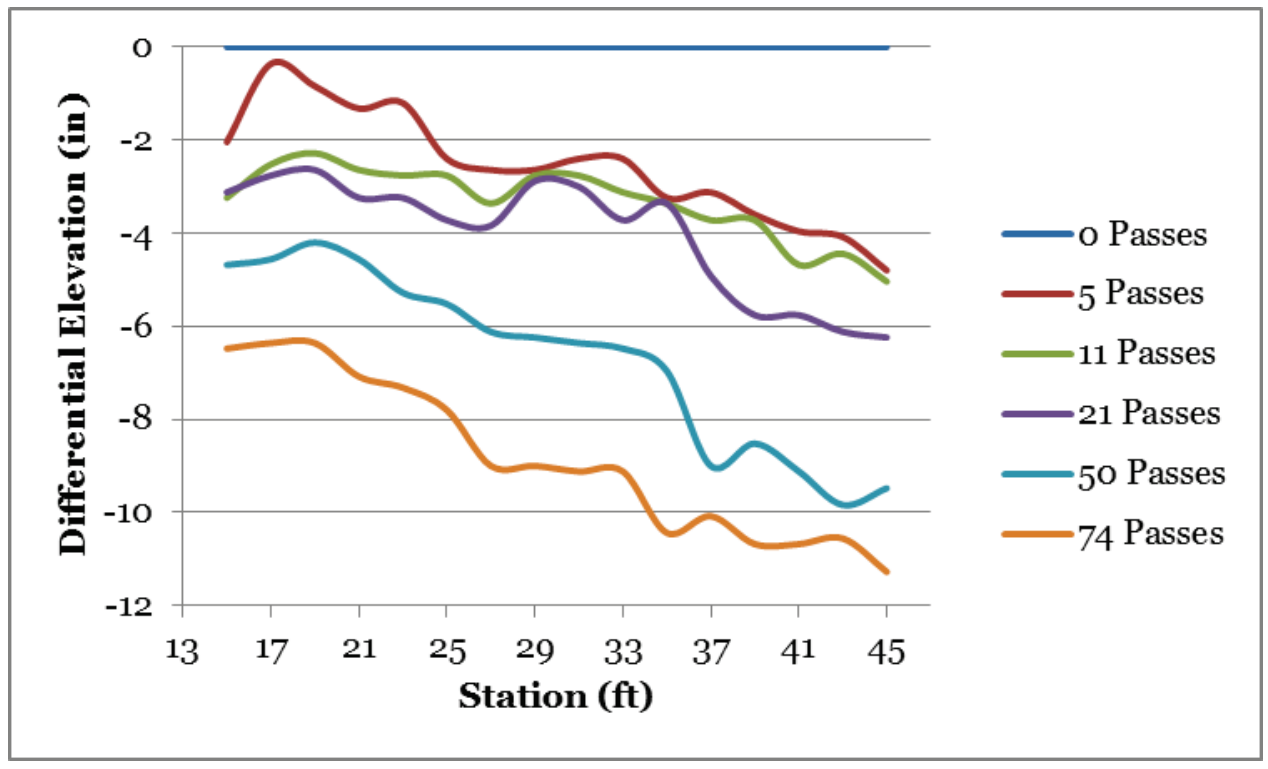


Figure 42. Typical damage from axle scraping.

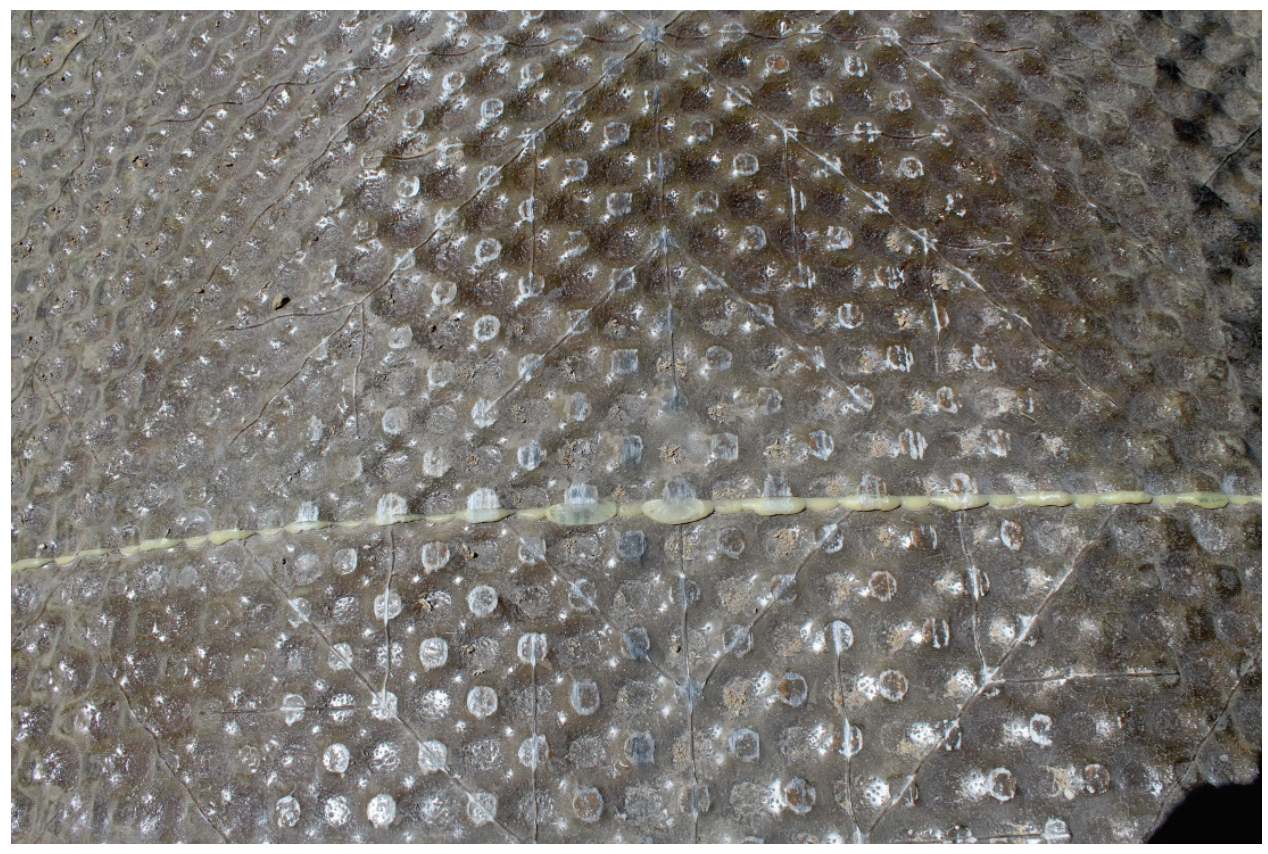

Figure 43. Dislodged portion of WavTrac EMMS.

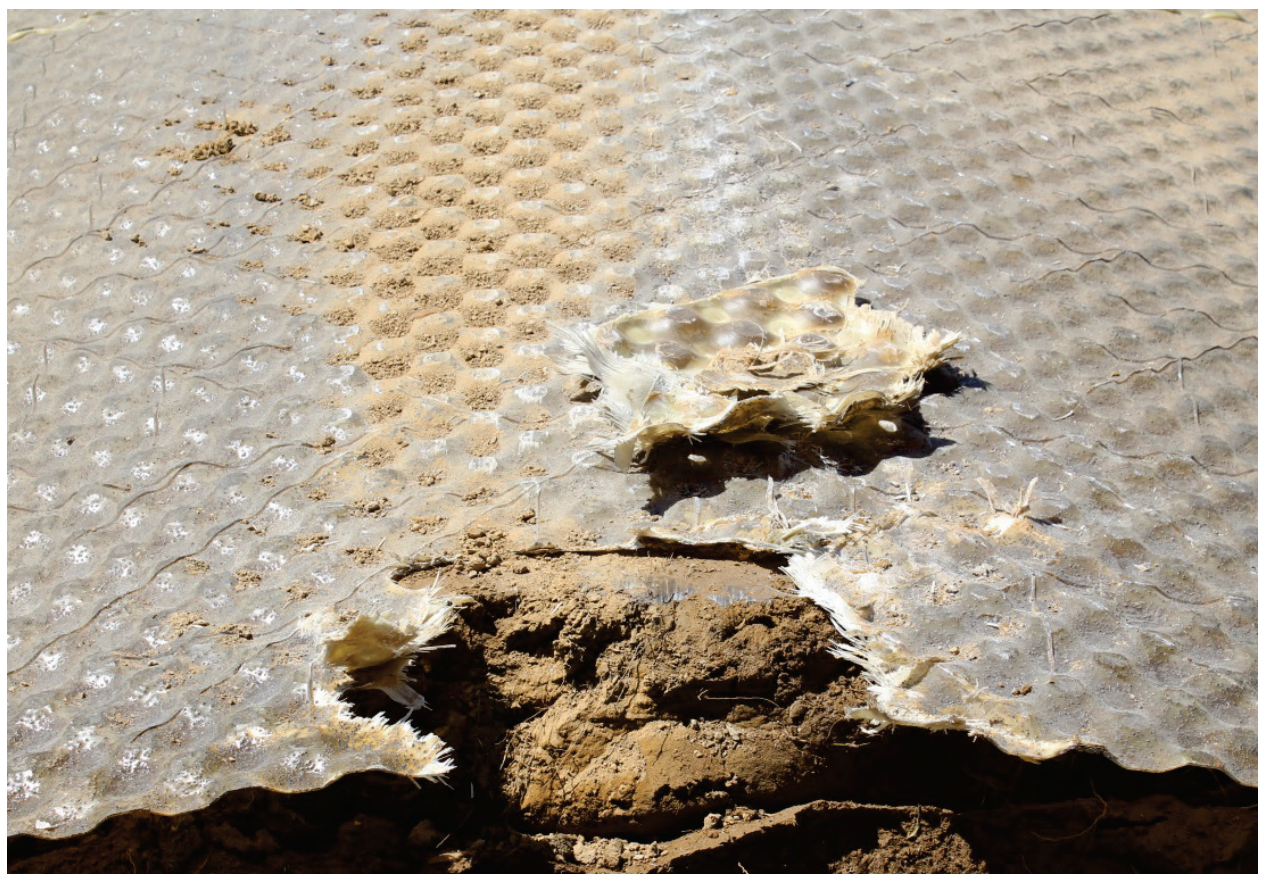

Following the completion of full-scale traffic testing, the WavTrac prototype EMMS was recovered from the CL-3 test section. Timing data were not collected due to atypical recovery conditions caused by mat breakage and severe rutting. 


\subsubsection{Control test item CL-3 results}

Traffic on the control test area was applied directly to the CL-3 subgrade by the MTVR test vehicle. A total of 10 passes was applied to the test area during testing. The average rate of rut accumulation under full-scale traffic testing for the CL-3 control test area can be seen in Figure 36. Figures 44, 45 , and 46 present the change in cross-sectional profile for each of the three cross sections at all data collection traffic intervals, while Figure 47 depicts the change in longitudinal profile between cross sections 1 and 3 versus the number of MTVR passes for the control test area on the CL-3 subgrade.

Figure 44. Control test item cross section 1 transverse profiles (CL-3).

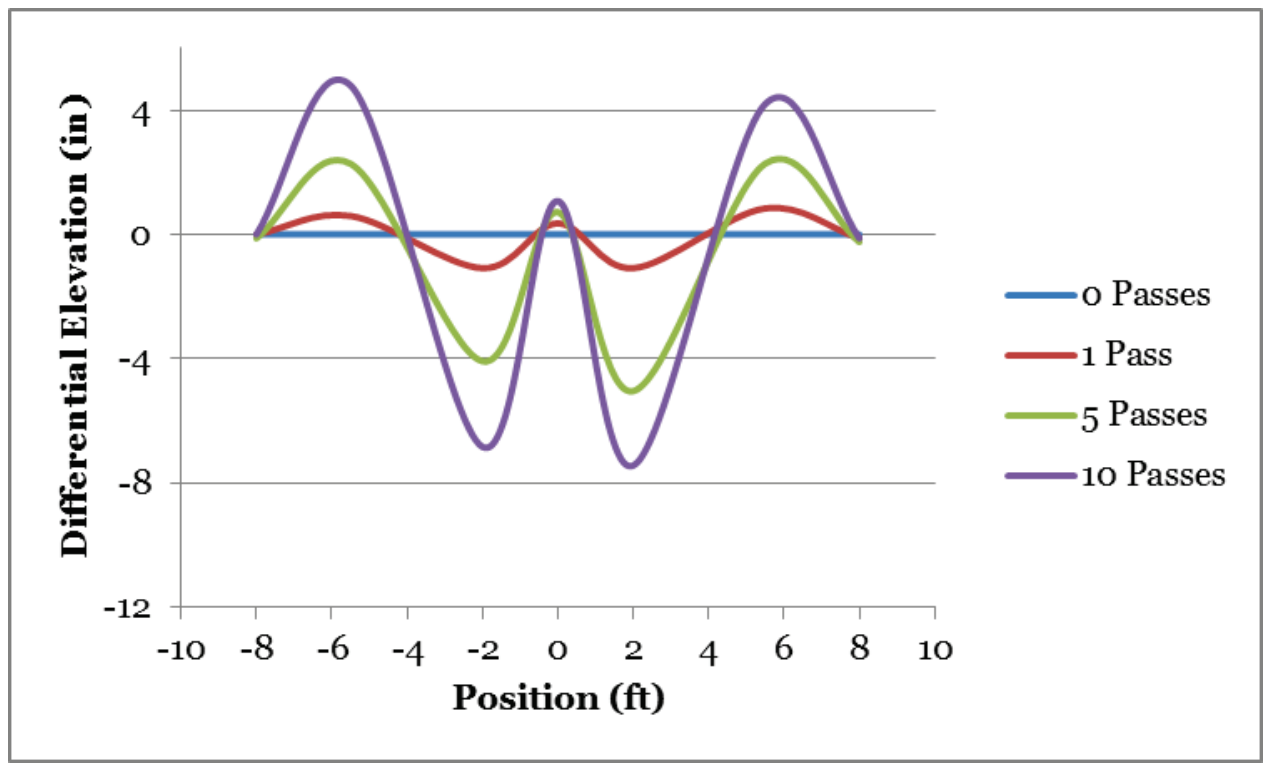

Figure 45. Control test item cross section 2 transverse profiles (CL-3).

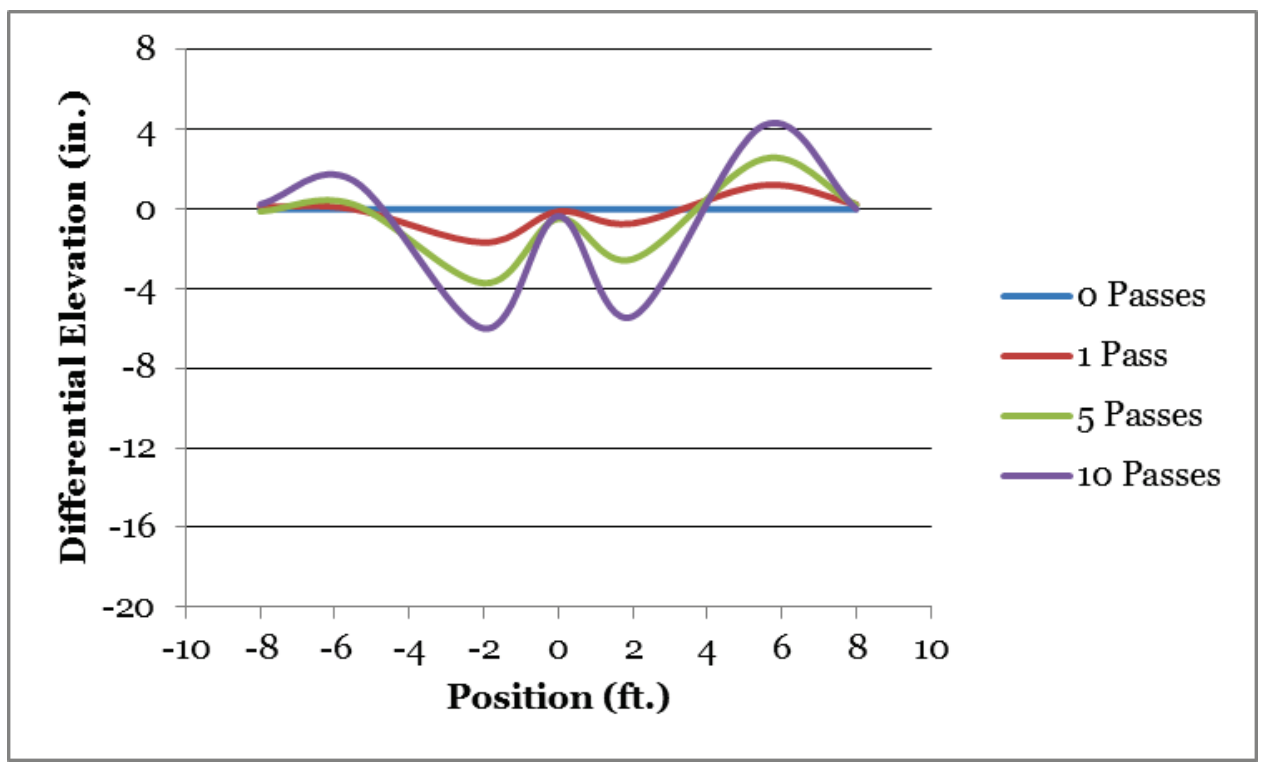


Figure 46. Control test item cross section 3 transverse profiles (CL-3).

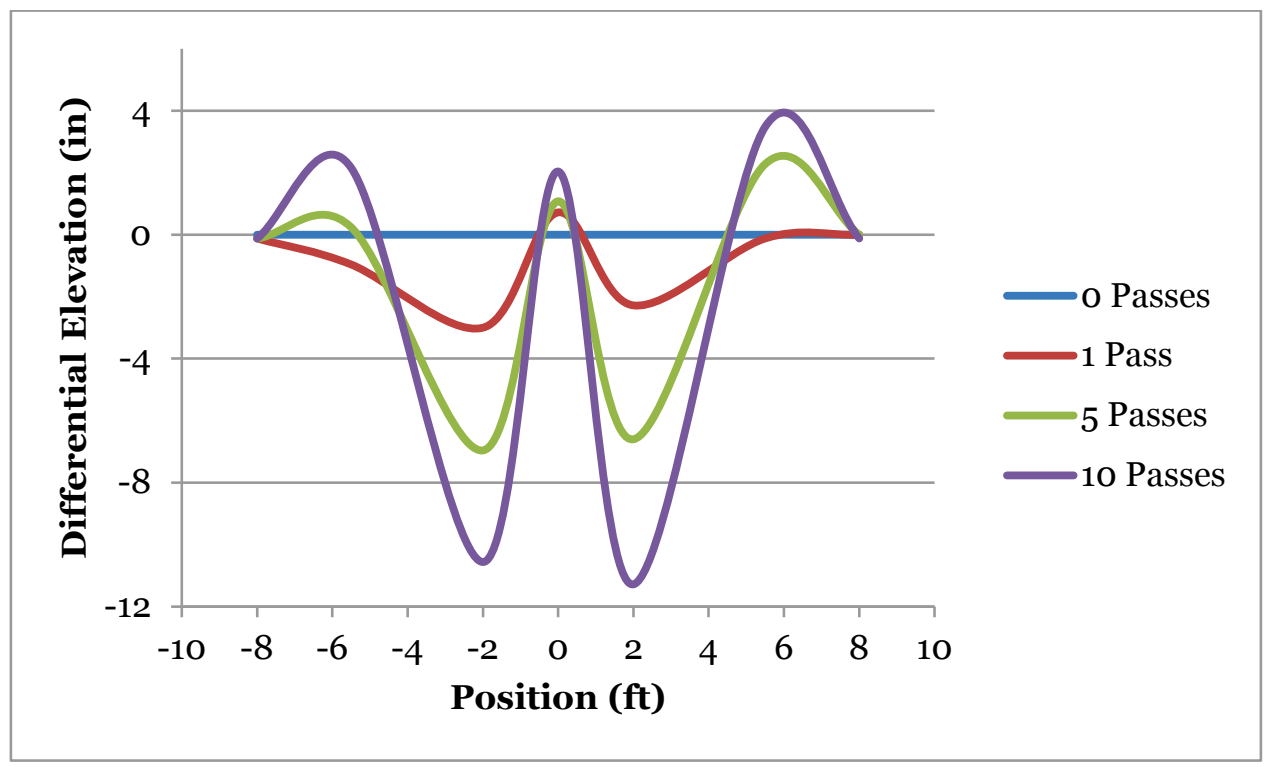

Figure 47. Control test item longitudinal profiles (CL-3).

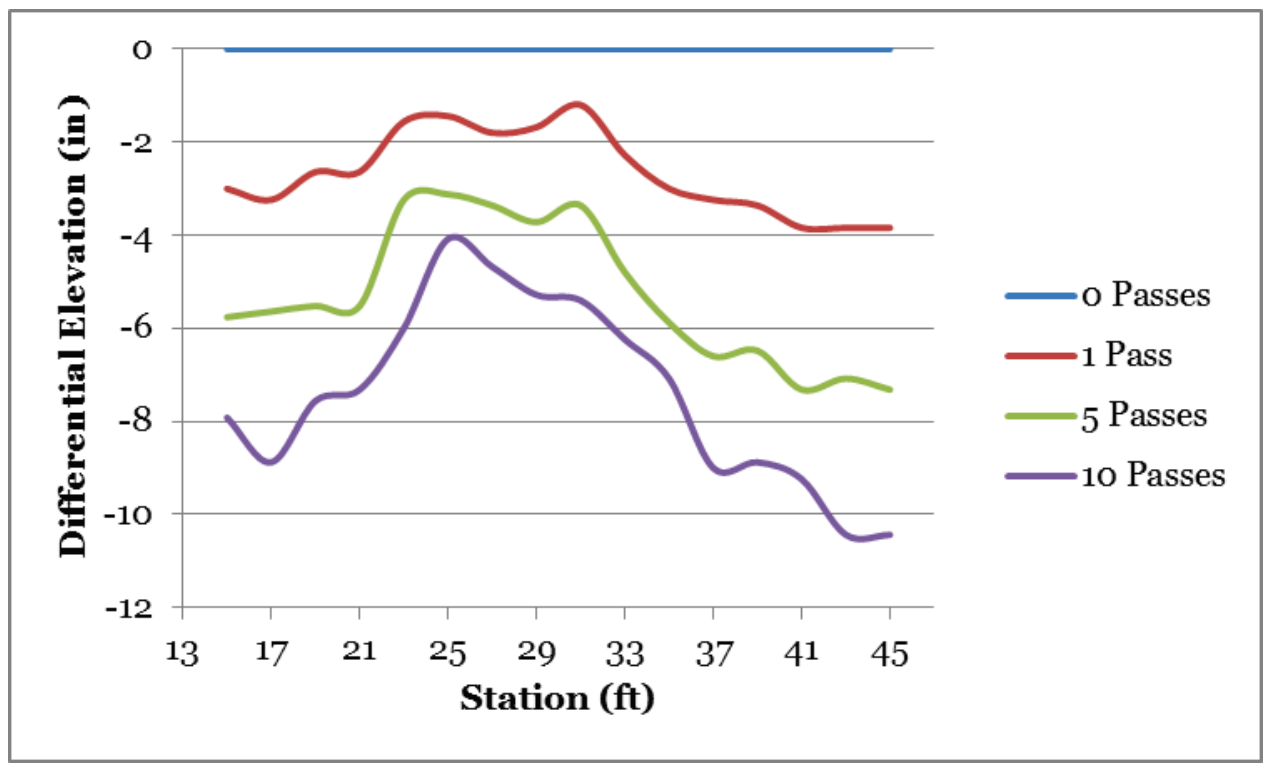




\section{Analysis of the Full-Scale Traffic Test Results}

This chapter summarizes the results of the full-scale testing of the EMMSs. The test data are compared to assess the suitability of the WavTrac EMMS. In general, the average rate of rut accumulation data presented herein is consistent with the data reported by Rushing and Rowland (2012). However, the WavTrac EMMS did not meet all requirements defined by MCSC in the November 2011 requirements document (Appendix A). This section provides an analysis of the full-scale traffic test results and a comparison of test results to MCSC EMMS requirements. Section 3 provides a comparison of laboratory strength values.

\subsection{SP-15 analysis}

Loose, cohesionless soil subgrade conditions have the potential to decrease vehicular mobility following repeated trafficking of the same route. As with other subgrade types, loose beach sand tends to rut under repeated channelized traffic, which can eventually lead to vehicle immobilization. Mobility matting systems, such as the two EMMSs evaluated in this effort, help to confine cohesionless subgrade materials. This confinement promotes particle interlocking and effectively increases the bearing capacity and shear strength of the subgrade material. Not only does an EMMS confine cohesionless material to promote increased shear strength, but an EMMS also helps to distribute wheel loads more uniformly around a wheel path. This distribution of load helps to prevent shear deformations and rut development.

As can be seen in the results presented in Section 6, both EMMSs evaluated met the 2,000 pass threshold for the SP-15 subgrade. No mat damage was noted to either system within the bounds of the data collection items of each test item. The final rut depths for the WavTrac and Mo-Mat systems were 4.0 and 4.1 in., respectively. This difference in rut depth on the mat surface of $0.1 \mathrm{in}$. is negligible and can be attributed to small deviations in subgrade strength or traffic patterns between locations in the SP-15 test section. Thus, based on the results of full-scale MTVR traffic testing, the performance of the WavTrac EMMS is comparable to that of the legacy Mo-Mat EMMS when placed over a loose beach sand. 


\subsection{CL-3 analysis}

Fine-grained soft soil subgrade conditions are among the least desirable when considering vehicular mobility. The low shear strength of this type of subgrade material promotes rapid rut development, and the typically high moisture contents of these materials in a mud flat crossing scenario can limit vehicle traction. Unlike cohesionless soils like sands, fine-grained soils are not stress dependent materials, and confinement does not produce the same strength increases. The use of a mobility matting system such as the two EMMSs evaluated in this effort can help to reduce the load transferred to any discrete point in the subgrade by effectively distributing this load over a larger area. This reduction of load experienced by the subgrade will serve to increase the number of times a given vehicle can traverse across a route. The quantity of load distribution is a function of the section moduli of the mat systems. The two mat systems evaluated in this report have relatively small section moduli due to their small thickness. However, some load distribution was expected. Both EMMSs evaluated in this effort also include a nonskid surface, which helps to increase vehicle traction in undesirable situations.

The results presented in Chapter 6 revealed that neither the legacy Mo-Mat nor the WavTrac EMMS met the 500-pass threshold pass level for the CL-3 subgrade. Prior to traffic stoppage due to mat breakage, the Mo-Mat EMMS withstood four passes of the test vehicle, while the WavTrac EMMS withstood 74 test vehicle passes. The WavTrac system's response to traffic was more desirable than that of the legacy Mo-Mat system. As was noted in Chapter 6, the premature failure of both systems with respect to the MCSC requirement can likely be attributed to the large plastic deformations in the soft subgrade and/or low section moduli of the systems. However, based on tensile and flexural elongation values at maximum load reported in Chapter 3, the WavTrac EMMS should perform better than the Mo-Mat EMMS in soft soil conditions due to the fact that the WavTrac EMMS is able to withstand higher loads and larger deflections prior to plastic failure. 


\section{Conclusions and Recommendations}

\subsection{Conclusions}

1. The tensile strength, flexural strength, and elongation results from laboratory testing indicate that the WavTrac EMMS is stronger and more durable than the legacy Mo-Mat EMMS.

2. Both EMMSs met the installation and recovery rate requirements set forth by MCSC. Both systems were easy to install and recover with a small amount of time and light MHE. Thus, the WavTrac EMMS met the requirements for installation and recovery and was comparable to the legacy Mo-Mat system.

3. Both EMMSs met the 2,000 pass level threshold during trafficking on the SP-15 subgrade. Thus, the WavTrac system met the performance requirements when installed over a sand subgrade and provided comparable performance to the legacy Mo-Mat system.

4. Neither EMMS met the 500 pass level threshold during trafficking on the CL-3 subgrade. However, the WavTrac EMMS outperformed the legacy Mo-Mat EMMS by a relatively large margin. Thus, the WavTrac system did not meet the performance requirement when placed over soft finegrained soil typical of mud flats, but it did provide better performance than the legacy Mo-Mat system.

\subsection{Recommendations}

Based on the results of the testing reported herein, ERDC recommends that alternate mat systems with higher section moduli be used for sustained operations (>100 passes) over soft fine-grained soils. The use of these systems will require a logistics tradeoff to meet the performance standard. 


\section{References}

ASTM International. 2007. Standard test method for tensile properties of polymer matrix composite materials. Designation D3039. West Conshohocken, PA: ASTM International. www.astm.org.

2010a. Standard test method for flexural properties of unreinforced and reinforced plastics and electrical insulating materials by four-point bending. Designation D6272. West Conshohocken, PA: ASTM International. www.astm.org.

. 2010b. Standard test methods for liquid limit, plastic limit, and plasticity index of soils. Designation D4318. West Conshohocken, PA: ASTM International. www.astm.org.

. 2011. Standard practice for classification of soils for engineering purposes (United Soil Classification System). Designation D2487. West Conshohocken, PA: ASTM International. www.astm.org.

2015. Standard test method for use of the dynamic cone penetrometer in shallow pavement applications. Designation D6951. West Conshohocken, PA: ASTM International. www.astm.org.

Rushing, T. W., and J. F. Rowland. 2012. Comparison of original Mo-Mat and prototype replicas for expeditionary roads. ERDC/GLS TR-12-18. Vicksburg, MS: U.S. Army Engineer Research and Development Center.

Rushing, T. S., J. S. Tingle, and Q. S. Mason. 2007. Evaluation of expeditionary mat surfacings for beach roads. ERDC/GSL TR-07-1. Vicksburg, MS: U.S. Army Engineer Research and Development Center.

Webster, S. L., R. H. Grau, and T. P. Williams. 1992. Description and application of dual mass dynamic cone penetrometer. Technical Report GL-98-10. Vicksburg, MS: U.S. Army Engineer Waterways Experiment Station. 


\title{
Appendix A: USMC EMMS Requirements Document
}

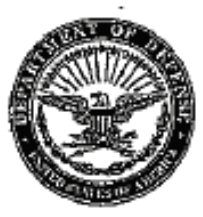

\author{
DEPARTMENT OF THE NAVY \\ HEADOUARTERS UNITED STATES MARINE CORPS \\ 3300 RUSSELL ROAD \\ QUANTICO, VA 22134.5001
}

In REen: 20

3900

C 13

NOV 0.92011

From: Deputy Commandant, Combat Development and Integration To: Commander, Marine Corps Systerns Command (Attn: PG-15 GTES, PM Engineers), 2200 Lester Street, Quantico, VA 22134

SUbj: STATEMENT OF NEED FOR EXPEDITIONARY MOBILITY MATTING SYSTEM (BMMS)

Ref: (a) DC, CDI Itr 3900/C 394 of 07 Dec 05

(b) 10 U.S.C. 2304 (c)

1. Background. Reference (a) provided approval to replace the existing EMMS capability. The legacy EMMS is no longer manufactured; as a result, replacement components can no longer be requisitioned. The next generation EMMS requirements have changed and therefore ref (a) is cancelled and superseded by this letter. Pursuant to reference (b), a new EMMS capability wil be procured to enhance the operating force's ability to maneuver wheeled vehicles across adverse and difficult terrain by providing improved traction that ensures mobility and freedom of movenent during ground operations.

2. Concept of Operations. The new BMis is modular, comprised of kit with interchangeable parts which could be assembled into different configurations to support misston specific tasks. different configurations to support meficability across beach landings and making passable paths along supply routes. This EMMS supports operations in temperate, cold weather, and desert environments.

3. Concept of Employment. The EMMS can be assembled, employed, and retrieved by Marines across all MOSs. Some EMMS configurations may require MHE for deployment and retrieval, while other configurations may be totally man-portable.

4. Performance Characteristics. To ensure the EMMS meets the desired capability to support a wide range of operational missions, the following performance parameters are required: 
Subj: STATEMENT OF NEED FOR EXPEDITIONARY MOBILITY MATTING SYSTEM (EMMS)

a. The BMMS must support a minimum of 2,000 passes of a 7-ton MTVR truck loaded to a standard off-road payload capacity, when placed over a doose band subgrade with a California Bearing Ratio (CBR) (of 15 percent.)

b. The RMMS must support a minimum of 500 passes of a 7-ton MTVR truck loaded to its off-road payload capacity, when placed over a soft fine grained subgrade with a CBR of 3 percent.

c. The EMMS must be capable of deploying at a threshold rate of 2,500 square feet per man-hour with a 4-person crew. The of jective rate of deployment is 4,000 square feet per man-hour with a 4-person crew. Material handling equipment (MHE) may be used to move the EMIS into position for deployment.

d. The EMlMs weight must be less than $2.5 \mathrm{lbs} / \mathrm{ft}^{2}$.

e. The EMMS shipping volume, to include ancillary connectors and parts, must be optimized for both, storage in International organization for Standardization (ISO) Containers and for airlift on a $\mathrm{C}-130$. The threshold shipping volume is 8 square feet per cubic foot with an objective of 12 square feet per cubic foot. When packaged for shipping, the threshold configuration for the EMMS is two connected $463 \mathrm{~L}$ pallets with an objective of a single $463 \mathrm{~L}$ pallet.

f. The EMMS must be capable of being retrieved at a minimum rate of 400 square feet per man-hour of effort.

g. The EMMS interior panels and as sembled mat sub-systens must be removable to allow the replacement of damaged panels or to allow for maintenance of the subgrade below groups of panels.

$\mathrm{h}$. The EMMS subsystem panels mast be recoverable and suitable for reuse after being cleaned and repacked.

1. The EMMS material must resist damage under load, and be capable of sustaining vehicle braking and turning actions of a 7-ton MTVR with an off-road payload.

j. The EMMS subsystem panels must have a nonskid surface.

k. The EMISS subsystem panels must be capable of being placed over subgrade crowned up to 108 grade. 
Subj: STATEMENT OE NEED FOR EXPEDITIONARY MOBILITY MATTING SYSTEM (EMMS)

I. The EMMS subsystem panels must be able to resist exposure to JP series of fuels, hydraulic fluids, and other liquids typically found in an expeditionary environment.

m. The EMMS subsystem panels should not require specialized, tools to assemble and maintain.

n. Any HAZMAT used as a part of the system's operations, maintenance, support or disposal activities, must be identified. Adequate procedures and equipment to include engineering control.s, appropriate personal protective equipment, or acministrative controls must be included with the delivered system to minimize environmental safety and health risks.

o. The EMMS shall function in temperatures ranging from -25 degrees Fahrenheit to +125 degrees Fahrenheit. The EMMS shal1 be capable of storage in temperatures ranging from -40 degrees Fahrenheit to +160 degrees Fahrenheit without degradation.

p. The EMMS dimensions will be between 12 and 14 feet wide by 60 feet long, with the ability to incorporate an unlimited length and width expansion.

5. Approved Acquisition Objective. The EMMS planned quantities and distribution is as follows:

\begin{tabular}{|l|c|}
\hline \multicolumn{1}{|c|}{ Organization } & AAO \\
\hline I MEF & 160 \\
\hline II MIEF & 108 \\
\hline III MEF & 172 \\
\hline MAREORRES & 150 \\
\hline SupPOIting Establishments & 6 \\
\hline MCPR-N & 65 \\
\hline MPF & 189 \\
\hline
\end{tabular}

6. POA\&M. Request that Commandex Marine Corps Systems Command take all necessary actions to procure and fleld this capability to the Operating Forces. Please provide a POAdM to this headquarters within 30 days.

7. Point of contact. The point of contact in this matter is Engineer Capabilities Branch, Logistics Integration Division, commercial $703-784-6214$ or DSN 278-6214. 
Subj: STATEMENT OF NEED FOR EXPEDITIONARY MOBIEITY MATTING SXSTEM (EMMS)

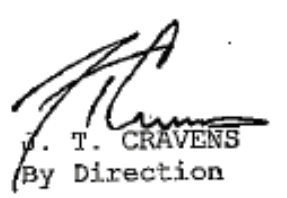




\section{Appendix B: Subgrade Test Data}




\section{SP-15 DCP Profile (Station 0+50)}

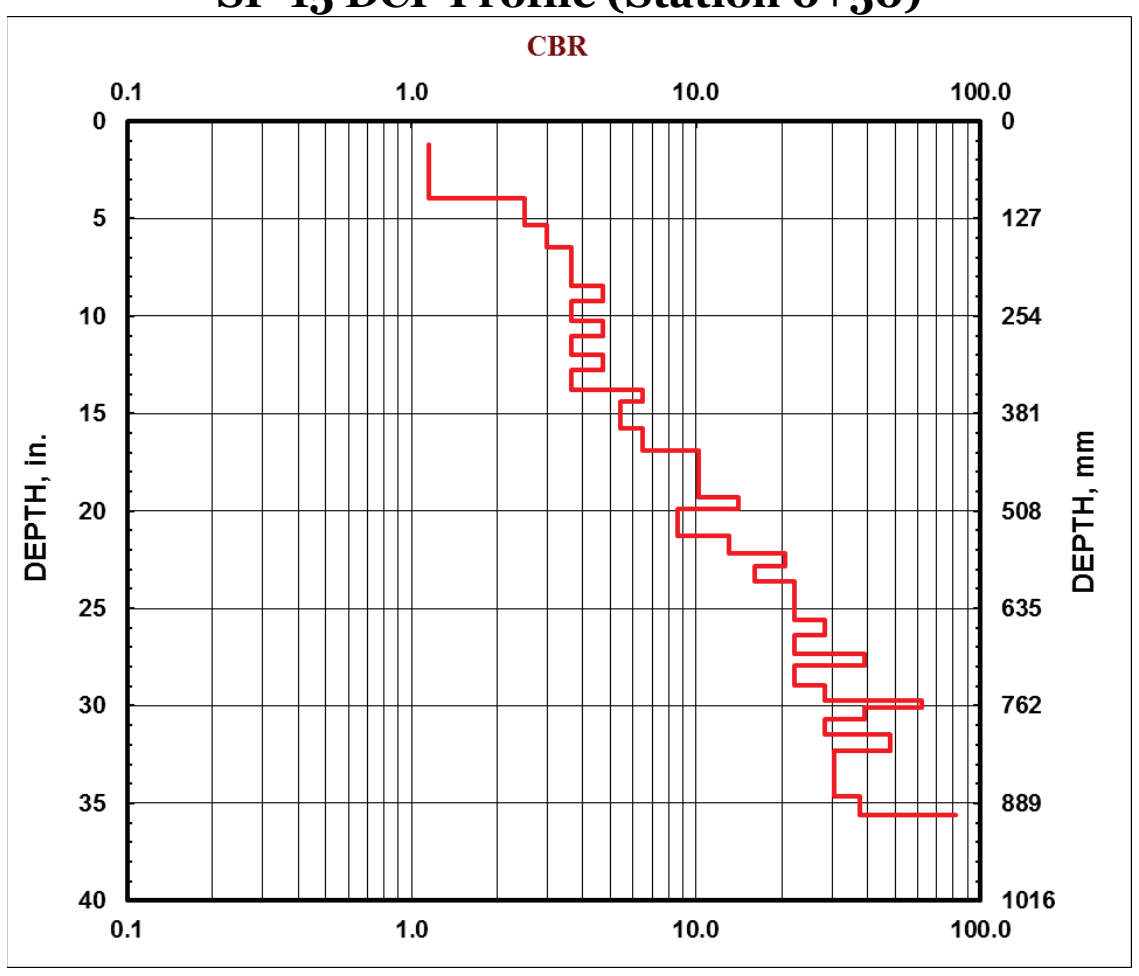

SP-15 DCP Profile (Station 1+oo)

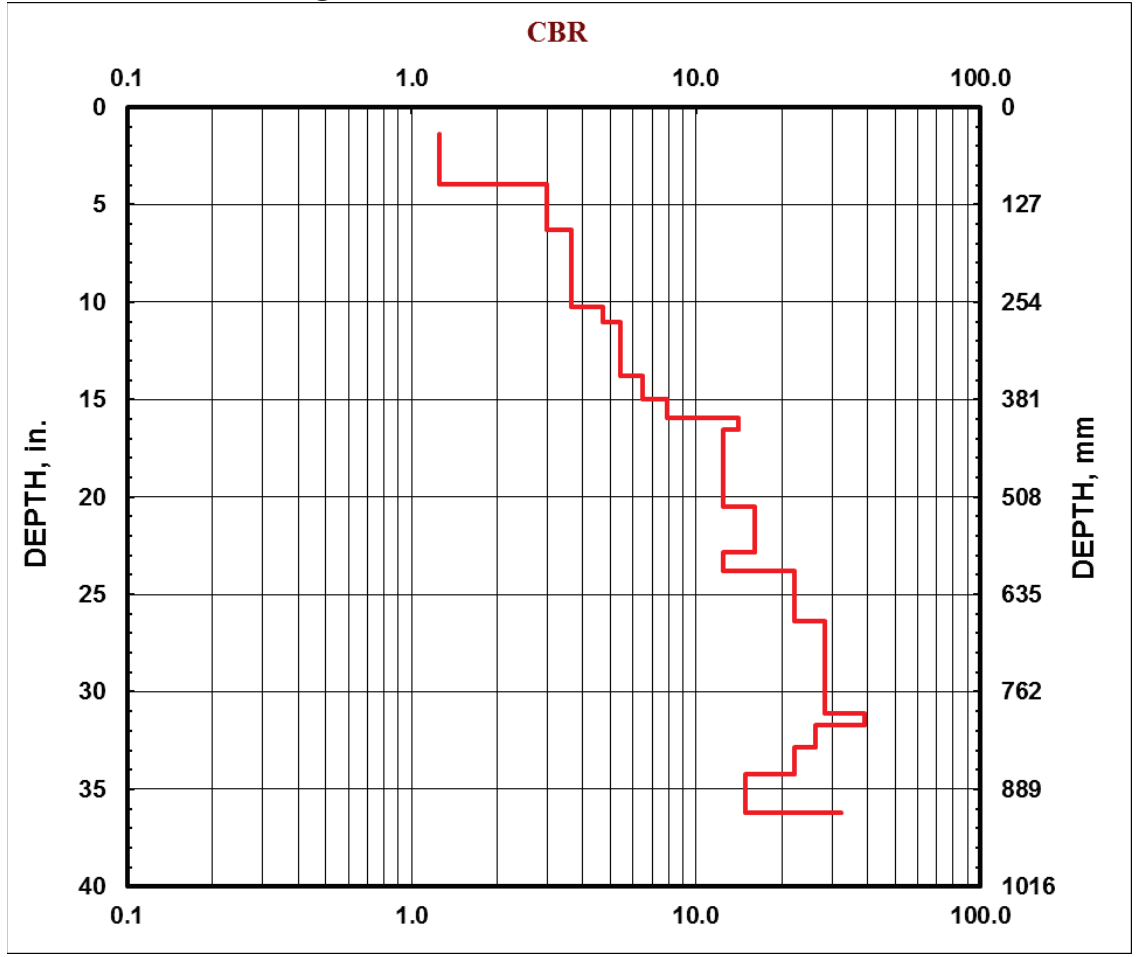


SP-15 DCP Profile (Station 1+50)

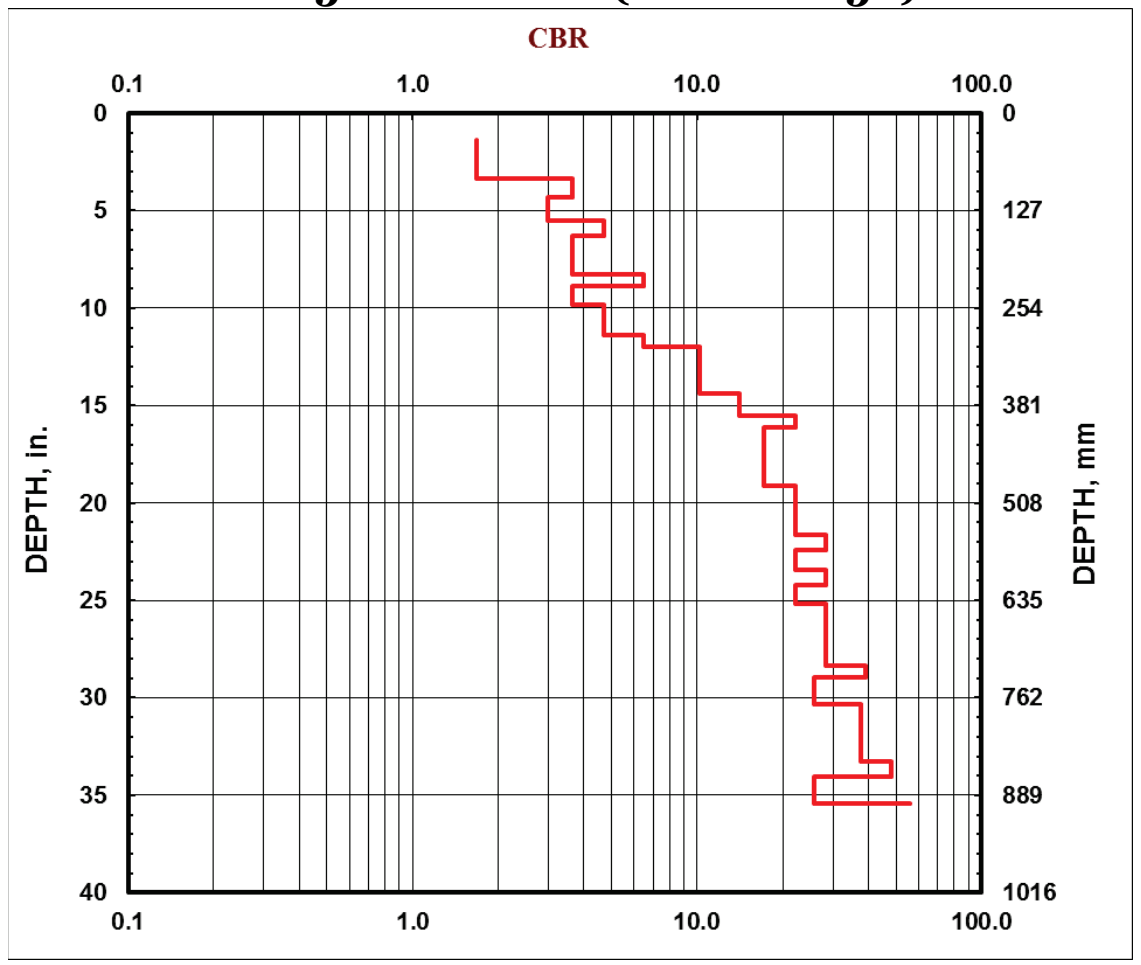

SP-15 Material Gradation Properties

\begin{tabular}{|c|c|c|c|c|c|c|c|c|c|c|}
\hline \multirow{2}{*}{ Cobbles } & \multicolumn{4}{|c|}{ Gravel } & \multicolumn{4}{|c|}{ Sand } & \multicolumn{3}{c|}{ Fines } \\
\cline { 2 - 11 } & Coarse & Fine & Total & Coarse & Medium & Fine & Total & Silt & Clay & Total \\
\hline 0.0 & 0.0 & 6.7 & 6.7 & 14.3 & 34.9 & 43.7 & 92.9 & & & 0.4 \\
\hline
\end{tabular}

\begin{tabular}{|c|c|c|c|c|c|c|c|c|c|c|c|}
\hline $\mathrm{D}_{\mathbf{5}}$ & $\mathrm{D}_{\mathbf{1 0}}$ & $\mathrm{D}_{\mathbf{1 5}}$ & $\mathrm{D}_{\mathbf{2 0}}$ & $\mathrm{D}_{\mathbf{3 0}}$ & $\mathrm{D}_{\mathbf{4 0}}$ & $\mathrm{D}_{\mathbf{5 0}}$ & $\mathrm{D}_{\mathbf{6 0}}$ & $\mathrm{D}_{\mathbf{8 0}}$ & $\mathrm{D}_{\mathbf{8 5}}$ & $\mathrm{D}_{\mathbf{9 0}}$ & $\mathrm{D}_{\mathbf{9 5}}$ \\
\hline 0.2233 & 0.2635 & 0.2916 & 0.3149 & 0.3575 & 0.4033 & 0.4632 & 0.5607 & 2.1500 & 2.9004 & 3.9319 & 5.1747 \\
\hline
\end{tabular}

\begin{tabular}{|c|c|c|}
\hline $\begin{array}{c}\text { Fineness } \\
\text { Modulus }\end{array}$ & $\mathrm{c}_{\mathrm{u}}$ & $\mathrm{c}_{\mathrm{c}}$ \\
\hline 2.71 & 2.13 & 0.86 \\
\hline
\end{tabular}


CL-3 DCP Profile (Cross Section One, WT, Pretest)

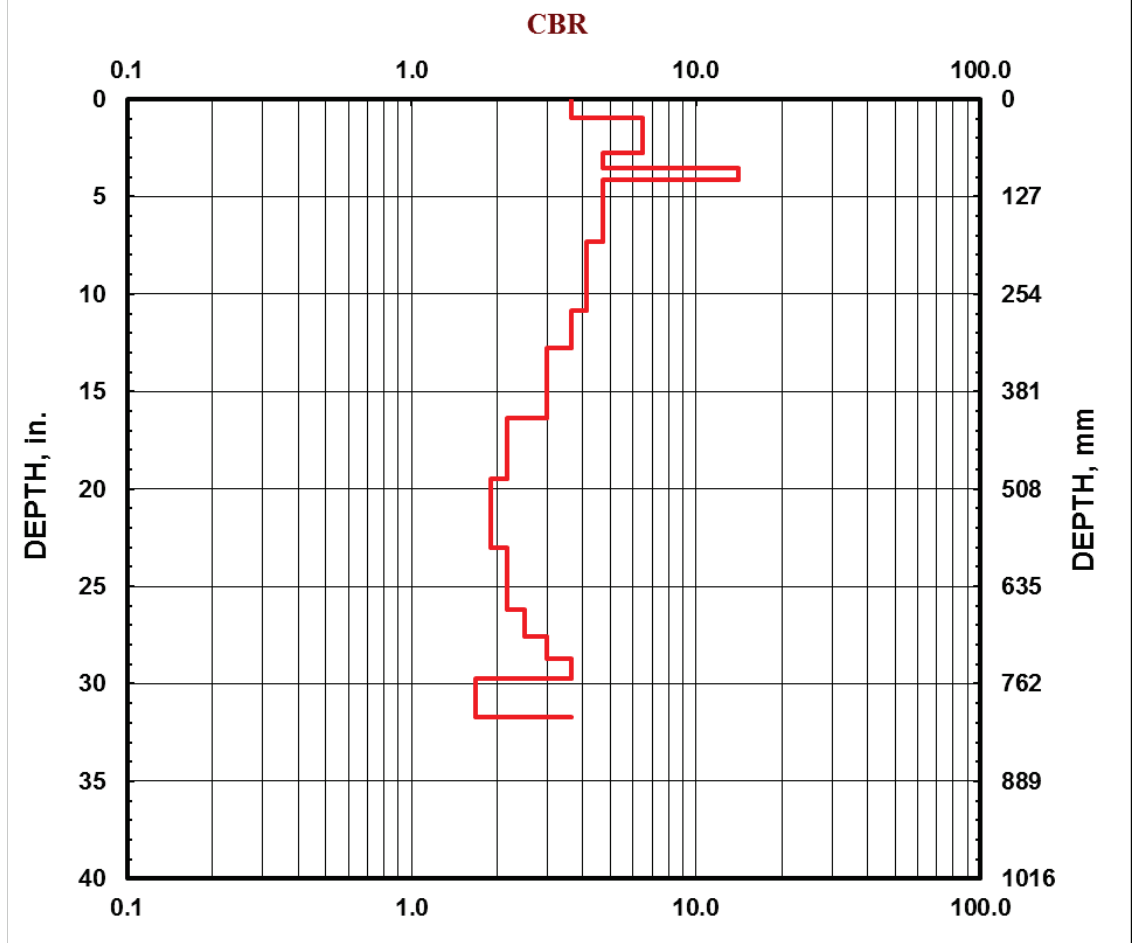

\section{CL-3 DCP Profile (Cross Section Three, WT, Pretest)}

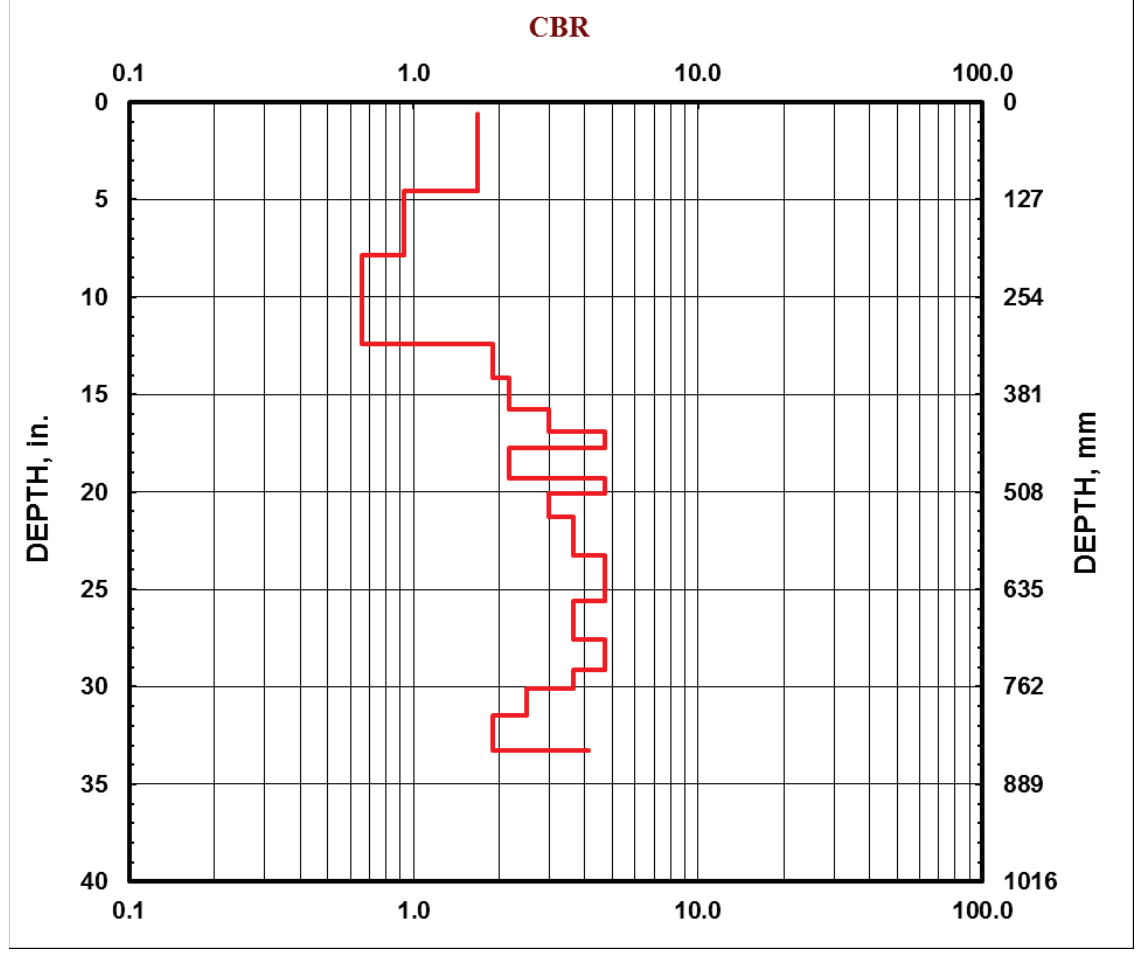


CL-3 DCP Profile (Cross Section One, MM, Pretest)

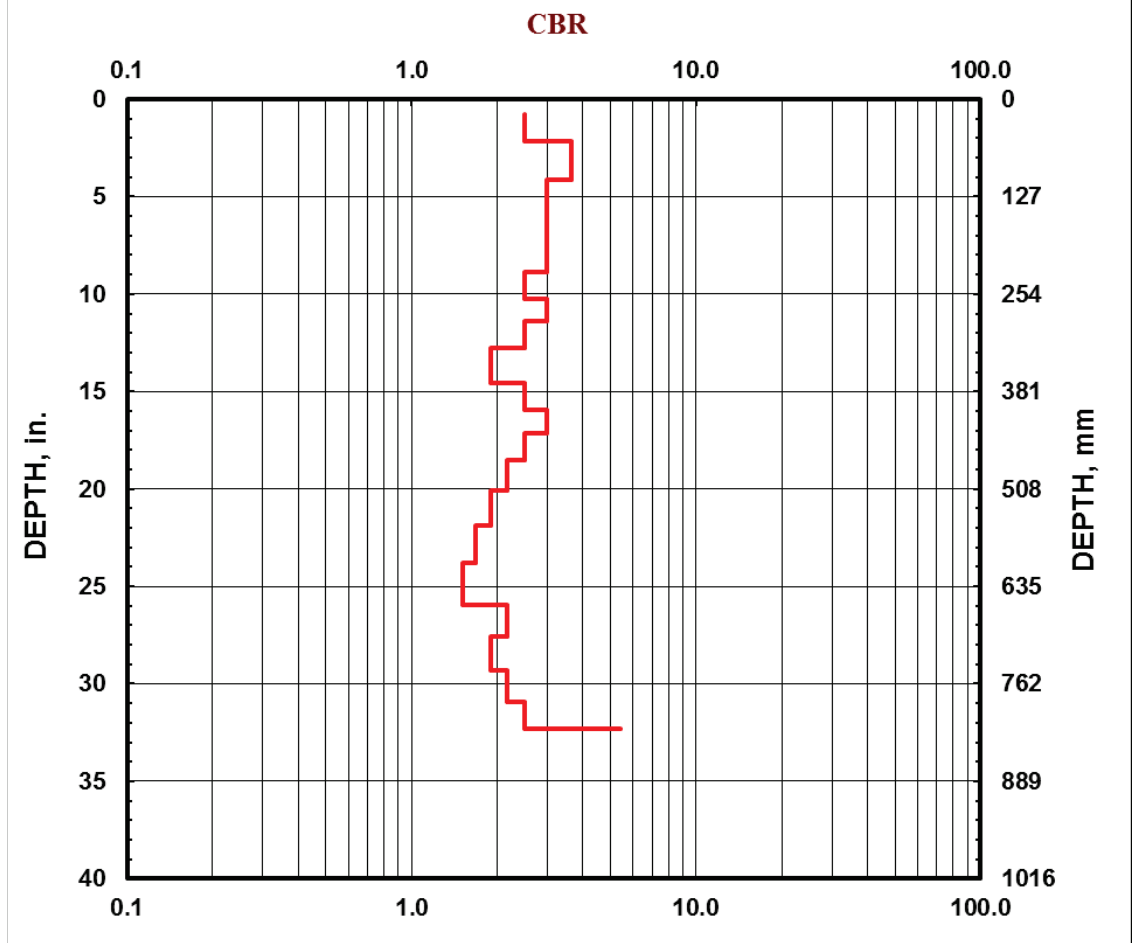

CL-3 DCP Profile (Cross Section Three, MM, Pretest)

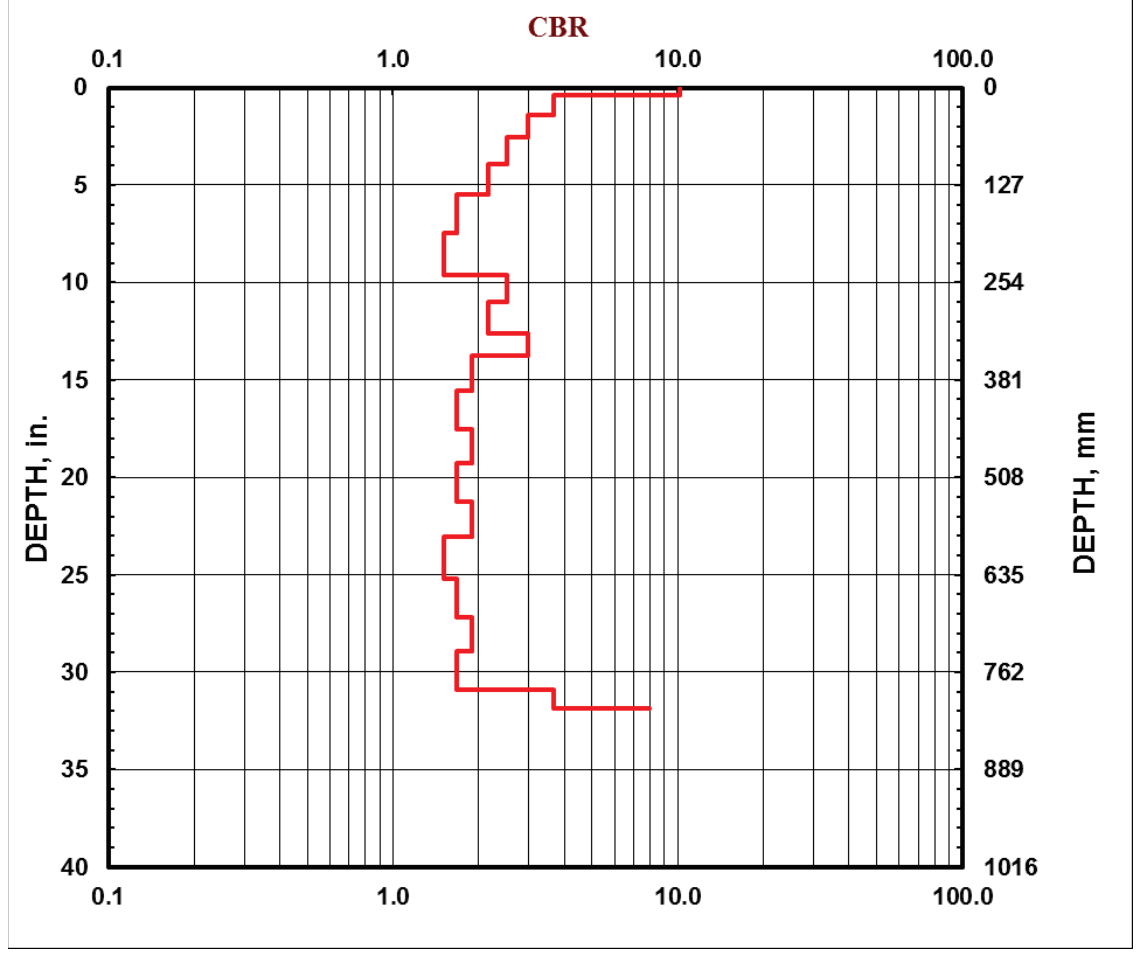


CL-3 DCP Profile (Cross Section One, WT, Posttest)

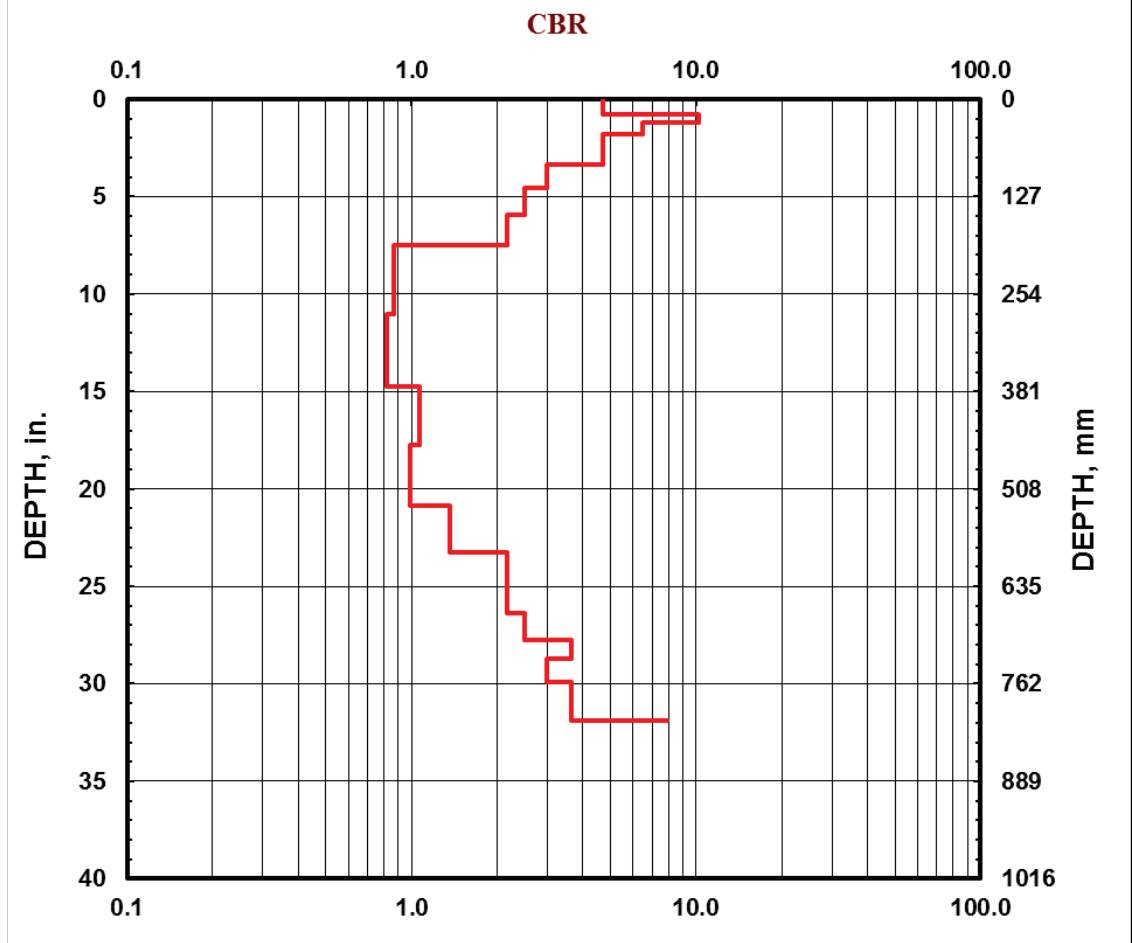

CL-3 DCP Profile (Cross Section Two, WT, Posttest)

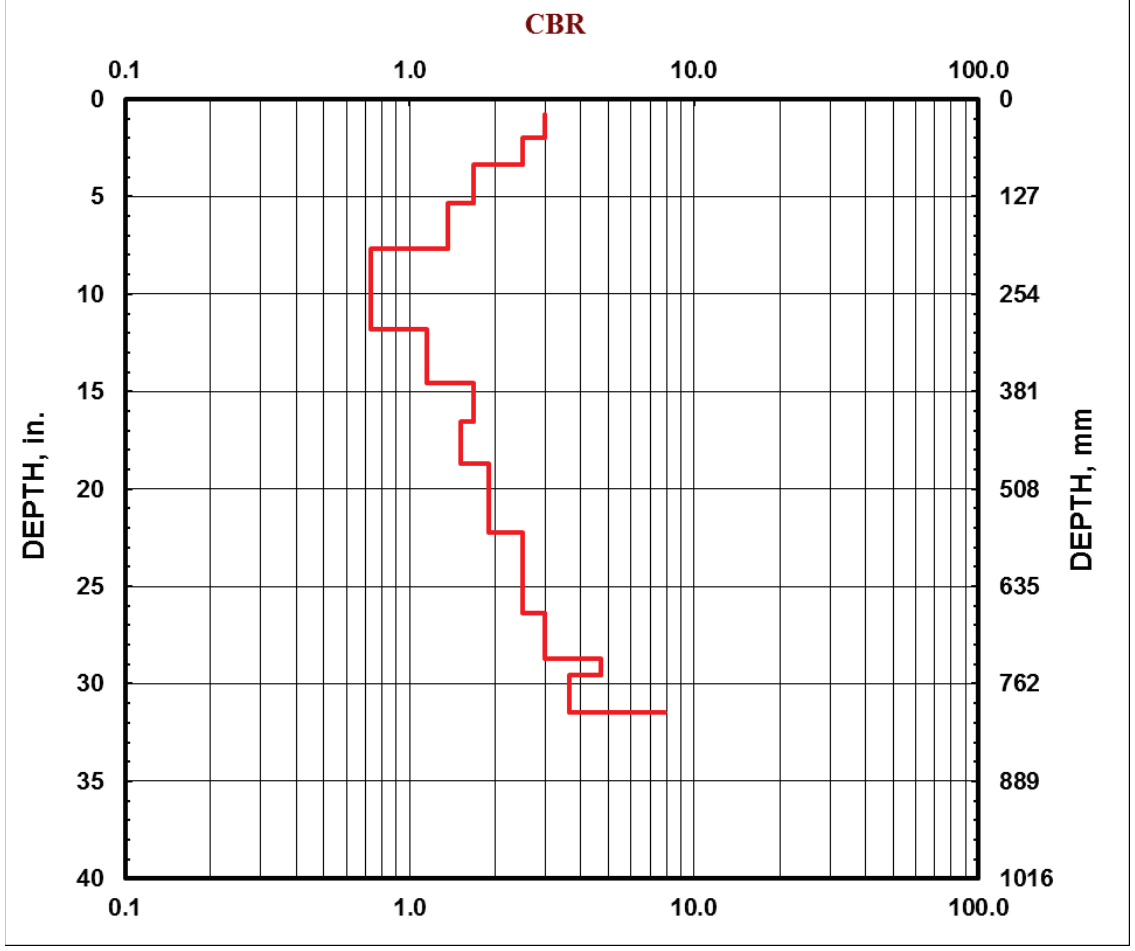


CL-3 DCP Profile (Cross Section Three, WT, Posttest)

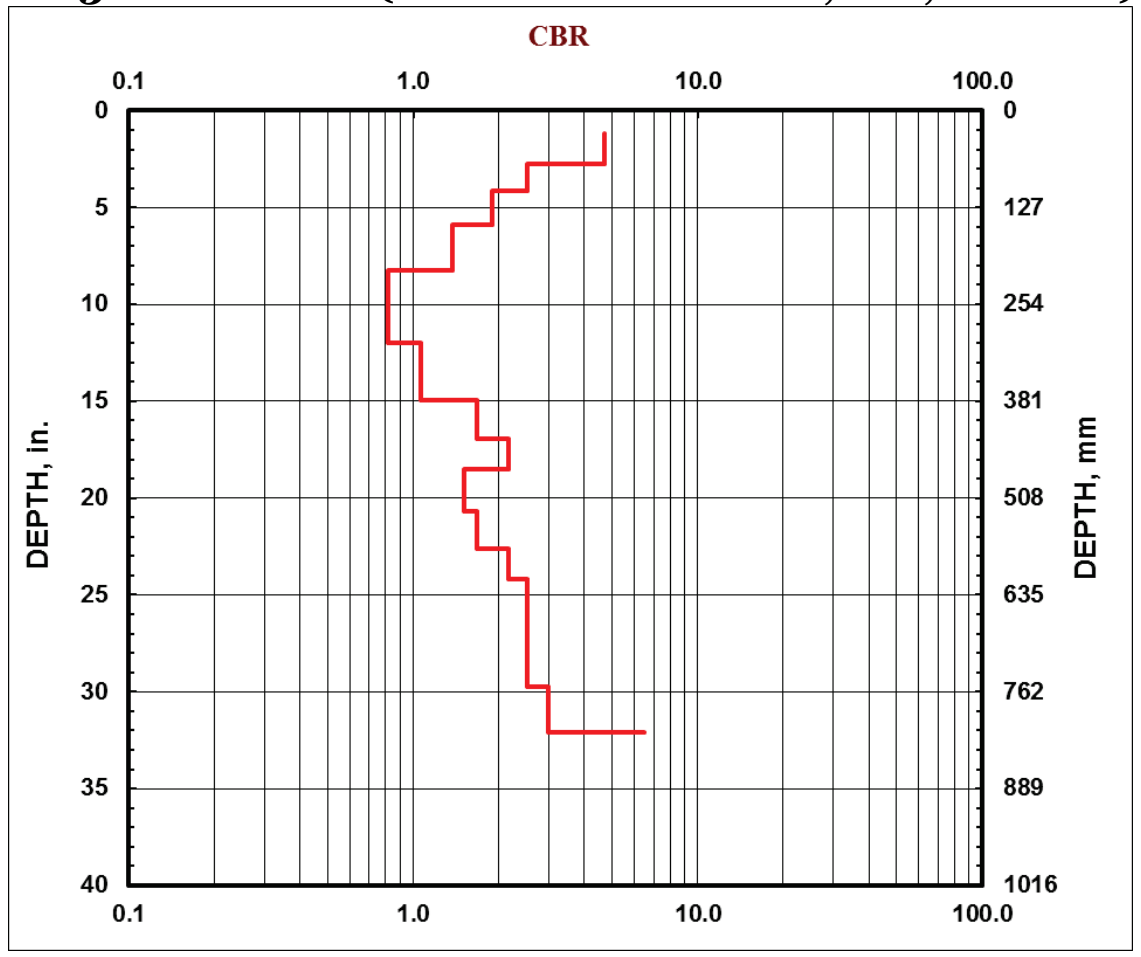

\section{CL-3 DCP Profile (Cross Section One, Control, Pretest)}

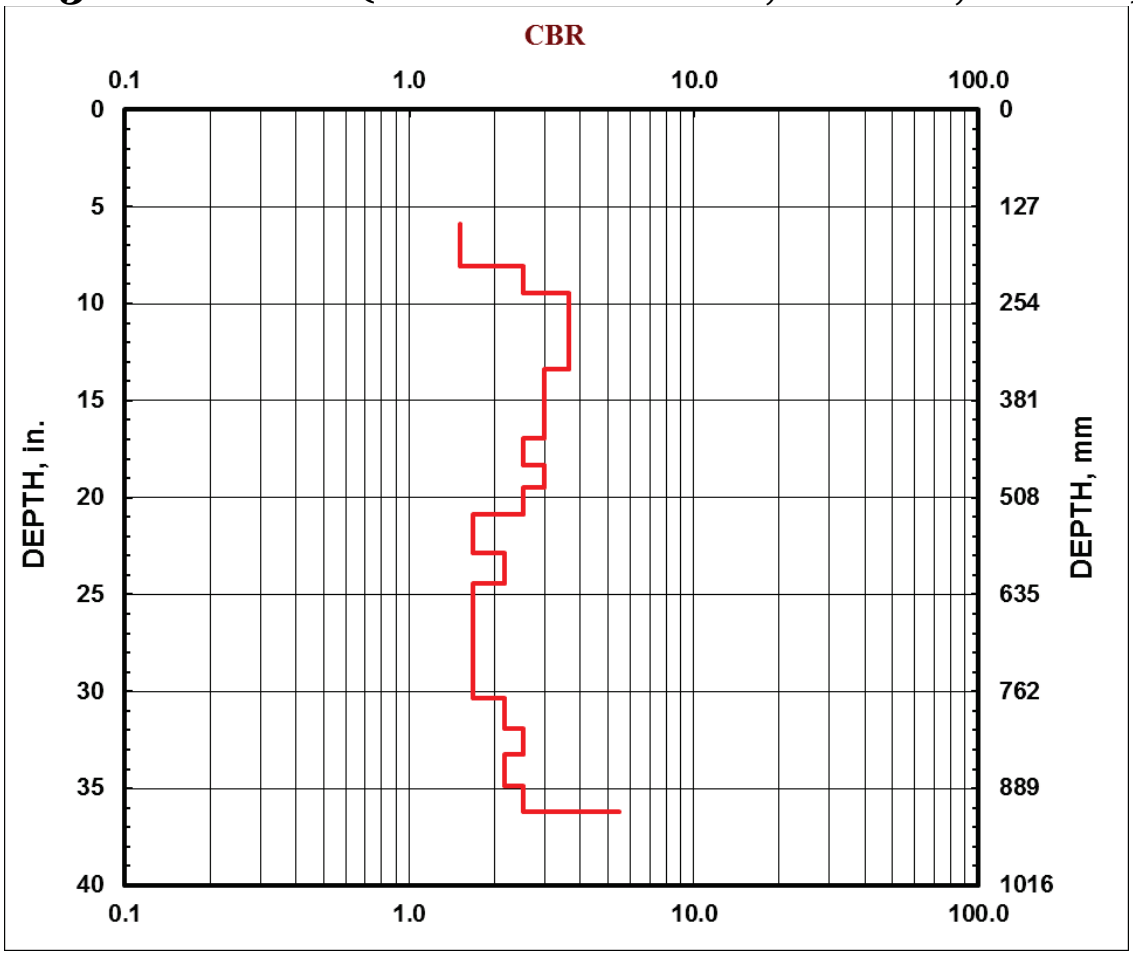


CL-3 DCP Profile (Cross Section Two, Control, Pretest)

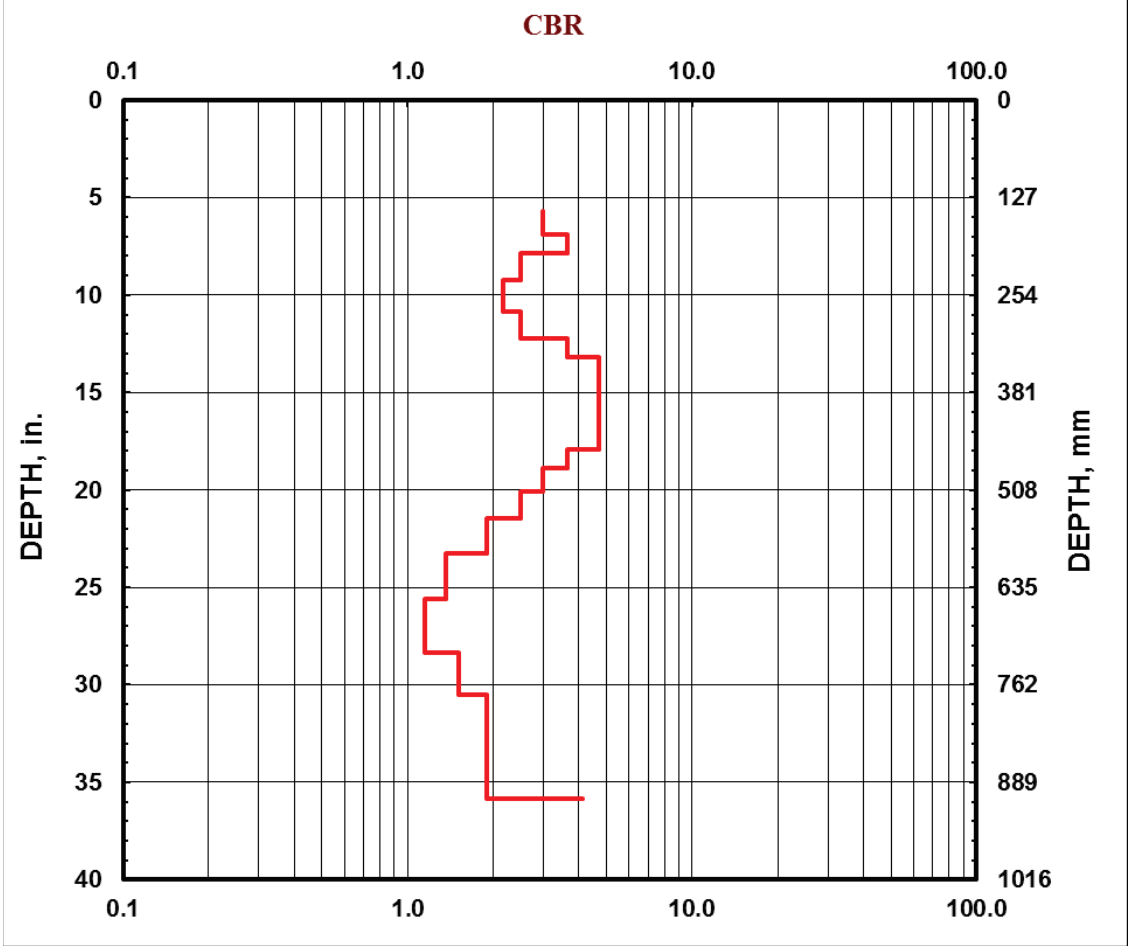

CL-3 DCP Profile (Cross Section Three, Control, Pretest)

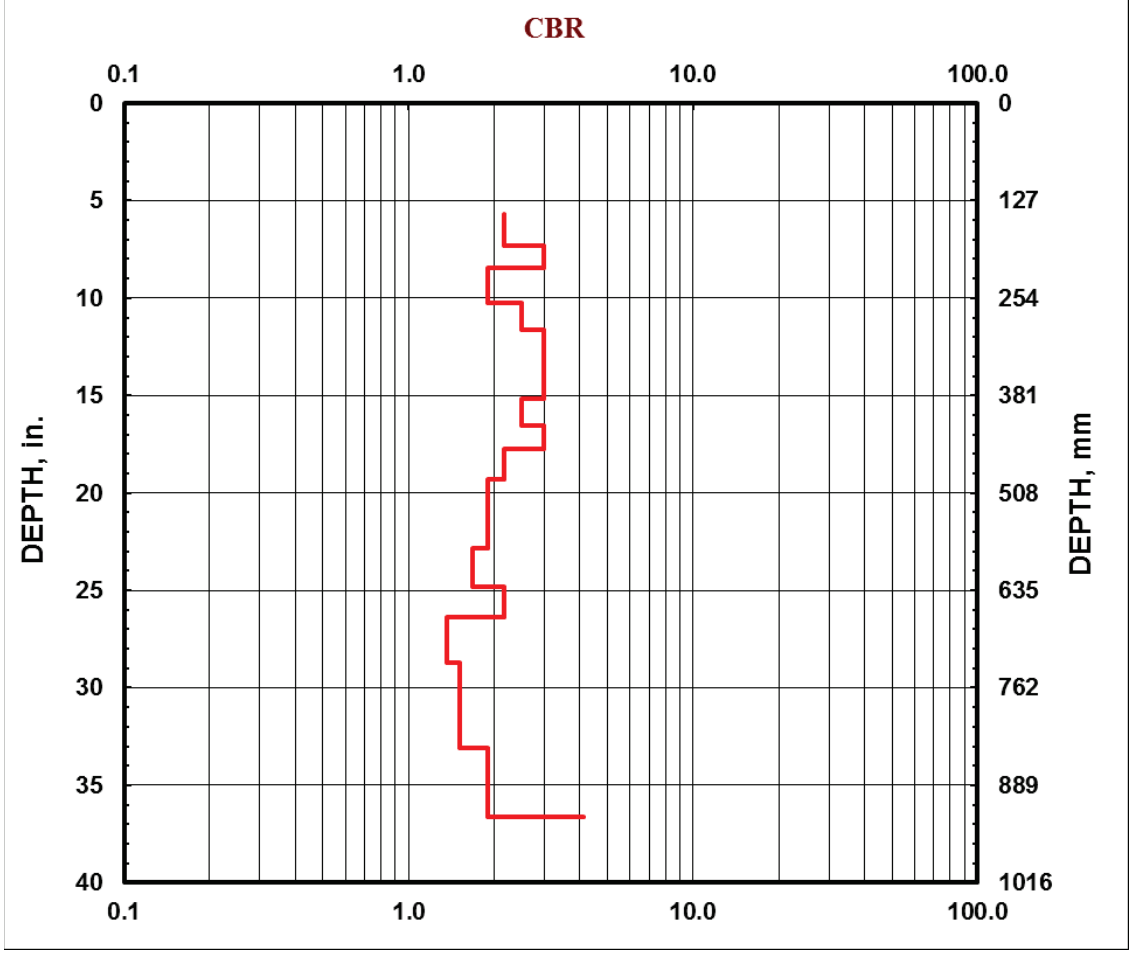




\section{CL-3 Material Characterization (Sample One)}

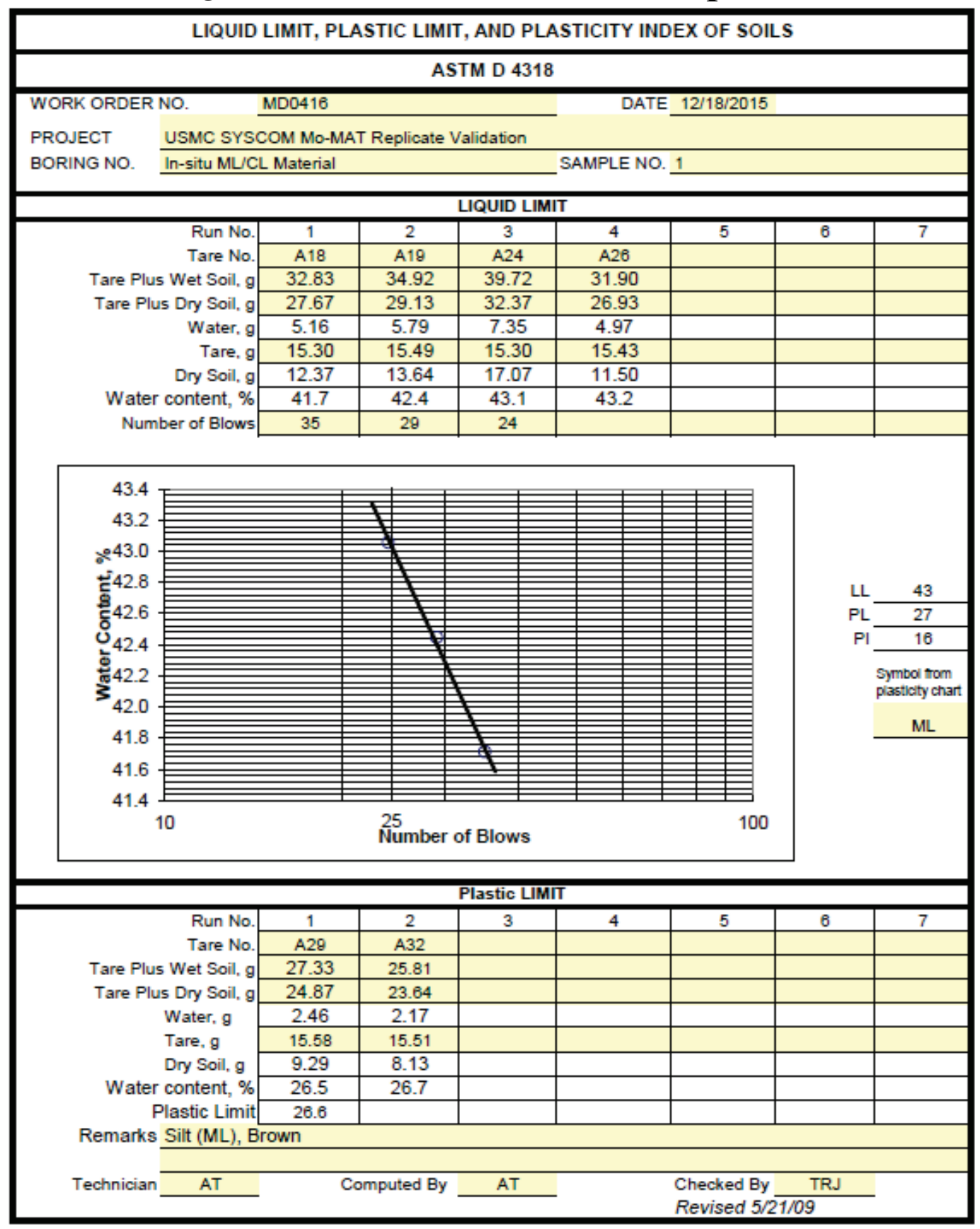




\section{CL-3 Material Characterization (Sample Two)}

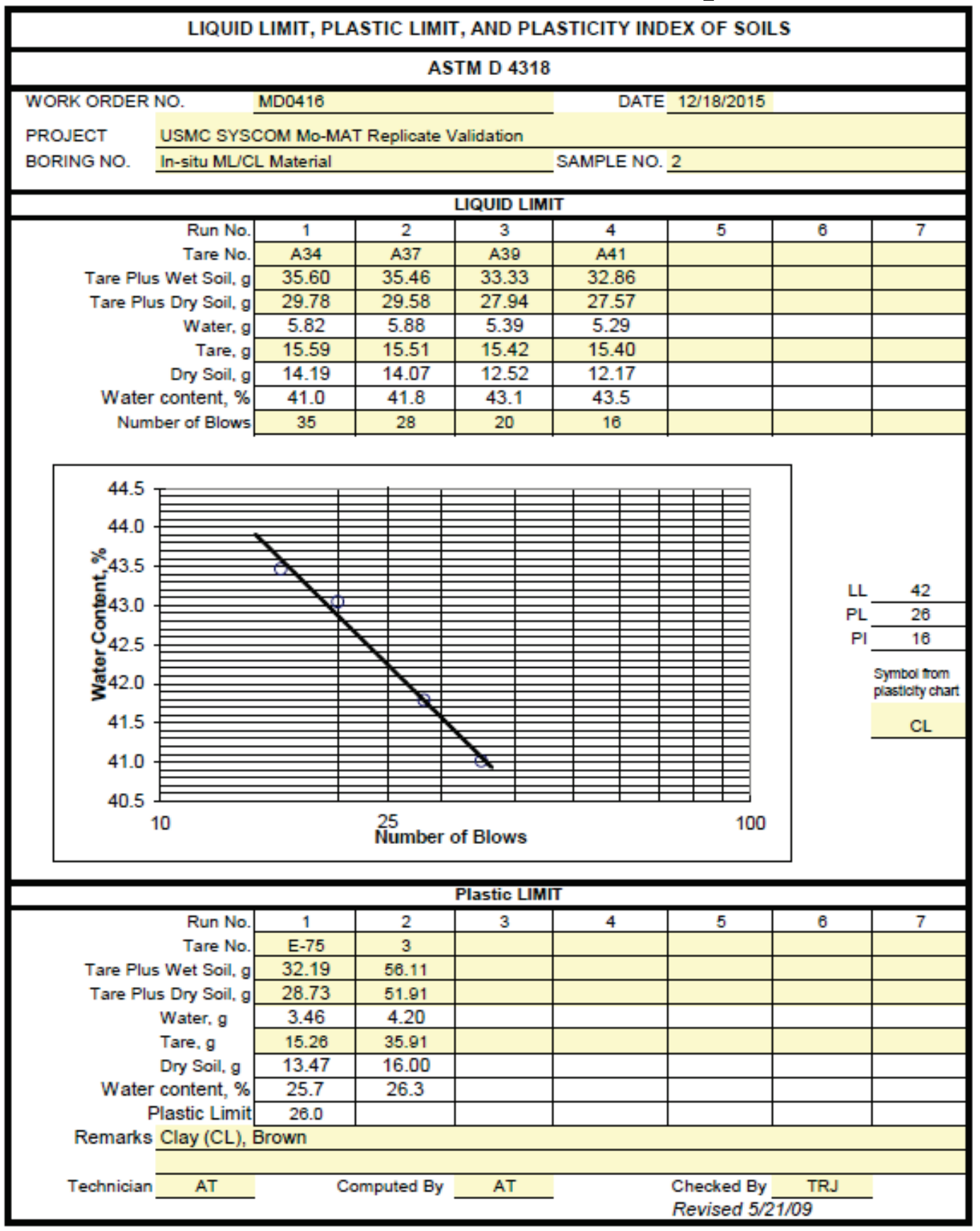


CL-3 Material Characterization (Sample Three)

LIQUID LIMIT, PLASTIC LIMIT, AND PLASTICITY INDEX OF SOILS

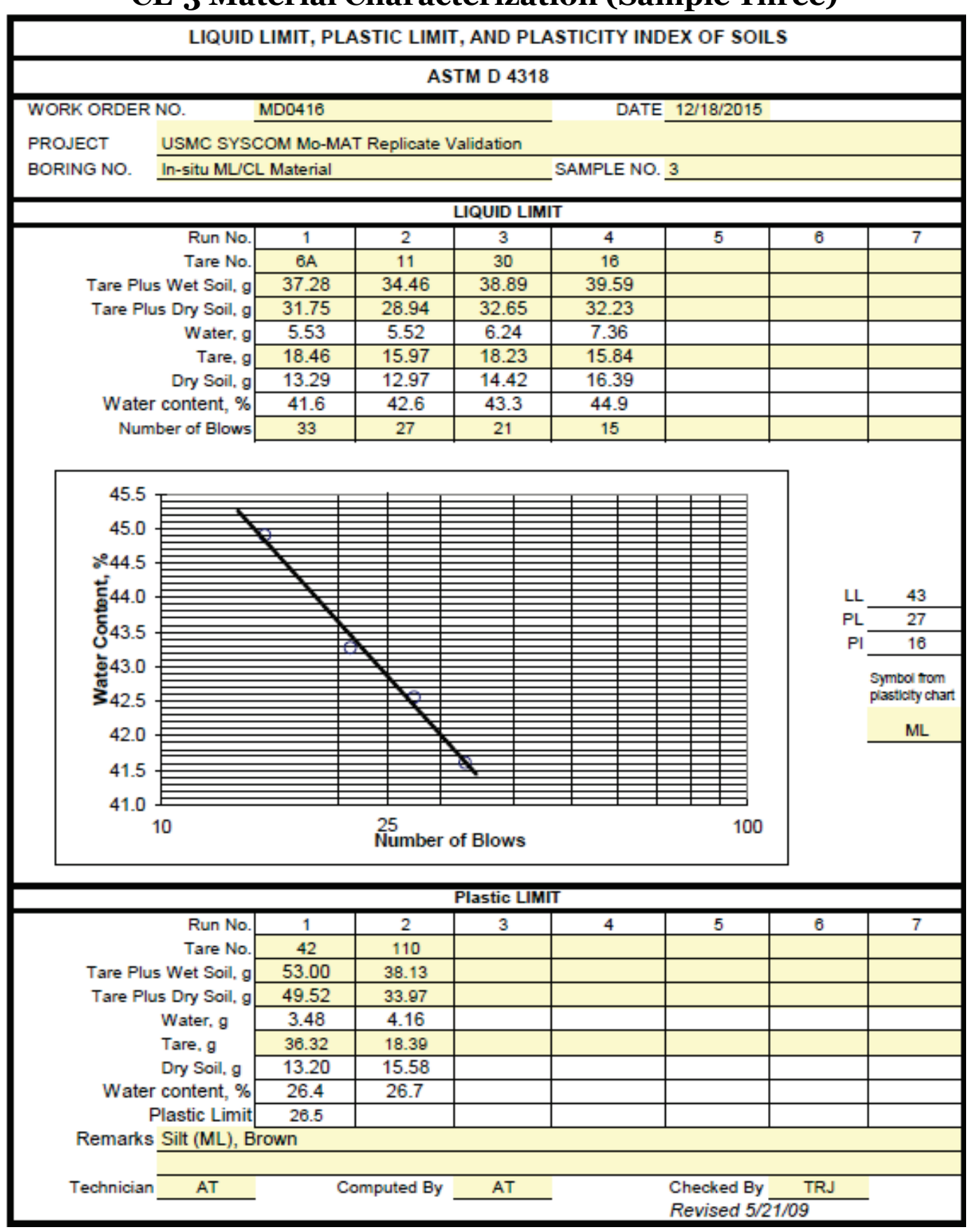




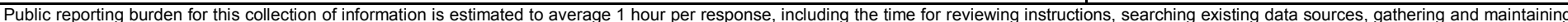

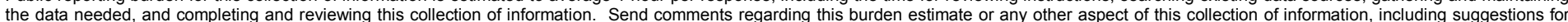

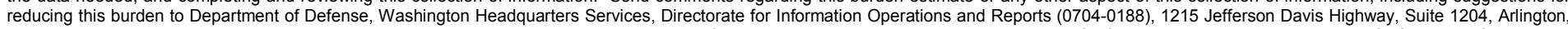

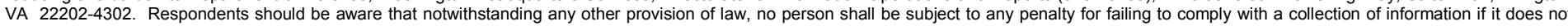
display a currently valid OMB control number. PLEASE DO NOT RETURN YOUR FORM TO THE ABOVE ADDRESS.

\begin{tabular}{l|l}
$\begin{array}{l}\text { 1. REPORT DATE (DD-MM-YYYY) } \\
\text { April } 2017\end{array}$ & $\begin{array}{c}\text { 2. REPORT TYPE } \\
\text { Final report }\end{array}$ \\
\hline
\end{tabular}

\section{TITLE AND SUBTITLE}

Evaluation of the WavTrac Expeditionary Mobility Matting System

\section{AUTHOR(S)}

Webster C. Floyd
3. DATES COVERED (From - To) Sep2015 - Sep2016

5a. CONTRACT NUMBER

N/A

5b. GRANT NUMBER

$\mathrm{N} / \mathrm{A}$

5c. PROGRAM ELEMENT NUMBER

$\mathrm{N} / \mathrm{A}$

5d. PROJECT NUMBER

455599

5e. TASK NUMBER 38254J

5f. WORK UNIT NUMBER N/A

\section{PERFORMING ORGANIZATION NAME(S) AND ADDRESS(ES)}

8. PERFORMING ORGANIZATION REPORT NUMBER

U.S. Army Engineer Research and Development Center

Geotechnical and Structures Laboratory

ERDC/GSL TR-17-4

3909 Halls Ferry Road

Vicksburg, MS 39180-6199

\section{SPONSORING / MONITORING AGENCY NAME(S) AND ADDRESS(ES)}

Marine Corps System Command

2202 Lester Street

Quantico, VA 22134
10. SPONSOR/MONITOR'S ACRONYM(S)

MARCORSYSCOM, MCSC

11. SPONSOR/MONITOR'S REPORT NUMBER(S)

$\mathrm{N} / \mathrm{A}$

\section{DISTRIBUTION / AVAILABILITY STATEMENT}

Approved for public release; distribution is unlimited.

\section{SUPPLEMENTARY NOTES}

\section{ABSTRACT}

The legacy Mo-Mat expeditionary mobility matting system used extensively by the U.S. Marine Corps is no longer manufactured. Work performed by the U.S. Army Engineer Research and Development Center (Rushing and Rowland 2012) indicated that replication of the legacy matting system was feasible. Therefore, the U.S. Marine Corps System Command initiated a Small Business Innovative Research effort in order to identify a small business that could develop a replicate system. This report details the evaluation of the WavTrac prototype expeditionary mobility matting system. Under full-scale truck traffic, the WavTrac system performed comparably to the legacy Mo-Mat system on a loose sand subgrade and outperformed the legacy system on a soft soil subgrade typical of a mud flat crossing.

15. SUBJECT TERMS (see reverse)

16. SECURITY CLASSIFICATION OF: Distribution Statement $A$

a. REPORT

UNCLASSIFIED

b. ABSTRACT
UNCLASSIFIED

c. THIS PAGE

UNCLASSIFIED
17. LIMITATION OF ABSTRACT

$\mathrm{N} / \mathrm{A}$

\section{NUMBER} OF PAGES

73 19a. NAME OF RESPONSIBLE PERSON Webster C Floyd

19b. TELEPHONE NUMBER (include area code) 601-634-2681 
15. SUBJECT TERMS (concluded)

Mo-Mat

WavTrac

Mat

Road Mat

Expeditionary Mobility Matting System

Fiberglass

Pultrusion

Amphibious warfare

Logistics

Landing operations

Transportation, Military

Sandy soils

Soil stabilization

Mobility matting 